INSTITUTO DE PESQUISAS ENERGÉTICAS E NUCLEARES

Autarquia associada à Universidade de São Paulo

DESENVOLVIMENTO DE MATRIZES EPOXÍDICAS E ESTUDO DOS PARÂMETROS DE CURA POR FEIXE DE ELÉTRONS PARA FABRICAÇÃO DE COMPÓSITOS POLIMÉRICOS

\author{
DELMO AMARI NISHITSUJI
}

Dissertação apresentada como parte dos requisitos para obtenção do Grau de Mestre em Ciências na Área de Tecnologia Nuclear - Materiais

Orientador:

Dr. Gerson Marinucci 
Aos meus pais, Mitino e Katsuaki 


\section{AGRADECIMENTOS}

Ao Centro Tecnológico da Marinha em São Paulo - CTMSP, pela oportunidade concedida e apoio à realização deste estudo.

Ao meu orientador Dr. Gerson Marinucci, pelo incentivo, colaboração e participação direta de todas as etapas do trabalho.

Ao Dr. Leonardo G. de Andrade e Silva, do Centro de Tecnologia das Radiações do IPEN, pela colaboração e participação de todas as etapas do trabalho e aos colegas Carlos Gaia da Silveira, Elizabeth S. Ribeiro Somessari, Hélio Antônio Paes e Samir Luiz Somessari, pela etapa de irradiação dos materiais.

Ao Dr. Luis Filipe C. P. Lima, pela colaboração e participação da técnica de DMTA no Centro de Ciência e Tecnologia de Materias - IPEN.

Aos colegas da OFCOMP do CTMSP, Osni de Carvalho, João Claudino de Godois Netto e Daniel Bina, pela fabricação dos corpos-de-prova de compósitos. À colega do Instituto de Estudos Avançados - CTA, Maria Cecília C. Évora, pela colaboração e participação no trabalho.

Aos colegas de trabalho da Divisão de Tecnologia de Materiais do CTMSP, Ailton Chagas Noya, Álvaro A. S. Carvalho, Cláudio L. Brasil, José Ferreira da Silva Filho, Lea Sarita Montagna, Marcos Augusto e Reinaldo de Toledo, pela participação das análises e ensaios dos corpos-de-prova.

Aos colegas de trabalho da Divisão de Projetos e Desenvolvimentos Eletro-eletrônicos, Maria A. Fernandes Lioi e Tárcio A. de Oliveira, pela etapa de monitoração de temperatura dos corpos-de-prova durante a irradiação.

Aos funcionários da CPG do IPEN, pela colaboração no decorrer do trabalho.

Aos funcionários da biblioteca do IPEN, pela colaboração no decorrer do trabalho. 


\title{
DESENVOLVIMENTO DE MATRIZES EPOXÍDICAS E ESTUDO DOS PARÂMETROS DE CURA POR FEIXE DE ELÉTRONS PARA FABRICAÇÃO DE COMPÓSITOS POLIMÉRICOS
}

\author{
Delmo Amari Nishitsuji
}

\begin{abstract}
RESUMO
O objetivo deste trabalho foi desenvolver matrizes epoxídicas e estudar os parâmetros de processo de cura para fabricação de compósitos poliméricos curados por feixe de elétrons. A fabricação de compósitos poliméricos estruturais pelo processo térmico necessita de um ciclo de cura de algumas horas e elevada temperatura, implicando num alto custo de produção. A tecnologia de cura por feixe de elétrons permite curar matrizes epoxídicas em poucos minutos à temperatura ambiente e proporcionar temperaturas de transição vítrea superiores às obtidas pelos sistemas curados pelo processo térmico.

Neste trabalho foi utilizada uma resina epoxídica do tipo éter diglicidílico de bisfenol A (DGEBA) e o hexafluoroantimonato de diariliodônio como iniciador catiônico. $O$ tempo do ciclo de cura do compósito polimérico obtido por feixe de elétrons foi de 40 minutos até completar uma dose total aproximada de $200 k$ ky.

O grau de cura e a temperatura de transição vítrea foram avaliados por técnicas de análise térmica. A temperatura de transição vítrea determinada por meio da técnica de termodinâmico-mecânica (DMTA) foi de $167^{\circ} \mathrm{C}$ (tan $\delta$ ) e o grau cura de $96 \%$ obtido pela técnica de calorimetria exploratória diferencial (DSC). A mesma resina epoxídica curada pelo processo térmico por um período de 16 horas, com um endurecedor à base de anidrido, atingiu uma temperatura de transição vítrea de $125^{\circ} \mathrm{C}(\tan \delta)$.
\end{abstract}




\title{
DEVELOPMENT OF EPOXIES MATRICES AND STUDY OF PROCESS \\ PARAMETERS ON ELECTRON BEAM CURING OF POLYMERIC COMPOSITES
}

\author{
Delmo Amari Nishitsuji
}

\begin{abstract}
The aim of this work was to develop epoxies matrices and study of process parameters on electron beam curing of polymeric composites. The production of advanced polymeric composites cured by thermal process needs a cure cycle of quite a few hours as well as high temperatures which result in high production costs. The electron beam curing technology makes possible to cure epoxy matrices in a few minutes at room temperature and it results in glass transition temperatures which are far better than those obtained with systems cured by thermal process.

In this work an epoxy resin of the diglycidyl ether of bisphenol $A$ (DGEBA) type was used, as well as, a diaryliodonium hexafluoroantimonate as the cationic initiator. The cure cycle time for the electron beam curing polymeric composite was 40 minutes to complete an approximated total dose of 200kGy.

The degree of cure and the glass transition temperature were determined by thermal analysis techniques. The glass transition temperature was determined by a dynamic mechanical analyzer (DMTA) and was 167 ${ }^{\circ} \mathrm{C}(\tan \delta)$ and the degree of cure was $96 \%$, which was determined by differential scanning calorimetry technique (DSC). The same epoxy resin with an anhydride curing agent, took 16 hours when cured by thermal process and its glass transition temperature was $125^{\circ} \mathrm{C}(\tan \delta)$.
\end{abstract}




\section{SUMÁRIO}

Página

1 INTRODUÇÃO

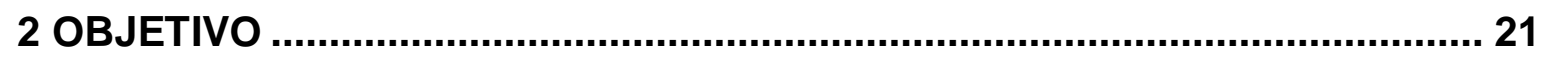

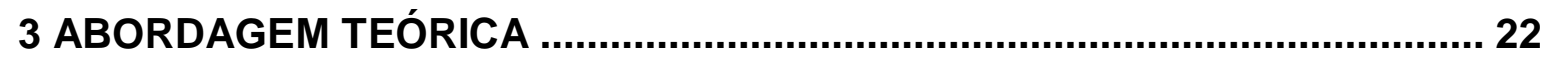

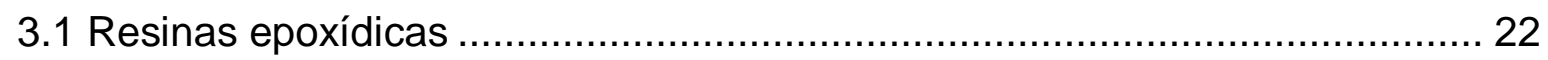

3.2 Matrizes epoxídicas curadas a temperatura ambiente e pelo processo

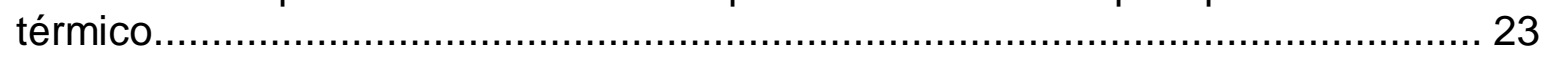

3.3 Matrizes epoxídicas curadas por feixe de elétrons..................................... 26

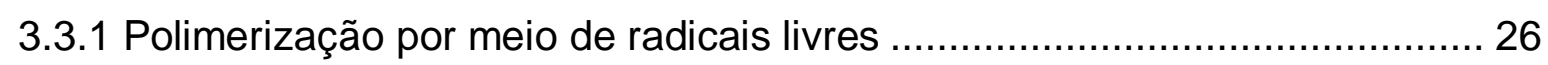

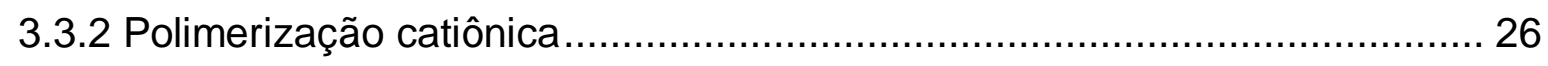

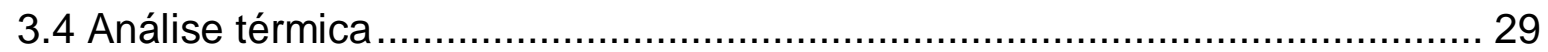

3.4.1 Calorimetria exploratória diferencial (DSC) ……................................... 30

3.4.2 Termodinâmico-mecânica (DMTA) …………..................................... 30

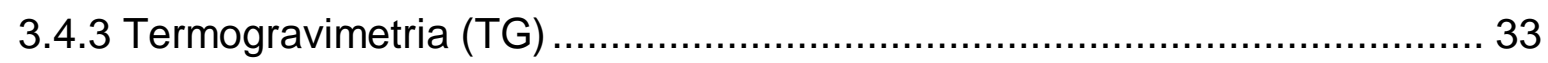

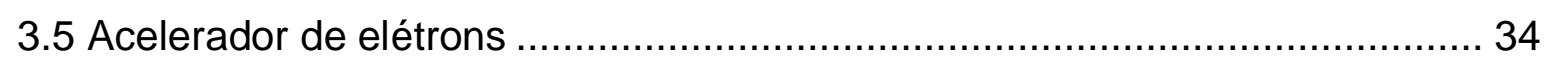

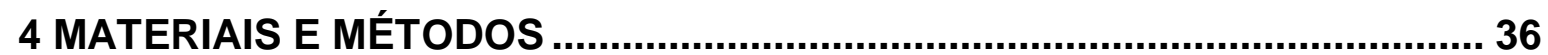

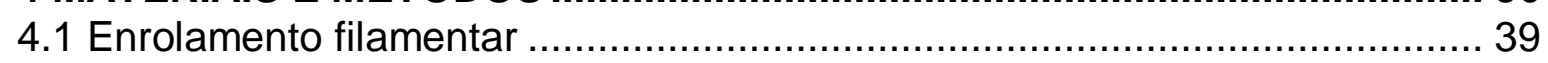

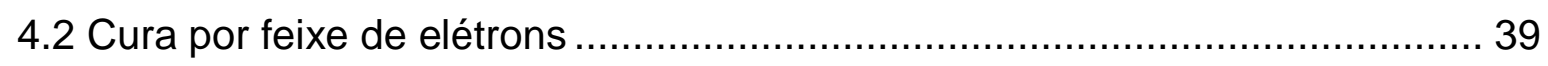

4.2.1 Preparação das formulações das matrizes poliméricas ............................. 40

4.2.2 Preparação dos corpos-de-prova de matrizes poliméricas......................... 41

4.2.3 Preparação dos corpos-de-prova de compósitos ..................................... 47

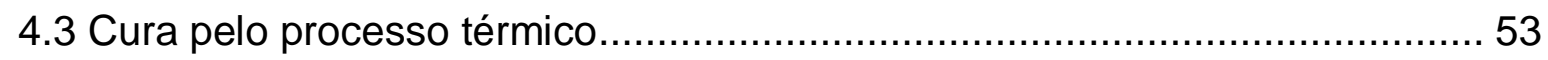

4.3.1 Preparação das formulações das matrizes poliméricas ............................. 53

4.3.2. Preparação dos corpos-de-prova da matriz polimérica .............................. 53

4.3.3 Preparação dos corpos-de-prova de compósitos poliméricos ..................... 54

4.4 Controle da temperatura durante o processo de cura por feixe de elétrons... 55

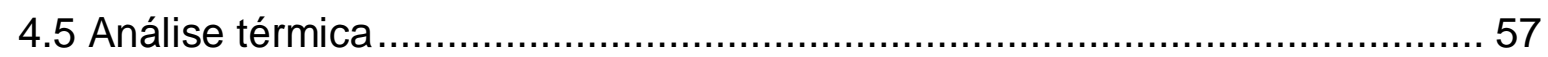

4.5.1 Calorimetria exploratória diferencial (DSC) ….................................... 57

4.5.2 Termodinâmico-mecânica (DMTA) …………................................... 58

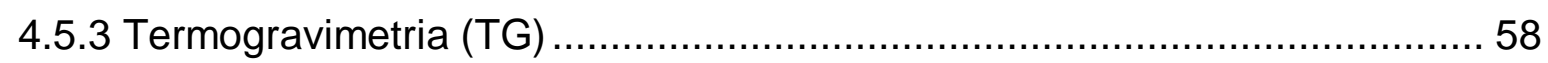

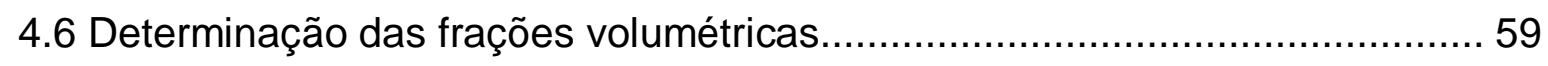

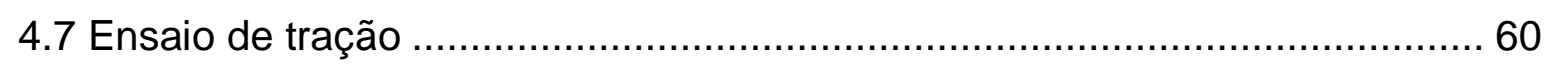


5 RESULTADOS E DISCUSSÃO

5.1 Controle de temperatura durante o processo de cura por feixe de elétrons... 62

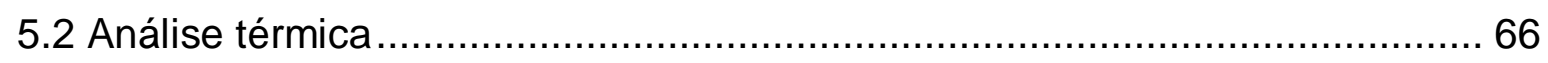

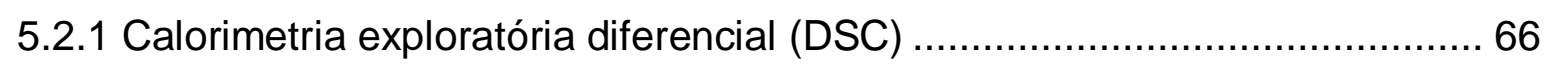

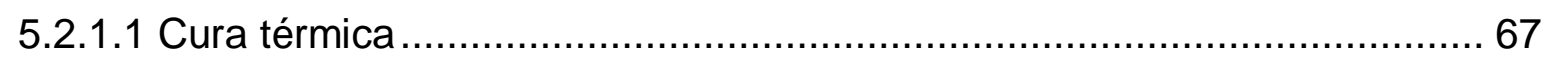

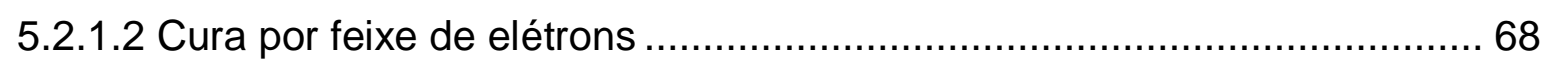

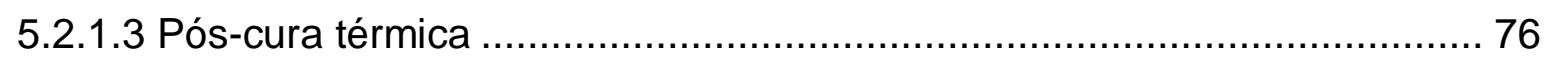

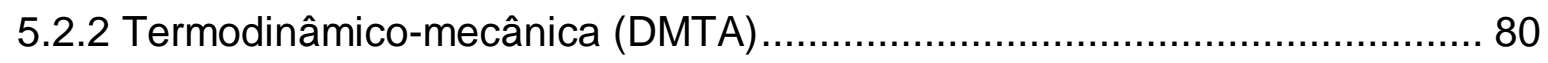

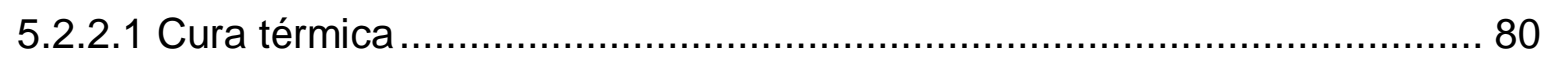

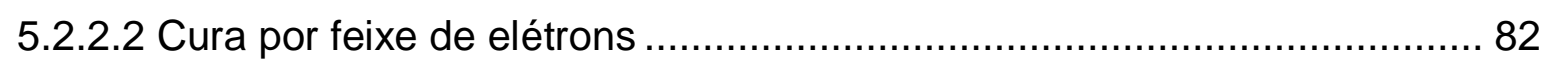

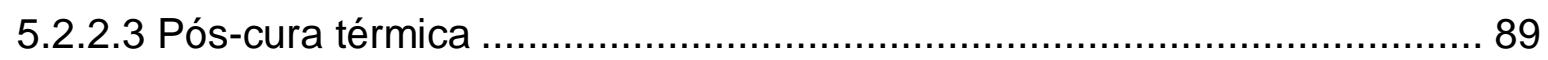

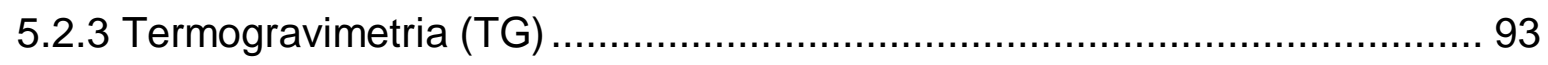

5.3 Determinação das frações volumétricas................................................... 95

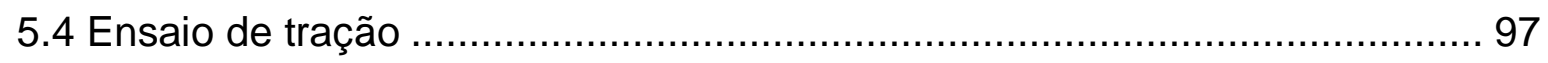

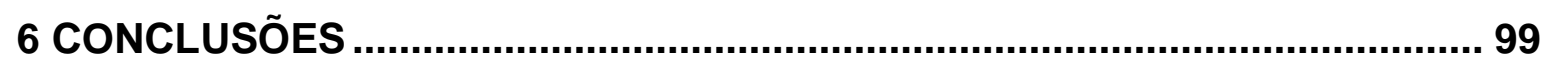

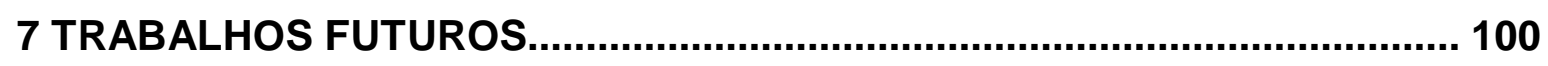

APÊNDICE A - CURVAS DMTA DAS MATRIZES CURADAS POR FEIXE DE

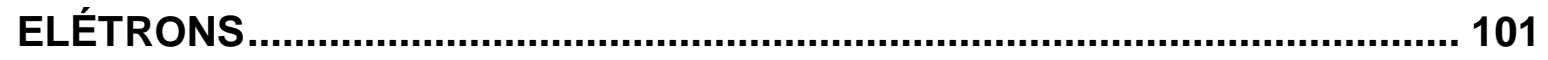

APÊNDICE B - CURVAS DMTA DOS COMPÓSITOS CURADOS POR FEIXE

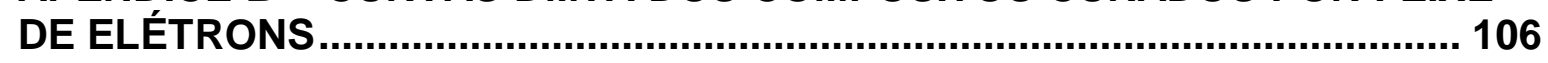

APÊNDICE C - CURVAS DMTA DAS MATRIZES E COMPÓSITOS CURADOS POR FEIXE DE ELÉTRONS E PÓS-CURADOS

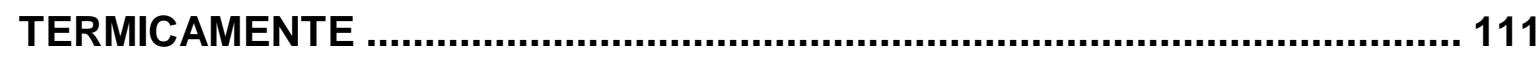

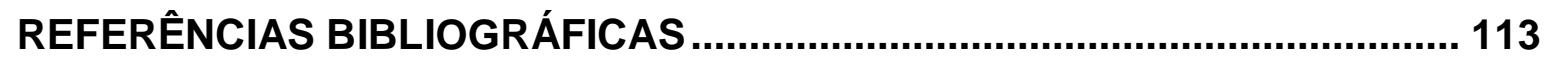




\section{LISTA DE FIGURAS}

Página

FIGURA 3.1 - Grupo epoxídico 22

FIGURA 3.2 - Reação de uma amina primária com o grupo epoxídico

FIGURA 3.3 - Reação de um anidrido e de um acelerador com o grupo epoxídico

FIGURA 3.4 - Estrutura molecular do oligômero diacrilato de bisfenol A 26

FIGURA 3.5 - Ativação do iniciador catiônico 28

FIGURA 3.6 - Iniciação da polimerização catiônica. 28

FIGURA 3.7 - Propagação da cadeia. 28

FIGURA 3.8 - Transferência da cadeia 29

FIGURA 3.9 - Terminação da cadeia. 29

FIGURA 3.10 - À esquerda a panela com a amostra e à direita a panela vazia (referência) no forno do equipamento de DSC.

FIGURA 3.11 - Forno do equipamento de DMTA com um corpo-de-prova de matriz.

FIGURA 3.12 - Forno do equipamento de TG com uma amostra dentro do cadinho de platina.

FIGURA 3.13 - Sistema de varredura do feixe de elétrons. 34

FIGURA 4.1 - Estrutura molecular da resina epoxídica DGEBA... 38

FIGURA 4.2 - Enrolamento filamentar.

FIGURA 4.3 - Estrutura molecular do hexafluoroantimonato de diariliodônio

FIGURA 4.4 - Molde de silicone para corpos-de-prova de matrizes para DMTA......

FIGURA 4.5 - Os corpos-de-prova de matrizes para a irradiação 
FIGURA 4.6 - Molde de silicone para corpos-de-prova de tração de matriz polimérica.

FIGURA 4.7 - Bandeja com as amostras das matrizes.

FIGURA 4.8 - Corpo-de-prova de DMTA da matriz curada por feixe de elétrons.

FIGURA 4.9 - Corpo-de-prova de tração da matriz curado por feixe de elétrons.

FIGURA 4.10 - Molde para a fabricação de corpos-de-prova de compósito.

FIGURA 4.11 - Enrolamento filamentar do corpo-de-prova de compósito. 48

FIGURA 4.12 - Banho de impregnação da matriz.

FIGURA 4.13 - Vista geral do molde após o processo de enrolamento filamentar. 49

FIGURA 4.14 - Bandeja para irradiação dos compósitos.

FIGURA 4.15 - Amostras das placas dos compósitos curados por feixe de elétrons.

FIGURA 4.16 - Placa de compósito adequadamente cortada e um corpo-de-prova de DMTA.

FIGURA 4.17 - Estrutura molecular do anidrido metiltetrahidroftálico. 53

FIGURA 4.18 - Estrutura molecular do acelerador benzildimetilamina.

FIGURA 4.19 - Corpo-de-prova de DMTA da matriz curado pelo processo térmico.

FIGURA 4.20 - Corpo-de-prova de tração da matriz curado pelo processo térmico.

FIGURA 4.21 - Placa do compósito curado pelo processo térmico e um corpo-de-prova de DMTA.

FIGURA 4.22 - Equipamento de monitoração de temperatura. 56

FIGURA 4.23 - Termorresistência PT 100 no molde de matriz. 57

FIGURA 4.24 - Termorresistência PT 100 num molde de compósito. 57

FIGURA 4.25 - Aparato para a determinação da densidade. 59

FIGURA 4.26 - Balança com o aparato para determinação da densidade. 60 FIGURA 4.27 - Ensaio de tração do corpo-de-prova da matriz com extensômetro. 
FIGURA 5.1 - Temperatura sob o feixe de elétrons durante a irradiação.

FIGURA 5.2 - Temperaturas das matrizes A1, A2 e A3 durante a cura por feixe de elétrons com taxa de dose de 1,82 kGy.s ${ }^{-1}$ até completar a dose parcial de 52,2kGy e 57,6 kGy.s ${ }^{-1}$ até completar a dose total de 206,4kGy

FIGURA 5.3 - Temperatura dos compósitos FCA1, FCA2 e FCA3 durante a cura por feixe de elétrons com taxas de dose de 1,82 kGy.s ${ }^{-1}$ até completar a dose parcial de 52,2kGy e 57,6 kGy.s ${ }^{-1}$ até completar a dose total de 206,4kGy.

FIGURA 5.4 - Temperaturas da matriz A2 e do compósito FCA2 durante a cura por feixe de elétrons com taxa de dose de 1,82 kGy.s ${ }^{-1}$ até completar 206,4kGy

FIGURA 5.5 - Curva DSC da matriz curada pelo processo térmico. 67

FIGURA 5.6 - Curva DSC do compósito curado pelo processo térmico.

FIGURA 5.7 - Curvas DSC da entalpia residual da reação de cura da matriz A2 curada por feixe de elétrons com taxa de dose de 1,82 kGy.s ${ }^{-1}$ e doses totais de 103,6 kGy, 155,0 kGy e 206,4kGy.

FIGURA 5.8 - Curvas DSC da entalpia residual da reação de cura das matrizes $\mathrm{A} 1, \mathrm{~A} 2, \mathrm{~A} 3$ e $\mathrm{H} 2$ curadas por feixe de elétrons com taxas de dose de $1,82 \mathrm{kGy} \cdot \mathrm{s}^{-1}$ e $57,6 \mathrm{kGy} . \mathrm{s}^{-1}$ e dose total de 206,4kGy.

FIGURA 5.9 - Curvas DSC da entalpia residual da reação de cura da matriz A2 curada por feixe de elétrons com taxas de dose de 1,82 kGy.s ${ }^{-1}$ e 57,6 kGy.s ${ }^{-1}$ e doses totais de 103,6kGy, 155,0kGy e 206,4kGy.

FIGURA 5.10 - Curvas DSC da entalpia residual da reação de cura dos compósitos FCA1, FCA2, FCA3 e FCH2 curados por feixe de elétrons com taxas de dose de 1,82 kGy.s $\mathrm{s}^{-1}$ e 57,6 kGy.s ${ }^{-1}$ e dose total de 206,4kGy

FIGURA 5.11 - Curvas DSC da entalpia residual da reação de cura dos compósitos FCA2 curados por feixe de elétrons com taxa de dose de $1,82 \mathrm{kGy} \cdot \mathrm{s}^{-1}$ e dose total de 103,6kGy, 155,0kGy e 206,4kGy 
FIGURA 5.12 - Curvas DSC da entalpia residual da reação de cura dos compósitos FCA2 curados por feixe de elétrons com taxas de dose de 1,82 kGy.s $\mathrm{s}^{-1}$ e 57,6 kGy.s ${ }^{-1}$ e doses totais de 103,6kGy, 155,0kGy e 206,4kGy.

FIGURA 5.13 - Curvas DSC da entalpia de reação de cura das matrizes A1, A2, A3 e $\mathrm{H} 2$ de cura por feixe de elétrons e da matriz de cura térmica (Tactix 123/HY 917/DY 062).

FIGURA 5.14 - Curvas DSC da entalpia da reação de cura dos compósitos FCA1, FCA2, FCA3 e FCH2 de cura por feixe de elétrons.

FIGURA 5.15 - Curvas DSC do iniciador catiônico e da formulação da matriz A2.

FIGURA 5.16 - Curvas DSC da matriz A2 curada por feixe de elétrons com taxa de dose de $1,82 \mathrm{kGy} \cdot \mathrm{s}^{-1}$, dose total de $206,4 \mathrm{kGy}$ e pós-curada termicamente.

FIGURA 5.17 - Curvas DSC da matriz A2 curada por feixe de elétrons com taxas de dose de 1,82 kGy.s. ${ }^{-1}$ e 57,6 kGy.s ${ }^{-1}$, dose total de 206,4kGy e póscurada termicamente.

FIGURA 5.18 - Curvas DSC do compósito FCA2 curado por feixe de elétrons com taxa de dose de $1,82 \mathrm{kGy} . \mathrm{s}^{-1}$, dose total de $206,4 \mathrm{kG}$ y e pós-curado termicamente.

FIGURA 5.19 - Curvas DSC do compósito FCA2 curado por feixe de elétrons com taxas de dose de 1,82 kGy.s ${ }^{-1}$ e 57,6 kGy.s ${ }^{-1}$, dose total de 206,4kGy e pós-curado termicamente.

FIGURA 5.20 - Curvas DMTA da matriz curada pelo processo térmico. 82

FIGURA 5.21 - Curvas DMTA do compósito curado pelo processo térmico......

FIGURA 5.22 - Curvas DMTA de tan $\delta$ das matrizes A1, A2, A3 e H2 curadas por feixe elétrons com taxas de dose de $1,82 \mathrm{kGy} \cdot \mathrm{s}^{-1}$ e $57,6 \mathrm{kGy} \cdot \mathrm{s}^{-1}$ e dose total de 206,4kGy.

FIGURA 5.23 - Curvas DMTA de $\tan \delta$ das matrizes A2 curadas por feixe de elétrons com taxa de dose de 1,82 kGy.s ${ }^{-1}$ e doses totais de 103,6kGy, 155,0kGy e 206,4kGy 
FIGURA 5.24 - Curvas DMTA de tan $\delta$ das matrizes A2 curadas por feixe de elétrons com taxas de dose de 1,82 kGy.s ${ }^{-1}$ e $57,6 \mathrm{kGy} . \mathrm{s}^{-1}$ e doses totais de 103,6kGy, 155,0kGy e 206,4kGy.

FIGURA 5.25 - Curvas DMTA de tan $\delta$ dos compósitos FCA2 curado por feixe de elétrons com taxa de dose de 1,82 kGy.s ${ }^{-1}$ e doses totais de 103,6kGy, 155,0kGy e 206,4kGy.

FIGURA 5.26 - Curvas DMTA de tan $\delta$ dos compósitos FCA1, FCA2, FCA3 e $\mathrm{FCH} 2$ curados por feixe elétrons com taxas de doses de 1,82 kGy.s ${ }^{-1}$ e 57,6 kGy.s. ${ }^{-1}$ e dose total de 206,4kGy.

FIGURA 5.27 - Curvas DMTA de tan $\delta$ compósitos FCA2 curados por feixe de elétrons com taxas de doses de 1,82 kGy.s $\mathrm{s}^{-1}$ e $57,6 \mathrm{kGy} . \mathrm{s}^{-1}$ e doses totais de 103,6kGy, 155,0kGy e 206,4kGy.

FIGURA 5.28 - Curvas DMTA de tan $\delta$ da matriz A2 curada por feixe de elétrons com taxa de dose de 1,82 kGy.s ${ }^{-1}$, dose total de 206,4kGy e da amostra pós-curada termicamente

FIGURA 5.29 - Curvas DMTA de tan $\delta$ da matriz A2 curada por feixe de elétrons com taxas de doses de 1,82 kGy.s ${ }^{-1}$ e 57,6 kGy.s ${ }^{-1}$, dose total de 206,4kGy e da amostra pós-curada termicamente.

FIGURA 5.30 - Curvas DMTA de tan $\delta$ do compósito FCA2 curado por feixe de elétrons com taxa de dose de 1,82 kGy.s ${ }^{-1}$, dose total de 206,4kGy e da amostra pós-curada termicamente

FIGURA 5.31 - Curvas DMTA de tan $\delta$ do compósito FCA2 curado por feixe de elétrons com taxas de doses de 1,82 kGy.s $\mathrm{s}^{-1}$ e 57,6 kGy.s ${ }^{-1}$, dose total de 206,4kGy e da amostra pós-curada termicamente.

FIGURA 5.32 - Curvas TG das matrizes A1, A2, A3 e H2 curadas por feixe de elétrons e da matriz Tactix123/HY915/DY062 curada pelo processo térmico. 


\section{LISTA DE TABELAS}

Página

TABELA 4.1 - Características da resina epoxídica

TABELA 4.2 - Propriedades mecânicas e características da fibra de carbono.

TABELA 4.3 - Formulações das matrizes para o processo por feixe de elétrons.

TABELA 4.4 - Condições de irradiação da matriz A2. 44

TABELA 4.5 - Condições de irradiação da matriz A2. 44

TABELA 4.6 - Condições de irradiação da matriz A2. 45

TABELA 4.7 - Condições de irradiação das matrizez A1, A2, A3 e H2 45

TABELA 4.8 - Condições de irradiação do corpo-de-prova de tração da matriz A2.

TABELA 4.9 - Condições de irradiação do compósito FCA2. 50

TABELA 4.10 - Condições de irradiação do compósito FCA2. 50

TABELA 4.11 - Condições de irradiação do compósito FCA2. 51

TABELA 4.12 - Condições de irradiação dos compósitos FCA1, FCA2, FCA3 e $\mathrm{FCH} 2$

TABELA 4.13 - Calor específico de alguns materiais utilizados no processo de cura por feixe de elétrons

TABELA 5.1. - As temperaturas de transição vítrea pela técnica de DSC da matriz TACTIX 123/HY 917/DY 062 e do compósito de mesma matriz curados pelo processo térmico

TABELA 5.2 - Entalpias de reação de cura das matrizes de cura térmica e por feixe de elétrons obtido pelo DSC

TABELA 5.3. - Entalpias de reação de cura dos compósitos de cura por feixe de elétrons obtido pelo DSC.

TABELA 5.4 - Grau de cura das matrizes curadas por feixe de elétrons. 74

TABELA 5.5 - Grau de cura dos compósitos curados por feixe de elétrons...... 
TABELA 5.6 - Temperaturas de transição vítrea pela técnica de DSC das matrizes e compósitos curados por feixe de elétrons e pós-curados termicamente.

TABELA 5.7 - Temperatura de transição vítrea pela técnica de DMTA da matriz TACTIX 123/HY 917/DY 062 e do compósito de mesma matriz curados pelo processo térmico

TABELA 5.8 - Temperaturas de transição vítrea pela técnica de DMTA das matrizes curadas por feixe de elétrons.

TABELA 5.9 - Temperaturas de transição vítrea pela técnica de DMTA dos compósitos curados por feixe de elétrons

TABELA 5.10 - Temperaturas de transição vítrea das matrizes e compósitos curados por feixe de elétrons e pós-curados termicamente. 90

TABELA 5.11 - Resíduo da matriz curada pelo processo térmico. 94

TABELA 5.12 - Resíduos das matrizes curadas por feixe de elétrons.

TABELA 5.13 - Frações mássicas de fibra de carbono e de matriz do compósito curado pelo processo térmico

TABELA 5.14 - Frações mássicas de fibra de carbono e de matriz dos compósitos curados por feixe de elétrons.

TABELA 5.15 - Densidade da matriz curada pelo processo térmico 95

TABELA 5.16 - Densidades das matrizes curadas por feixe de elétrons.

TABELA 5.17 - Densidade, fração volumétrica de fibra de carbono, fração volumétrica da matriz e fração volumétrica de vazio do compósito curado pelo processo térmico

TABELA 5.18 - Densidades, frações volumétricas de fibras de carbono, frações volumétricas das matrizes e frações volumétricas de vazios dos compósitos curados por feixe de elétrons.

TABELA 5.19 - Propriedades mecânicas da matriz curada pelo processo térmico.

TABELA 5.20 - Propriedades mecânicas da matriz A2 curada por feixe de elétrons. 


\section{LISTA DE ABREVIATURAS E SÍMBOLOS}

$\mathrm{DSC}=$ Calorimetria exploratória diferencial

DMTA = Termodinâmico-mecânica

$T G=$ Termogravimetria

DGEBA = resina epoxídica do tipo éter diglicidílico de bisfenol $A$

DGEBF = resina epoxídica do tipo éter diglicidílico de bisfenol $F$

NOVOLAC = resina epoxídica do tipo éter diglicidílico de novolac fenólico

$T_{g}=$ temperatura de transição vítrea

$\mathrm{T}_{\mathrm{m}}=$ temperatura de fusão

$\mathrm{C}_{\mathrm{p}}=$ calor específico

$\mathrm{E}^{\prime}$ = módulo de elasticidade ou armazenamento

$\mathrm{E}^{\prime \prime}=$ módulo de perda

$\tan \delta=$ amortecimento (damping) ou fator de perda

kGy = unidade que expressa a dose absorvida em Gray ou dose de radiação que é a quantidade de energia absorvida por unidade de massa do material irradiado $\mathrm{kGy} \cdot \mathrm{s}^{-1}=$ unidade de taxa de dose que é a unidade de energia absorvida por unidade de tempo

TACTIX 123 = resina epoxídica do tipo DGEBA da Huntsman

PC2506 = hexafluoroantimonato de diariliodônio $\left(\mathrm{Ar}_{2} \mathrm{ISbF}_{6}\right)$ da Polyset

molecular sieves = alumino-silicato de sódio ou $\mathrm{Na}_{12}\left[\left(\mathrm{AlO}_{2}\right)_{12}\left(\mathrm{SiO}_{2}\right)_{12}\right] \cdot \mathrm{xH}_{2} \mathrm{O}$

$A 1$ = matriz (TACTIX 123) com 1\% em massa de PC2506 e $25 \%$ em massa de molecular sieves

A2 = matriz (TACTIX 123) com $2 \%$ em massa de PC2506 e $25 \%$ em massa de molecular sieves

A3 = matriz (TACTIX 123) com 3\% em massa de PC2506 e $25 \%$ em massa de molecular sieves

$\mathrm{H} 2$ = matriz (TACTIX 123) com $2 \%$ em massa de PC2506

FCA1 = compósito com reforço de fibra de carbono e a matriz A1

FCA2 = compósito com reforço de fibra de carbono e a matriz A2

FCA3 = compósito com reforço de fibra de carbono e a matriz A3

$\mathrm{FCH} 2$ = compósito com reforço de fibra de carbono e a matriz $\mathrm{H} 2$ 
HY 917 = endurecedor à base de anidrido metiltetrahidroftálico da Huntsman

DY 062 = acelerador de amina terciária benzildimetilamina da Huntsman

$\Delta \mathrm{H}_{\mathrm{a}}=$ entalpia da reação de cura residual da amostra

$\Delta \mathrm{H}_{\mathrm{t}}=$ entalpia da matriz polimérica não curada e determinada quando esta é submetida à análise de DSC

$\% \mathrm{FC}=$ massa de reforço em porcentagem

$\Delta \mathrm{m}_{\mathrm{c}}=$ perda de massa do compósito

$\Delta \mathrm{m}_{\mathrm{m}}=$ perda de massa da matriz

$\mathrm{d}_{\mathrm{a}}=$ densidade de um corpo sólido

$\mathrm{m}_{\mathrm{a}}=$ massa da amostra ao ar

$\mathrm{m}_{\mathrm{ap}}=$ massa aparente da amostra ou massa da amostra quando imersa

$\mathrm{d}_{\mathrm{l}}=$ densidade do líquido de imersão

$v_{f}=$ frações volumétricas de fibra de carbono

$\mathrm{v}_{\mathrm{m}}=$ frações volumétricas de matriz

$\mathrm{V}_{\mathrm{V}}=$ frações volumétricas de vazio

$\mathrm{d}_{\mathrm{f}}=$ densidade da fibra de carbono

$\mathrm{d}_{\mathrm{m}}=$ densidade da matriz

$\mathrm{d}_{\mathrm{c}}=$ densidade do compósito 


\section{INTRODUÇÃO}

Um material compósito polimérico é definido como uma combinação macroscópica de dois ou mais materiais distintos possuindo uma interface bem definida entre eles. Os compósitos são utilizados em virtude das suas propriedades estruturais e a sua definição pode ser restringida aos materiais que contêm um reforço (partículas e fibras contínuas ou descontínuas) ligado por uma matriz (Chawla, 1987).

$\mathrm{Na}$ fabricação de componentes de compósitos poliméricos, a matriz tem uma contribuição importante no desempenho desejado do produto. A matriz é responsável pela forma geométrica do componente e pela interface que tem a função de transferir as tensões oriundas do carregamento mecânico para os elementos de reforços, além de ser responsável pela resistência química e térmica.

De acordo com a aplicação, os compósitos poliméricos podem ser fabricados utilizando-se matrizes termofixas ou termoplásticas. As matrizes termofixas, como a resina poliéster insaturada, a estervinílica, a fenólica e a epoxídica, são selecionadas especialmente para atenderem requisitos de resistência mecânica e química. Estas matrizes necessitam de agente de cura para que ocorra a formação das ligações cruzadas ou a reação de cura. Dependendo da resina ou do agente de cura, esta reação ocorre à temperatura ambiente ou com a ação de calor. As matrizes termoplásticas de elevado desempenho, por sua vez, devem ser aquecidas até a temperatura de amolecimento ou fusão para serem processadas e pode exigir temperaturas entre $300^{\circ} \mathrm{C}$ e $450^{\circ} \mathrm{C}$. Os termoplásticos mais utilizados são polisulfona, polietersulfona, polieterimida, poliimida, poli(éter-éter-cetona) e poli(éter-cetona-cetona) (Campbell, 2006).

Embora os elementos de reforços dominem as propriedades mecânicas do compósito, a seleção da matriz pode ter influência na sua fabricação, condições de processamento e desempenho. Uma das propriedades mais importantes na seleção de uma matriz polimérica é a temperatura de transição vítrea e que esta seja pelo menos $30^{\circ} \mathrm{C}$ acima da temperatura de serviço do compósito (Campbell, 2006). 
$\mathrm{Na}$ elaboração de um componente de material compósito procura-se aproveitar as ótimas propriedades mecânicas dos reforços. A seleção do reforço leva sempre em conta os aspectos que variam desde o custo desta matéria-prima, desempenho pretendido e a técnica da fabricação empregada.

Os benefícios apresentados pelo uso de compósitos poliméricos, tais como a resistência química, a resistência à tração específica (razão entre a resistência à tração e a massa específica) e o módulo de elasticidade específico (razão entre o módulo de elasticidade e a massa específica) têm propiciado a utilização deste material em aplicações antes reservadas aos metais.

Os sistemas que utilizam matrizes poliméricas curadas pelo processo térmico necessitam de um tempo longo de cura e requerem uma logística bem estabelecida, uma vez que a quantidade de moldes e a ocupação das estufas ou autoclaves devem ser feitas de modo que a produção seja aproveitada ao máximo. Nos sistemas que utilizam resinas epoxídicas e endurecedores à base de anidridos, como no processo de enrolamento filamentar, por exemplo, necessita-se de um longo tempo de trabalho (pot life) e um ciclo de cura que pode atingir 16 horas e temperatura elevada, normalmente entre $100^{\circ} \mathrm{C}$ e $200^{\circ} \mathrm{C}$.

No processo de fabricação de compósitos poliméricos estruturais, as matérias-primas, os moldes, o consumo de energia elétrica e a mão-de-obra são fatores preponderantes no custo da produção. Este fato tem levado à aplicação de novas tecnologias no processo produtivo para garantir competitividade ao material.

A tecnologia de cura de compósitos poliméricos de matrizes epoxídicas utilizando radiação ionizante, como o feixe de elétrons (electron beam ou $\mathrm{EB}$ ), pode ser uma alternativa à cura de matrizes poliméricas termofixas. Uma das principais vantagens do processo é propiciar um ciclo de cura de poucos minutos a uma temperatura um pouco acima da ambiente (Crivello et al., 1997).

O estudo envolvendo a cura de compósitos poliméricos por feixe de elétrons compreende as etapas de seleção da matriz polimérica e iniciador catiônico, estudo dos parâmetros de processo como taxa de dose e dose total, a incorporação de tenacificadores, quando necessário, fabricação de moldes adequados ao processo e o estudo da interface entre a fibra e a matriz.

A cura pelo processo de feixe de elétrons apresenta também outras vantagens sobre a cura térmica (Lopata et al., 1999), tais como: 
i. A redução da contração da matriz epoxídica de $4 \%$ a $6 \%$ para $2 \%$ a $4 \%$;

ii. Os compósitos, os substratos metálicos e cerâmicos podem ser colados com adesivos que curam por feixe de elétrons, permitindo fabricar grandes peças ou estruturas;

iii. A fabricação de compósitos de grandes dimensões que não podem ser curadas em estufas ou autoclaves, por causa das limitações das dimensões destes equipamentos;

iv. O aumento da temperatura de transição vítrea utilizando a mesma resina;

v. A redução das tensões internas, pois neste processo é realizado a temperatura ambiente;

vi. A redução da geração de voláteis, pois não se utiliza endurecedores e aceleradores na sua formulação;

vii. A redução de custos para a fabricação de moldes, pois não é necessária a utilização de materiais resistentes à elevada temperatura;

viii. A redução do consumo de energia elétrica em razão do reduzido tempo do ciclo de cura;

ix. O tempo de trabalho ou pot life da formulação é longo, desde que protegida da radiação ultravioleta. A formulação pode ser armazenada a temperatura ambiente por um período de até dois anos.

O desenvolvimento do processo de fabricação e o reparo de compósitos por feixe de elétrons, sobretudo nas aplicações aeroespaciais, tiveram início em 1979 com o consórcio aeroespacial europeu Aerospatiale, que desenvolveu uma matriz epoxídica acrílica para a fabricação de tubos estruturais de material compósito para motores de foguete pelo processo de enrolamento filamentar (Beziers e Capdepuy, 1990). Neste mesmo período, a Atomic Energy of Canada Limited (AECL), iniciou o desenvolvimento de matrizes curadas por feixe de elétrons por meio da polimerização por radical livre.

Em 1994 a Lockheed Martin Skunk Works e a AECL iniciaram o desenvolvimento de fabricação de compósitos de geometria complexas e no ano de 1996 a Air Canada e a AECL desenvolveram o processo de reparo de aeronaves comercias (Lopata et al.,1998) por feixe de elétrons. No final da década de 90 a AECL transferiu o desenvolvimento e a tecnologia para a Acsion Industries (Lopata e Sidwell, 2003). 
Desde 1993 o Oak Ridge National Laboratory (ORNL) formou o grupo CRADA (Cooperative Research and Development Agreement) para desenvolver matrizes epoxídicas curadas por feixe de elétrons pelo mecanisno catiônico, ou seja, utilizando um iniciador catiônico (diariliodônio). Atualmente o grupo CRADA é patrocinado pelo governo federal dos Estados Unidos da América, incluindo o US Department of Energy, Office of Science, Laboratory Technology Research Program, NASA Langley Research Laboratory, US Air Force Research Laboratory Materials e US Army Research Laboratory Materials. Os parceiros e participantes da pesquisa e desenvolvimento incluem a Acsion Industries, Adherent Technologies Inc., Applied Poleramic Inc., Boeing Company, Cytec Industries Inc., E-Beam Services Inc., Hexcel Corporation, Lockheed Martin Corporation, STERIS Corporation, UCB Surface Specialties,YLA Inc., NASA Langley Research Laboratory e US Air Force Research Laboratory Materials. As subcontratadas incluem Michigan State University (contrato com a ORNL) e a National Research Council of Canada (contrato com a Acsion Industries) (Berejka, 2007).

O grupo CRADA é uma associação que reúne empresas de grande potencial financeiro e de desenvolvimento e pesquisa para o progresso desta tecnologia. 


\section{OBJETIVO}

O objetivo deste trabalho foi desenvolver matrizes poliméricas para 0 processo de cura por feixe de elétrons e determinar os parâmetros de irradiação para a fabricação de compósitos poliméricos com temperatura de transição vítrea similar ou superior à obtida pelos sistemas curados pelo processo térmico.

No presente estudo, utilizou-se uma matriz de resina epoxídica comercial do tipo éter diglicidílico de bisfenol A (DGEBA) e um iniciador catiônico (diariliodônio), que foi comparada com uma matriz de cura térmica formulada com a mesma resina epoxídica, um endurecedor à base de anidrido e um acelerador de amina. 


\section{ABORDAGEM TEÓRICA}

\subsection{Resinas epoxídicas}

Uma resina epoxídica é constituída de oligômeros que possuem grupos epoxídicos (FIG. 3.1) com capacidade de polimerizar e formar um termofixo.

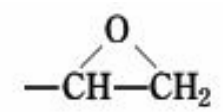

FIGURA 3.1 - Grupo epoxídico.

Os principais tipos de resinas epoxídicas comerciais são do tipo éter diglicidílico de bisfenol A (DGEBA), éter diglicidílico de bisfenol F (DGEBF), éter diglicidílico de novolac fenólico (NOVOLAC), as cicloalifáticas e os poliglicóis alifáticos. A escolha do tipo de resina e sua viscosidade são determinadas conforme a aplicação e processo de fabricação do produto. O mesmo tipo de resina freqüentemente é disponível com diferentes viscosidades.

Entre as matrizes termofixas utilizadas para compósitos poliméricos, as resinas epoxídicas apresentam vantagens, tais como:

i. Boa adesão em diversos tipos de cargas, reforços e substratos;

ii. Ampla variedade de resinas e agentes de cura, que proporcionam as mais diversas propriedades físico-químicas após a cura;

iii. Na reação de cura com o endurecedor não há a formação de água e ocorre a liberação de poucos produtos voláteis que propicia uma menor contração em relação às resinas fenólicas e poliéster;

iv. As resinas curadas possuem alta resistência química e bom isolamento elétrico.

As resinas epoxídicas são utilizadas em compósitos, revestimentos, circuitos impressos, encapsulamentos elétricos, adesivos, pisos e moldes. Em compósitos estruturais têm sido utilizadas em diversas aplicações industriais, componentes para o segmento aeroespacial, aeronáutico, naval e automobilístico. Podem ser formuladas para os mais diversos processos, tais como: enrolamento filamentar; pultrusão; moldagem por transferência de resina; infusão a vácuo; 
laminação por contato; laminação por projeção; estruturas sanduíche e prepreg (Campbell, 2006).

\subsection{Matrizes epoxídicas curadas a temperatura ambiente e pelo processo térmico}

A reação de cura de uma resina epoxídica é realizada com a adição de agente de cura ou endurecedor. O endurecedor promove a formação de ligações cruzadas, formando uma estrutura tridimensional denominada termofixo com a utilização ou não de energia térmica externa. $O$ perfil térmico que uma determinada formulação é submetida para que ocorra a formação das ligações cruzadas é denominado de ciclo de cura e consiste de intervalos de tempo e temperatura necessários para que a reação química ocorra, isto é, que a matriz seja curada.

A escolha do endurecedor é determinada em razão de sua aplicação, das condições de cura, das propriedades físico-químicas desejadas e tempo de manuseio, este último, definido como o tempo disponível para a utilização da matriz polimérica, que depende da temperatura e da quantidade de produto manuseado. Os agentes de cura mais utilizados são as aminas alifáticas, as aminas cicloalifáticas, as aminas aromáticas, os anidridos, as poliaminas e as polimercaptanas. As aminas e polimercaptanas reagem com a resina à temperatura ambiente e normalmente são pós-curadas termicamente para se obter uma maior temperatura de transição vítrea ( $\left.T_{g}\right)$ (Skeist, 1977).

Na FIG. 3.2 é mostrada a reação de cura de uma resina epoxídica com uma amina. Como pode ser observado, esta amina possui dois hidrogênios ligados num mesmo nitrogênio (amina primária) e cada hidrogênio reage com um grupo epoxídico. 
<smiles></smiles><smiles>[H][R10]CC(O)[C@@H]1OC1C</smiles><smiles>CC(O)COC(C)C1CO1</smiles>

FIGURA 3.2 - Reação de uma amina primária com o grupo epoxídico (Skeist, 1977).

As proporções de resina e endurecedor necessárias para obter a quantidade estequiométrica 1:1, podem ser calculadas por meio da equação 3.1 (Skeist, 1977).

massa molar de amina

$\begin{aligned} & \text { partes em massa de amina utilizada } \\ & \text { com } 100 \text { partes em massa de resina }\end{aligned}=\frac{\text { número de hidrogênios ativos por molécula }}{\text { equivalente epoxidico }} \cdot 100$

A reação de cura da resina epoxídica com o endurecedor de anidrido mostrada na FIG. 3.3 necessita de temperaturas acima de $100^{\circ} \mathrm{C}$ e a adição de uma pequena quantidade de um acelerador (0,5\% a $3 \%$ em massa), por exemplo, uma amina terciária para que a cura da matriz ocorra de maneira mais rápida. 

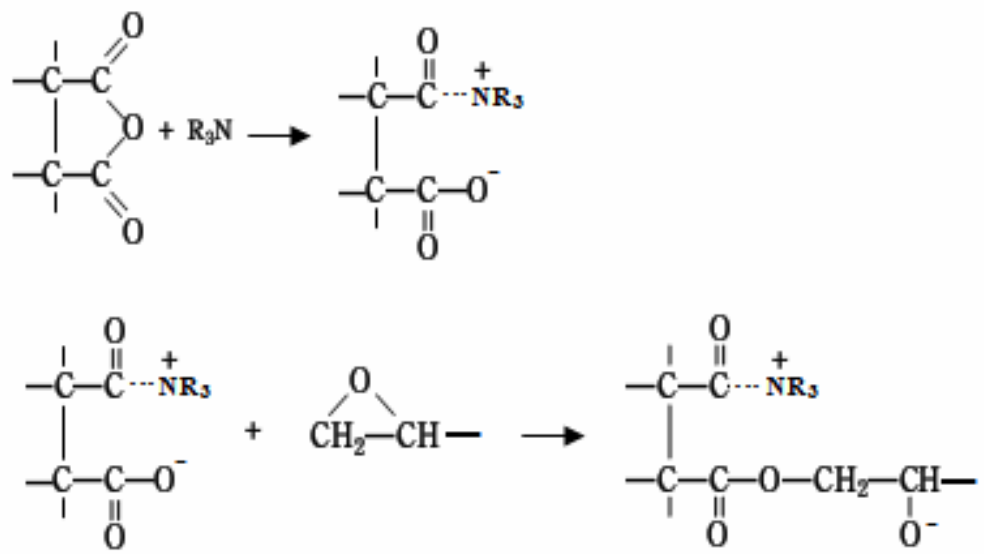

FIGURA 3.3 - Reação de um anidrido e de um acelerador com o grupo epoxídico (Skeist, 1977).

Um grupo anidrido reage com um grupo epoxídico e a quantidade necessária para obter a quantidade estequiométrica 1:1, pode ser calculada por meio da equação 3.2 (Skeist, 1977).

$$
\begin{aligned}
& \text { partes em massa do anidrido utilizado } \\
& \text { com } 100 \text { partes em massa de resina }
\end{aligned}=\frac{\frac{\text { massa molar do anidrido }}{\text { número de grupos anidridos }}}{\text { equivalente epoxidico }} .100
$$

Os anidridos proporcionam uma matriz com melhores propriedades térmicas (temperatura de transição vítrea mais elevada) e elétricas (maior isolamento elétrico) que as matrizes curadas com as aminas. Também são recomendados para processos que necessitam de longos tempos de fabricação, baixa viscosidade e reduzida exotermia durante a reação de cura (por exemplo, encapsulamentos elétricos).

As relações entre a estrutura química e as propriedades físico-químicas das resinas epoxídicas curadas são:

i. Quanto maior número de anéis aromáticos contidos na matriz curada, maior será sua estabilidade química e térmica;

ii. Menor densidade de ligações cruzadas, melhor tenacidade da matriz;

iii. Menor densidade de ligações cruzadas, menor a contração durante a cura da matriz; 
iv. Maior densidade de ligações cruzadas, melhor estabilidade química e térmica (aumenta a temperatura de transição vítrea) e maior fragilidade (Skeist, 1977).

\subsection{Matrizes epoxídicas curadas por feixe de elétrons}

Os elétrons de alta energia ao interagir com o material irradiado geram íons, radicais livres e moléculas em estado excitado capazes de iniciar e propagar uma polimerização. Dependendo do tipo da resina, a polimerização pode ocorrer pelo mecanismo de radicais livres ou iônicos. Para as resinas epoxídicas acrílicas com a reação de cura induzida por feixe de elétrons, a polimerização ocorre por meio de radicais livres, ao passo que para as resinas epoxídicas com iniciador catiônico (diariliodônio e triariliodônio) ocorre por meio de cátions (Koleske, 2002).

\subsubsection{Polimerização por meio de radicais livres}

Os oligômeros contendo ligação dupla não precisam de iniciadores quando irradiados por feixe de elétrons. A formação de radicais livres ocorre nos acrilatos ou metacrilatos contidos nos oligômeros epoxídicos (FIG. 3.4). Estes oligômeros são amplamente utilizados na composição de revestimentos e adesivos, entretanto, possuem alguns aspectos negativos, como a baixa temperatura de transição vítrea, baixa resistência à fratura e contração acima de $8 \%$, quando curadas em camadas espessas. Estes fatores contribuem para que sistemas formulados com estas resinas inviabilizem a fabricação de compósitos estruturais (Lopata e Chung, 1996).

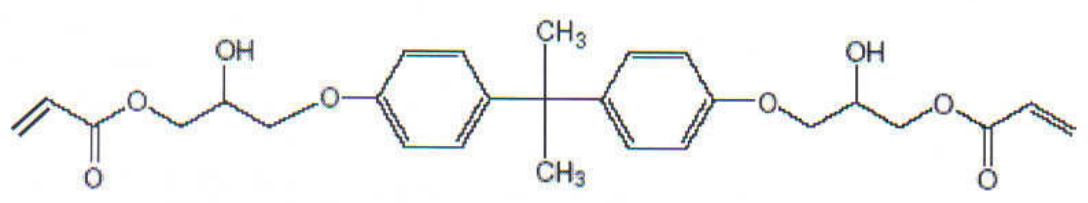

FIGURA 3.4 - Estrutura molecular do oligômero diacrilato de bisfenol A (Koleske, 2002).

\subsubsection{Polimerização catiônica}

As resinas epoxídicas comerciais do tipo éter diglicidílico de bisfenol $A$ (DGEBA), éter diglicidílico de bisfenol $F$ (DGEBF), cicloalifáticas e éter glicidílico de novolac fenólico (NOVOLAC) podem ser curadas quando irradiadas por feixe 
de elétrons (Ohamad e McLaughin, 1996, Crivello, 1999, Koleske, 2002 e Nishitsuji et al., 2007) e proporcionam matrizes com temperaturas de transição vítrea superiores e propriedades mecânicas similares ou um pouco inferiores às das mesmas resinas curadas pelo processo térmico. Este processo de cura necessita da adição de 1\% a 3\% de um iniciador catiônico (Lopata e Chung, 1996) em relação à massa de resina, energia alta fornecida pelo irradiador, com taxas de doses controladas para iniciar a polimerização e a formação de ligações cruzadas. A cura por feixe de elétrons é realizada à temperatura ambiente, entretanto, a entalpia de reação de cura pode elevar a temperatura da matriz até atingir aproximadamente $90^{\circ} \mathrm{C}$.

Dentre os iniciadores catiônicos existentes no mercado, o diariliodônio e o triarilsulfônio estão entre os mais utilizados, e para um mesmo ânion, o primeiro é mais eficiente e reativo que o segundo. A eficiência dos iniciadores catiônicos depende dos ânions e varia inversamente à nucleofilicidade destes. Dentro de uma dada família de iniciadores catiônicos, a reatividade do ânion no processo de cura segue a seguinte ordem (Lopata e Chung, 1996):

$$
\mathrm{SbF}_{6}^{-}>\mathrm{AsF}_{6}^{-}>\mathrm{PF}_{6}^{-}>\mathrm{BF}_{4}^{-}
$$

$\mathrm{Na}$ etapa da ativação do iniciador catiônico pelo feixe de elétrons, mostrada na FIG. 3.5, ocorre a formação de um ácido forte (ácido de Bronsted), responsável pela iniciação da polimerização (FIG. 3.6). As etapas seguintes da polimerização são a propagação, a transferência e a terminação da cadeia mostradas, respectivamente, nas FIG. 3.7, 3.8 e 3.9. 


$$
\begin{aligned}
& \mathrm{Ar}_{2} \mathrm{I}^{+} \mathrm{MF}_{6}^{-} \stackrel{\mathrm{e}^{-}}{\rightarrow}\left[\mathrm{Ar}_{2} \mathrm{I}^{+} \mathrm{MF}_{6}^{-}\right]^{*} \\
& \text { Iniciador catiônico estado excitado } \\
& {\left[\mathrm{Ar}_{2} \mathrm{I}^{+} \mathrm{MF}_{6}^{-}\right]^{*} \rightarrow \mathrm{Arl}^{+}+\mathrm{Ar} \cdot+\mathrm{MF}_{6}^{-}} \\
& \begin{array}{lll}
\text { estado excitado } & \begin{array}{c}
\text { cátion } \\
\text { radical }
\end{array} & \text { livre }
\end{array} \\
& \mathrm{Arl}^{+}+\mathrm{R}-\mathrm{H} \rightarrow \mathrm{Arl}^{+} \mathrm{H}+\mathrm{R} \cdot \\
& \text { hidrogênio } \\
& \text { ativo } \\
& \mathrm{Arl}^{+} \mathrm{H} \rightarrow \mathrm{Arl}+\mathrm{H}^{+} \mathrm{MF}_{6}^{-} \\
& \text {ácido de Bronsted }
\end{aligned}
$$

FIGURA 3.5 - Ativação do iniciador catiônico (Koleske, 2002).

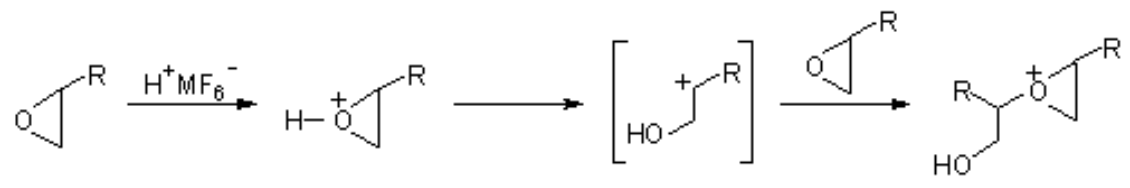

FIGURA 3.6 - Iniciação da polimerização catiônica (Koleske, 2002).
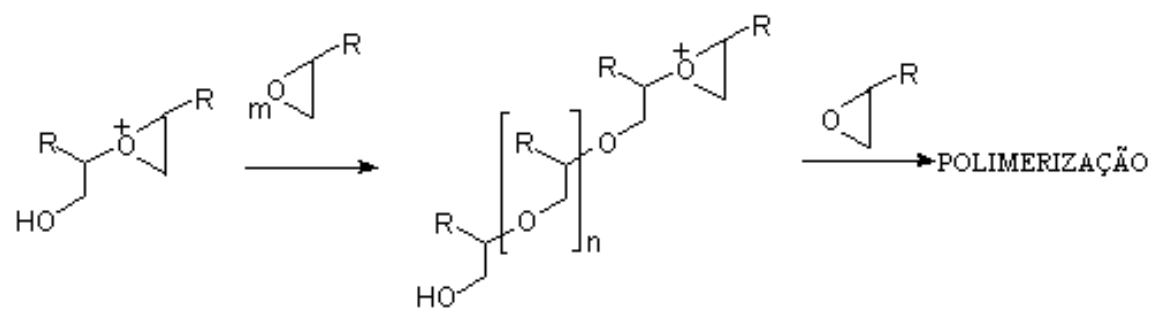

FIGURA 3.7 - Propagação da cadeia (Koleske, 2002). 


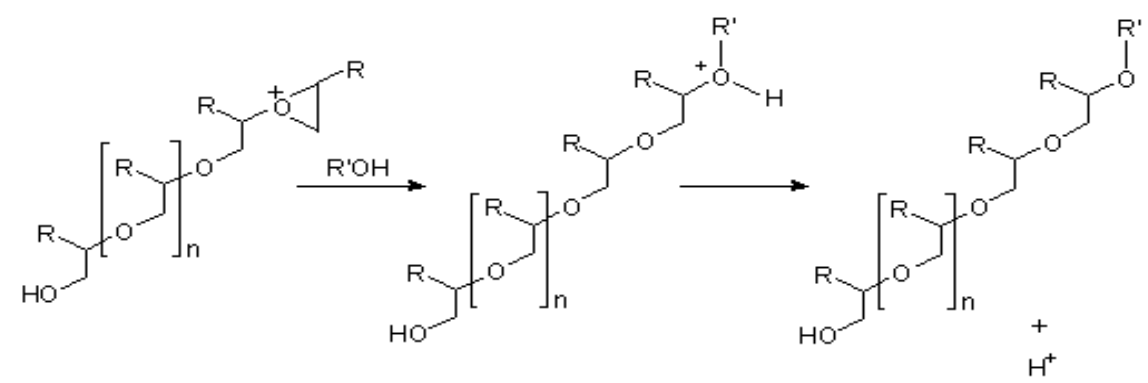

FIGURA 3.8 - Transferência da cadeia (Koleske, 2002).

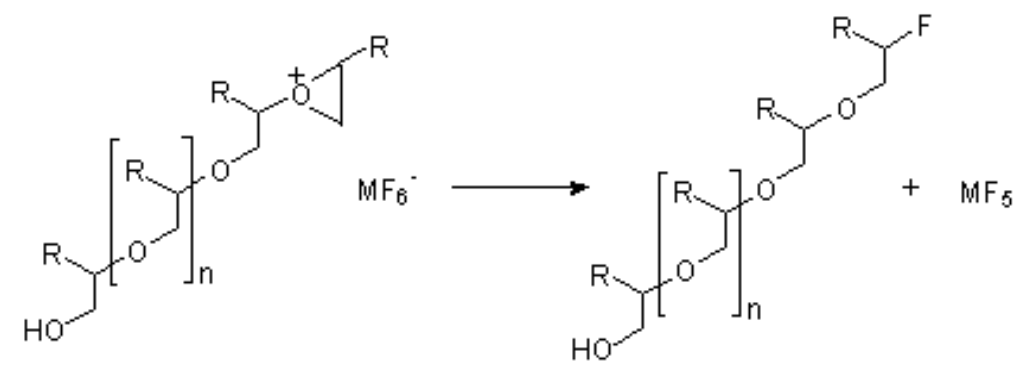

FIGURA 3.9 - Terminação da cadeia (Koleske, 2002).

A presença de aminas e substâncias contendo o grupo hidroxila na formulação da matriz ou no substrato provoca as terminações das cadeias (Lopata et al., 2001 e Zhang et al., 2002), ou seja, inibe a reação de cura da matriz, proporcionando um grau de cura baixo.

\subsection{Análise térmica}

O termo análise térmica é definido como um grupo de técnicas que medem a mudança de alguma propriedade física ou química de um material em função da temperatura. Esta técnica permite determinar o grau de cura, decomposição, cinética de reação, diagramas de fase, entalpia de reação, pureza, estabilidade térmica, oxidação, temperatura de transição vítrea $\left(T_{g}\right)$ e temperatura de fusão $\left(T_{m}\right)$, calor específico, condutividade térmica e teor de cristalinidade.

$A T_{g}$ é uma transição termodinâmica de segunda ordem (forças intermoleculares) que ocorre nas regiões amorfas de um material polimérico. A $T_{g}$ indica a transição de uma estrutura rígida para uma flexível, o que resulta na mudança de propriedades físicas, como por exemplo, a variação do calor 
específico $\left(C_{p}\right)$. Na temperatura abaixo da $T_{g}$, as macromoléculas não têm energia interna para mudanças conformacionais, tornando o polímero vítreo.

\subsubsection{Calorimetria exploratória diferencial (DSC)}

O DSC é uma técnica na qual se mede a diferença de energia fornecida para a amostra e para o material de referência inerte, por intermédio de uma programação controlada de temperatura. Uma vez que a técnica de DSC é sensível à variação do calor específico, determina-se a $T_{g}$ por esta técnica.

Existem duas modalidades utilizadas para se obter os dados de DSC. No DSC de compensação de potências, a amostra e a referência são aquecidas separadamente (fornos independentes), de maneira que suas temperaturas são mantidas iguais durante a análise. No DSC de fluxo de calor, a diferença no fluxo de calor na amostra e na referência é medida conforme a temperatura é aumentada ou diminuída linearmente. O fluxo diferencial de calor na amostra e na referência é monitorado por termopar formado pela junção do disco de Constantan e disco de Chromel que cobre a parte inferior de cada plataforma. A temperatura da amostra é medida diretamente pelo termopar Chromel-Alumel colocado sob o disco de Chromel (Koog et al., 2002).

Na FIG. 3.10 é mostrado o forno do equipamento DSC de fluxo de calor com uma amostra e uma referência (panela de alumínio).

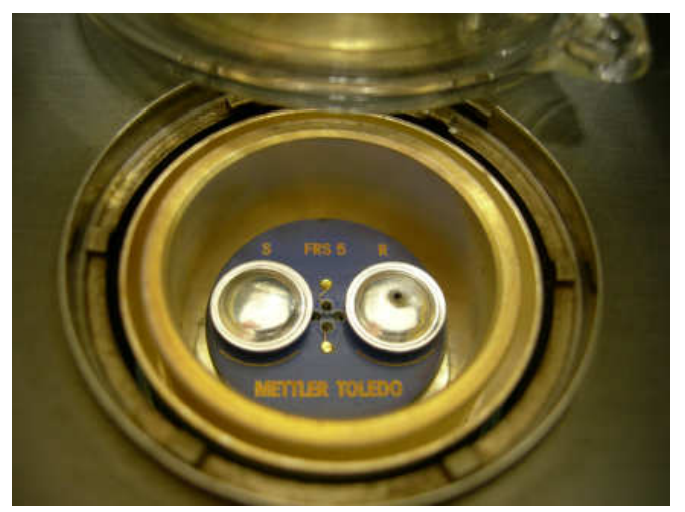

FIGURA 3.10 - À esquerda a panela com a amostra e à direita a panela vazia (referência) no forno do equipamento de DSC.

\subsubsection{Termodinâmico-mecânica (DMTA)}

É uma técnica na qual o comportamento mecânico do material sob carga oscilatória é medido em função da temperatura. As propriedades 
dinâmico-mecânicas são definidas a partir do comportamento do material frente à deformação e tensão oscilatórias de pequena amplitude.

O comportamento dinâmico-mecânico de um material depende da relação entre a escala de tempo do experimento e do tempo de relaxação característico do material. Este tempo da mobilidade das cadeias depende da estrutura, da temperatura e da pressão. Em experimentos dinâmico-mecânicos, a escala de tempo é controlada pela freqüência. À medida que diminui a freqüência, as cadeias poliméricas passam a ter mais tempo para relaxar e se acomodar à deformação sofrida. A temperatura influencia na mobilidade das cadeias e, conseqüentemente, no tempo de relaxação das mesmas. Estes ensaios são mais sensíveis às estruturas química e física dos materiais, fornecem mais informações sobre o material e diferentes freqüências podem ser extrapoladas para ensaios de longa duração.

O comportamento dinâmico-mecânico de um material é regido por sua viscoelasticidade, que é dependente do tipo de ensaio e da solicitação aplicada. Dependendo da resposta ao estímulo mecânico, o material pode ser classificado como elástico ou viscoso.

Para um material perfeitamente elástico, a deformação é proporcional à tensão aplicada e vice-versa, segundo a lei de Hooke, a relação é dada pelo módulo de elasticidade ou armazenamento ( $\left.E^{\prime}\right)$. Um material viscoso ideal obedece à lei de Newton, que estabelece que a tensão e a taxa de cisalhamento estão relacionadas por meio de uma característica intrínseca que é a viscosidade. Quando a deformação é permanente tem-se o comportamento viscoso com dissipação de energia representada pelo módulo de perda (E”).

Os materiais poliméricos apresentam comportamento mecânico intermediário ao elástico e ao viscoso, portanto, viscoelástico. A contribuição elástica e viscosa para o comportamento mecânico do polímero depende da temperatura e do tempo e é representada por um módulo complexo $\mathrm{E}^{*}$, composto por um componente elástico (E'), que representa a energia armazenada, e um componente viscoso (E"), que representa a energia dissipada. A relação entre estes parâmetros é dada pela equação 3.3 .

$$
E^{*}=E^{\prime}+i E^{\prime \prime}
$$

A dissipação de energia provoca uma defasagem entre a tensão aplicada e a deformação observada. No caso de tensão senoidal, a tangente do 
ângulo de defasagem $\delta$ representa o amortecimento (damping) ou fator de perda (equação 3.4).

$$
\tan \delta=\frac{E^{\prime \prime}}{E^{\prime}}
$$

A técnica de termodinâmico-mecânica permite caracterizar materiais em condições dinâmicas de deformação, obtendo-se módulo de armazenamento (E'), módulo de perda ( $E$ "), $T_{g}$, transições secundárias $(\beta, \gamma)$, efeito de cristalinidade, estrutura, reticulação, composição, cargas, relaxação de tensão e fluência.

O DMTA é composto de um forno, no qual o corpo-de-prova é posicionado num acessório adequado à análise, e a amostra fica em contato com uma haste acoplada a um motor que produz a deformação senoidal e sensores de força medem a tensão por ele transmitida. As variáveis envolvidas no experimento são a freqüência, temperatura, tensão e deformação. Na FIG. 3.11 é mostrado o forno, o acessório de flexão em três pontos e o sensor de força em contato com um corpo-de-prova.

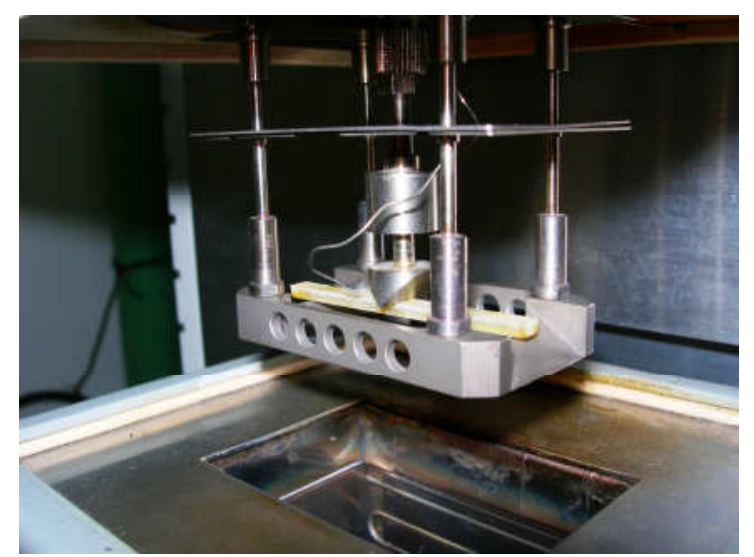

FIGURA 3.11 - Forno do equipamento de DMTA com um corpo-de-prova de matriz.

Os módulos E' e E" e tan $\delta$ refletem a mobilidade interna das moléculas que formam o material e dependem da estrutura molecular, ligações cruzadas, composição química, massa molecular, cristalinidade e orientação. Os fatores que dificultam a mobilidade molecular contribuem para um aumento de E' e diminuição E" e $\tan \delta$.

$\mathrm{Na}$ região da temperatura de transição vítrea ocorre uma maior mobilidade das cadeias poliméricas, proporcionando uma redução acentuada de E'. Isto traz como conseqüência, em razão do maior grau de liberdade que o 
material apresenta, a ocorrência de movimentos em porções maiores nas cadeias da região amorfa, aumentando a dissipação de energia em função da temperatura até um máximo de $\mathrm{E}$ " e de tan $\delta$. O valor máximo do módulo de perda na região da transição vítrea deve-se à alta conversão de energia mecânica em calor por meio dos movimentos das cadeias. Como a tan $\delta$ é a razão entre os módulos de perda e armazenamento, esta atingirá valores máximos em regiões próximas aos máximos observados para o E”, porém em temperaturas maiores. O máximo do pico da curva de E" corresponde a situação de máxima dissipação de energia mecânica, que na região de transição vítrea está associada à mudança do estado vítreo para o elástico (Wunderlich, 1997).

\subsubsection{Termogravimetria (TG)}

A TG é uma técnica na qual a perda de massa de uma substância é medida em função da temperatura sob atmosfera controlada. $O$ registro é a curva TG ou termogravimétrica, na qual a massa deve ser colocada na ordenada com valores decrescentes de cima para baixo e o tempo (t) ou temperatura $(T)$ na abscissa com valores crescentes da esquerda para a direita.

O equipamento consiste de uma balança analítica sensível, um forno, um sistema de gás de purga (atmosfera inerte ou reativa) e um microcomputador para o controle do instrumento, aquisição e apresentação dos dados. Esta técnica permite determinar as reações de decomposições e de oxidações, teor de umidade, voláteis, cinzas e cargas, estudos cinéticos, pirólise, corrosão em metais, reações de estado sólido, desidratação, diagrama de fase, propriedades magnéticas e outros (Koog, 2002). Na FIG. 3.12 é mostrado o forno do equipamento de TG com uma amostra dentro do cadinho de platina.

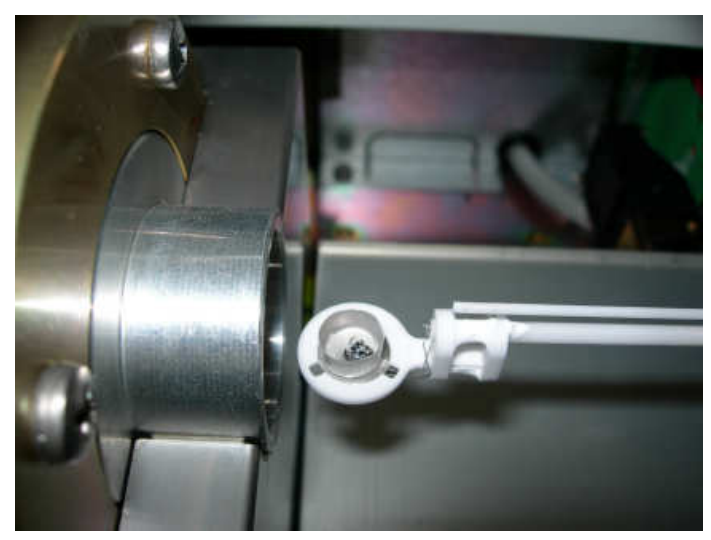

FIGURA 3.12 - Forno do equipamento de TG com o cadinho de platina. 


\subsection{Acelerador de elétrons}

O feixe de elétrons é uma radiação ionizante gerada pelos equipamentos denominados aceleradores de elétrons. Quando os elétrons dentro de uma faixa de energia, que pode variar de alguns keV até $\mathrm{MeV}$, são absorvidos pela matéria, originam os elétrons secundários resultantes dos processos de interação. Os elétrons acelerados perdem energia por interações de Coulomb com os átomos ou moléculas presentes no material irradiado. Isto resulta na formação de radicais livres, íons, elétrons e átomos ou moléculas no estado excitado. Os elétrons produzidos por aceleradores possuem energia suficiente para romper ligações químicas e propiciar o início de uma reação de polimerização.

Em todos os tipos de aceleradores, os elétrons são produzidos em um cátodo aquecido e mantido numa região de potencial mais elevado. Estes elétrons são acelerados por uma diferença de potencial aplicada entre o cátodo e o ânodo. Os elétrons adquirem energia suficiente para atravessar a janela de saída que é constituída de uma fina lâmina de titânio com espessura entre $20 \mu \mathrm{m}$ e $40 \mu \mathrm{m}$. Toda a região da produção e aceleração dos elétrons deve ser mantida em vácuo alto para permitir que a focalização e a aceleração do feixe em direção à janela sejam adequadas.

Na FIG. 3.13 é mostrada uma vista parcial de um acelerador, na qual no primeiro plano pode ser visto o sistema de varredura do feixe de elétrons.

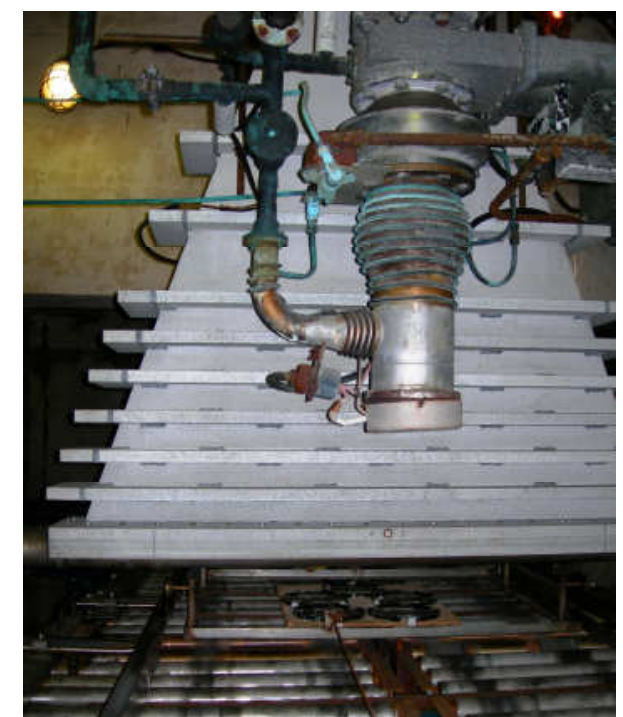

FIGURA 3.13 - Sistema de varredura do feixe de elétrons. 
A energia do feixe de elétrons é calculada em função da corrente no divisor de alta tensão do acelerador, levando-se em conta a espessura e a densidade do material alvo (material a ser irradiado). A energia é calculada para que os elétrons atravessem todo o material alvo, de modo que a dose no ponto de entrada e saída sejam iguais.

A dose de radiação ( $k G y$ ) é a quantidade de energia absorvida por unidade de massa do material irradiado ou a dose absorvida de radiação. $A$ taxa de dose $\left(\mathrm{kGy}_{\mathrm{s}} \mathrm{s}^{-1}\right)$ controla a velocidade da cura e, portanto, está intimamente ligado ao tempo necessário para a cura do material polimérico.

A dose é calculada levando-se em conta a distância do material alvo à janela do acelerador (por onde sai o feixe de elétrons) e a energia, que é diretamente proporcional à corrente do feixe, ao tempo de exposição e ao número de passadas do material debaixo do feixe de elétrons e inversamente proporcional à velocidade do processo que o material é submetido. 


\section{MATERIAIS E MÉTODOS}

Para desenvolver as matrizes poliméricas do presente trabalho foram feitas aproximadamente 50 formulações com diferentes tipos de resinas epoxídicas, iniciadores catiônicos com diversas concentrações, tenacificadores e cerca de 30 experimentos no acelerador de elétrons para o estudo dos parâmetros de irradiação (taxa de dose e dose total).

Os produtos que foram avaliados para o desenvolvimento de matrizes de cura por feixe de elétrons estão relacionados abaixo:

\section{A. Resinas epoxídicas:}

i. TACTIX 123: resina epoxídica líquida de pureza alta do tipo éter diglicidílico de bisfenol A (DGEBA) da Huntsman;

ii. GY 260: resina epoxídica líquida do tipo éter diglicidílico de bisfenol $A$ (DGEBA) da Huntsman;

iii. LY 1564: resina epoxídica líquida do tipo éter diglicidílico de bisfenol $A$ (DGEBA) da Huntsman;

iv. LY 5052: resina epoxídica líquida do tipo éter diglicidílico de bisfenol $A$ (DGEBA) da Huntsman;

v. GT 7071: resina epoxídica sólida do tipo éter diglicidílico de bisfenol A (DGEBA) da Huntsman;

vi. GY 281: resina epoxídica líquida do tipo éter diglicidílico de bisfenol $\mathrm{F}$ (DGEBF), da Huntsman;

vii. GY 282: resina epoxídica líquida do tipo éter diglicidílico de bisfenol $\mathrm{F}$ (DGEBF), da Huntsman;

viii. DER 354: resina epoxídica líquida do tipo éter diglicidílico de bisfenol $\mathrm{F}$ (DGEBF), da Dow;

ix. UVR 6110: resina epoxídica líquida do tipo cicloalifática da Dow;

X. CY 179: resina epoxídica líquida do tipo cicloalifática da Huntsman;

xi. EPN 1180: resina epoxídica semi-sólida do tipo éter glicidílico de novolac fenólico da Huntsman. 
B. Iniciadores catiônicos:

i. UVI-6976: solução de hexafluoroantimonato de triariliodônio em carbonato de propileno da DOW;

ii. Irgacure 250: solução de hexafluorofosfato de diariliodônio em carbonato de propileno da CIBA;

iii. 44583-5: hexafluoroantimonato de diariliodônio da Aldrich;

iv. UV9390C: solução de hexafluoroantimonato de diariliodônio em diluente reativo diglicidil éter da GE Silicones;

v. PC 2506: hexafluoroantimonato de diariliodônio da Polyset.

C. Tenacificadores:

i. DY 3601: diluente reativo de diglicidil éter de polioxipropileno glicol da Huntsman;

ii. DY 040: flexibilizante de polialquilenoglicol da Huntsman;

iii. UDEL P-1700: polisulfona da Solvay;

iv. RADEL A 105p: polietersulfona com grupos ativos da Solvay;

v. KRATON FG 1901X: borracha termoplástica (SEBS) funcionalizada com anidrido maleico da Kraton.

Como um dos objetivos do trabalho foi desenvolver matrizes poliméricas curadas por feixe de elétrons para fabricação de compósitos, houve a necessidade do estudo dos parâmetros de processo de irradiação fosse feito nas amostras de matrizes e de compósitos.

Foi observado em testes preliminares, utilizando somente a matriz polimérica, um aumento excessivo de temperatura no início da reação de cura. $\mathrm{O}$ aumento de temperatura, caso ocorresse no compósito, seria bastante indesejável, pois poderia provocar maior contração e tensões internas. Este fenômeno justificou a fabricação de corpos-de-prova de compósitos para o trabalho experimental.

Os compósitos fabricados pelo processo de enrolamento filamentar necessitam de matrizes poliméricas de viscosidade baixa. Dentre as resinas epoxídicas testadas e citadas anteriormente, foi escolhida a resina epoxídica TACTIX 123 líquida do tipo DGEBA (FIG. 4.1), em razão de sua viscosidade baixa e grau de pureza alto, assim como foi constatado sua reatividade de cura alta e 
temperatura de transição vítrea elevada quando curada. Na TAB. 4.1 são apresentadas as características desta resina (Huntsman, 2004).<smiles>CC(C)(c1ccc(CC2CO2)cc1)c1ccc(OCC2CO2)cc1</smiles>

FIGURA 4.1 - Estrutura molecular da resina epoxídica DGEBA.

TABELA 4.1 - Características da resina epoxídica.

\section{Características}

Tipo

Viscosidade (m.Pa.s)

Equivalente epoxídico (g.eq $\left.{ }^{-1}\right)$

Densidade $\left(\mathrm{g}_{\mathrm{cm}} \mathrm{cm}^{-3}\right.$ a $\left.25^{\circ} \mathrm{C}\right)$

Fabricante
TACTIX 123

DGEBA de pureza alta

3200 a $27^{\circ} \mathrm{C}$

$172-176$

1,16

Huntsman

Para a fabricação do compósito foi utilizada fibra de carbono contínua do tipo AS4 de 12k (doze mil filamentos), com tratamento superficial e sem sizing. Na TAB. 4.2 são apresentadas as propriedades mecânicas e características da fibra de carbono (Hexcel, 2004).

TABELA 4.2 - Propriedades mecânicas e características da fibra de carbono.

\section{Propriedades e características}

Limite de resistênica à tração (MPa)

Módulo de elasticidade (GPa)

Alongamento até a ruptura (\%)

Diâmetro da fibra $(\mu \mathrm{m})$

Densidade volumétrica $\left(\mathrm{g} . \mathrm{cm}^{-3}\right)$

Densidade linear $\left(\mathrm{g} \cdot \mathrm{m}^{-1}\right)$

Fabricante

\section{AS4 12K}

4070

228

1,8

7,1

1,79

0,80

Hexcel 


\subsection{Enrolamento filamentar}

No processo de enrolamento filamentar as fibras contínuas de carbono, vidro ou aramida, já previamente impregnadas com a matriz polimérica, como no caso do prepreg ou impregnadas durante o enrolamento são depositadas sobre um mandril em rotação (FIG. 4.2). O mandril geralmente é de aço ou de alumínio com uma superfície uniforme e deve apresentar um ótimo acabamento superficial.

Em aplicações estruturais o reforço contínuo é depositado com precisão sobre o mandril seguindo orientações e com o número requerido de camadas préestabelecidas pelo projeto. A peça gerada é uma superfície de revolução e pode ou não incluir fechamentos nas extremidades. O mandril é removido após a cura da matriz polimérica (Chawla, 1987).

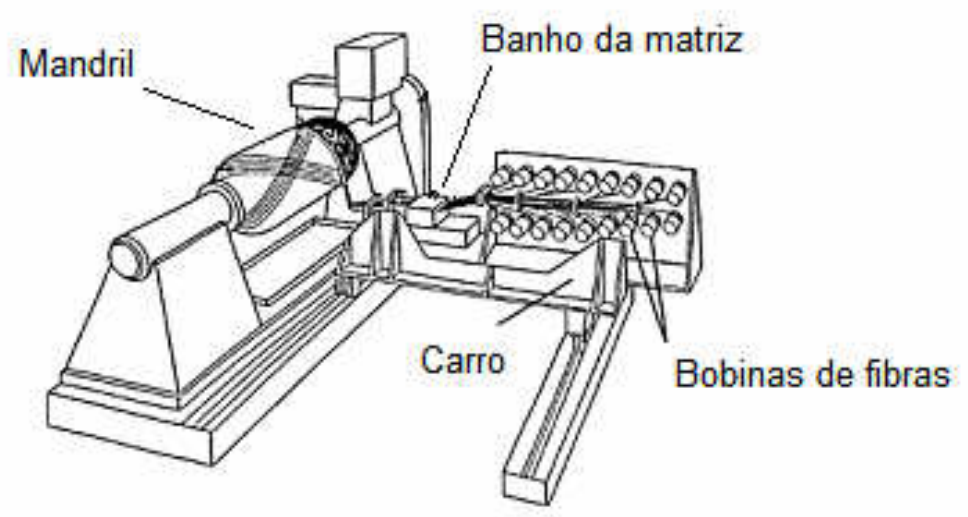

FIGURA 4.2 - Enrolamento filamentar (Strong, 1989).

\subsection{Cura por feixe de elétrons}

Para promover o início da polimerização catiônica foi utilizado o iniciador catiônico hexafluoroantimonato de diariliodônio $\left(\mathrm{Ar}_{2} \mathrm{ISbF}_{6}\right)$ com uma concentração de $1 \%$ a $3 \%$ em massa em relação à resina epoxídica (Lopata e Chung, 1996). Este produto decompõe quando submetido ao feixe de elétrons, à radiação ultravioleta na faixa de $240 \mathrm{~nm}$ a $300 \mathrm{~nm}$ ou quando aquecido a uma temperatura acima de $170^{\circ} \mathrm{C}$. O iniciador catiônico utilizado foi o PC 2506 da Polyset, por causa de sua maior reatividade em relação aos outros testados, cuja estrutura molecular é mostrada na FIG.4.3. 


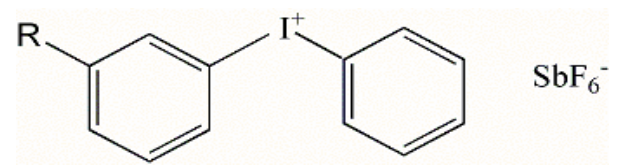

FIGURA 4.3 - Estrutura molecular do hexafluoroantimonato de diariliodônio.

A contaminação de água contida na resina epoxídica foi removida utilizando o produto molecular sieves (alumino-silicato de sódio ou $\mathrm{Na}_{12}\left[\left(\mathrm{AlO}_{2}\right)_{12}\left(\mathrm{SiO}_{2}\right)_{12}\right] \cdot \mathrm{xH}_{2} \mathrm{O}$ com poros de $0,4 \mathrm{~nm}$ e na forma de grão de $3,2 \mathrm{~mm}$ da Aldrich Chemical Company Inc. Segundo Lopata et al. (2001), é aceitável que, numa formulação de uma matriz para cura por feixe de elétrons, haja a presença de contaminantes com concentração máxima de água de $1 \%$ ou 10.000 ppm e $0,1 \%$ ou 1.000 ppm de amina utilizada como agente de cura.

\subsubsection{Preparação das formulações das matrizes poliméricas}

Foram preparadas três formulações denominadas de A1, A2 e A3 com respectivamente 1\%, 2\% e 3\% em massa de PC 2506 e 25\% em massa do produto molecular sieves. Uma quarta amostra $(\mathrm{H} 2)$ foi preparada somente com $2 \%$ em massa de PC 2506. Na TAB. 4.3 são apresentadas as formulações estudadas neste trabalho.

TABELA 4.3 - Formulações das matrizes para o processo por feixe de elétrons.

\begin{tabular}{ccccc}
\hline Formulação & A1 $(\mathrm{g})$ & A2 $(\mathrm{g})$ & A3 $(\mathrm{g})$ & H2 $(\mathrm{g})$ \\
\hline TACTIX 123 & 100,00 & 100,00 & 100,00 & 100,00 \\
PC 2506 & 1,00 & 2,00 & 3,00 & 2,00 \\
molecular sieves & 25,00 & 25,00 & 25,00 & - \\
\hline
\end{tabular}

As formulações foram homogeneizadas por 20 minutos, numa temperatura entre $70^{\circ} \mathrm{C}$ e $80^{\circ} \mathrm{C}$. O produto molecular sieves foi acondicionado a $120^{\circ} \mathrm{C}$ por 12 horas, adicionado à formulação e homogeneizado à temperatura ambiente. Em seguida as formulações foram novamente aquecidas a uma temperatura de $70^{\circ} \mathrm{C}$ e realizou-se vácuo por 20 minutos para retirar o ar contido na mistura. As formulações foram protegidas da luz ultravioleta e guardadas num dessecador. 


\subsubsection{Preparação dos corpos-de-prova de matrizes poliméricas}

A matriz curada por feixe de elétrons foi caracterizada por meio da análise térmica e ensaio mecânico de tração. A temperatura de transição vítrea foi determinada pela técnica de termodinâmico-mecânica (DMTA) e calorimetria exploratória diferencial (DSC), utilizando-se também esta última para quantificar o grau de cura das matrizes.

Os corpos-de-prova para o DMTA foram preparados conforme a norma ASTM E 1640-99, na forma de barras medindo $2,5 \mathrm{~mm} \times 4,0 \mathrm{~mm} \times 50,0 \mathrm{~mm}$, respectivamente, a espessura, a largura e o comprimento. Estas mesmas amostras foram utilizadas para a técnica de DSC.

Na FIG. 4.4 é mostrado o molde de silicone para a fabricação dos corpos-de-prova de DMTA para matrizes. Os moldes foram fabricados de silicone, em virtude da própria característica do material que permite uma desmoldagem fácil.

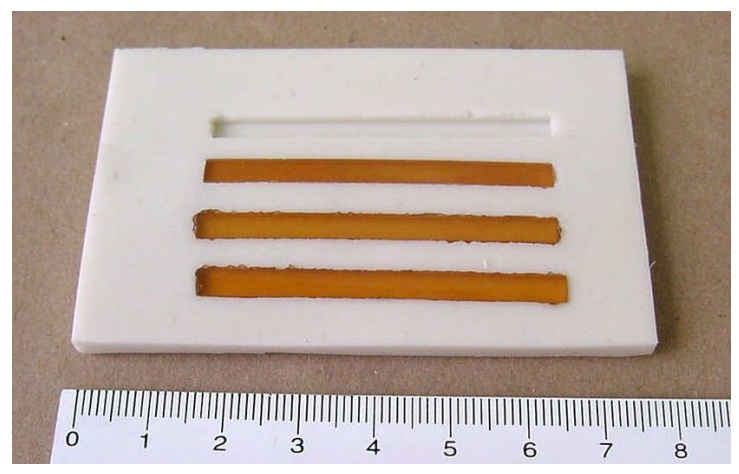

FIGURA 4.4 - Molde de silicone para corpos-de-prova de matrizes para DMTA.

$\mathrm{Na}$ FIG. 4.5 são mostrados os corpos-de-prova de matriz adequadamente preparados para serem irradiados. Os moldes foram envolvidos com um filme plástico para protegê-los da forte exaustão de ar presente durante 0 processo de irradiação. 


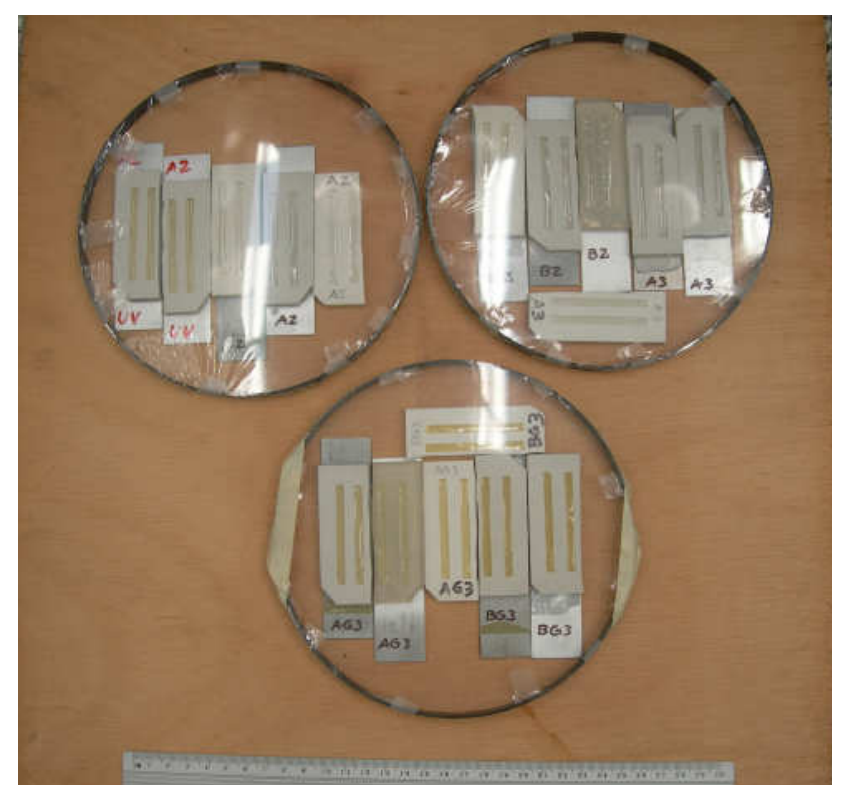

FIGURA 4.5 - Os corpos-de-prova de matrizes para a irradiação.

Na FIG. 4.6 é mostrado o molde de silicone para a fabricação dos corpos-de-prova de tração de matriz polimérica, os quais foram preparados seguindo as orientações da norma ASTM D 638-99 (com as dimensões do tipo I).

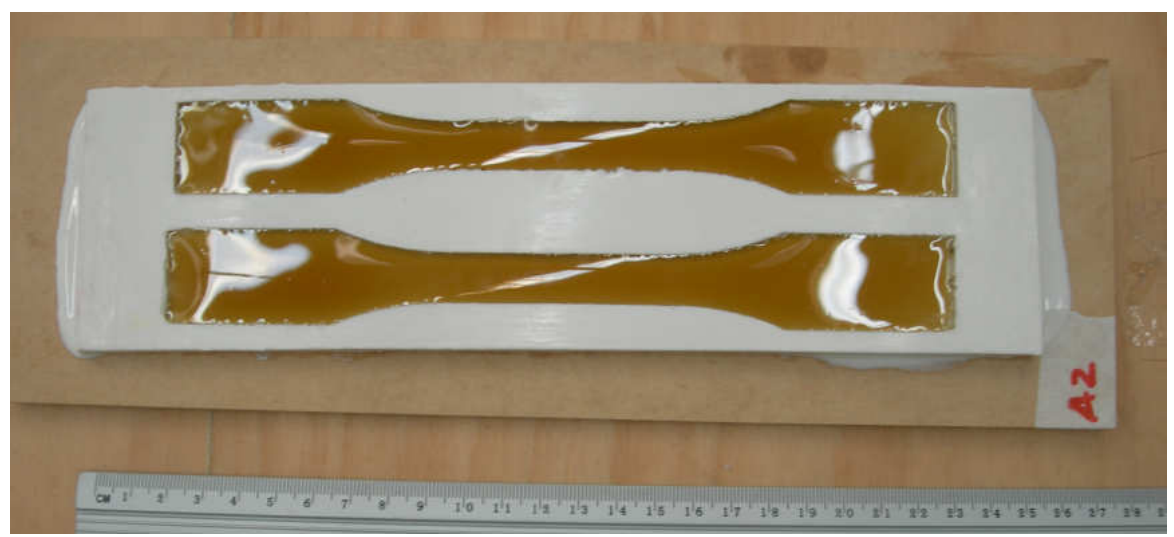

FIGURA 4.6 - Molde de silicone para corpos-de-prova de tração de matriz polimérica.

As irradiações foram feitas em um acelerador de elétrons Dynamitron JOB 188, de energia variável de 0,5MeV a 1,5MeV, corrente elétrica de 0,1mA a $25 \mathrm{~mA}$, potência de $37,5 \mathrm{~kW}$ e com varredura de feixe que varia de $60 \mathrm{~cm}$ a $120 \mathrm{~cm}$, do Instituto de Pesquisas Energéticas e Nucleares - IPEN em São Paulo.

Segundo Janke et al. (1997), a maioria dos compósitos poliméricos são curados com doses entre 70kGy e 250kGy. A dose específica é definida para 
cada tipo de resina, de iniciador e concentração utilizados, tipo da fibra e sua porcentagem em massa presente no compósito.

A entalpia da reação de cura das matrizes epoxídicas por feixe de elétrons é elevada quando comparada com o processo de cura térmica e por este motivo, a taxa de dose deve ser baixa no início do processo de cura para não ocorrer uma exotermia elevada. A menor taxa de dose utilizada neste processo foi de 1,82 kGy.s ${ }^{-1}$ em razão da limitação do equipamento. Uma taxa de dose alta contribui para reduzir o tempo do processo de cura, entretanto, somente pode ser utilizada após a solidificação da matriz para completar a dose total da irradiação, pois se fosse empregada na etapa inicial do processo, provocaria uma contração indesejável no material em virtude da reatividade alta do sistema. A maior taxa de dose empregada e que o equipamento proporcionou para este estudo foi de $57,6 \mathrm{kGy} \cdot \mathrm{s}^{-1}$. Utilizou-se a velocidade de $3,36 \mathrm{~m} \cdot \mathrm{min}^{-1}$ na bandeja onde os corpos-de-prova foram irradiados a temperatura de $25^{\circ} \mathrm{C}$.

A combinação dos parâmetros de processo e formulações das matrizes poliméricas permitiu inúmeras condições de irradiação, o que produziria uma excessiva quantidade de amostras para o tempo previsto para este estudo. Diante destas circunstâncias, optou-se por dois processos diferentes de irradiação com três doses totais para a amostra $A 2$, ao passo que para as amostras $A 1, A 3$ e H2 apenas um processo com uma dose total.

No primeiro processo de irradiação da amostra A2 foi utilizada somente a taxa de dose de 1,82 kGy.s ${ }^{-1}$ até completar as doses totais de 103,6kGy, 155,0kGy e 206,4kGy, conforme apresentada na TAB. 4.4. No segundo processo foi utilizada a taxa de dose de 1,82 kGy.s ${ }^{-1}$ na etapa inicial do processo, seguida da taxa de dose de 57,6 kGy.s ${ }^{-1}$ até completar as doses totais de 103,6kGy, 155,0kGy e 206,4kGy e são apresentadas respectivamente nas TAB. 4.5, TAB. 4.6 e TAB. 4.7.

As matrizes $\mathrm{A} 1, \mathrm{~A} 3$ e $\mathrm{H} 2$ foram irradiadas utilizando taxa de dose de $1,82 \mathrm{kGy} \cdot \mathrm{s}^{-1}$ na etapa inicial do processo, seguida da taxa de dose de 57,6 kGy.s ${ }^{-1}$ até completar a dose total de 206,4 kGy, conforme a TAB. 4.7.

A escolha da matriz A2 para ser irradiada com diferentes processos de irradiação e doses totais, foi em razão dos testes preliminares que indicaram que a concentração de $2 \%$ do iniciador catiônico, seria a mais adequada. 
Nas condições em que foi utilizada a taxa de dose de 57,6 kGy.s ${ }^{-1}$, o tempo de espera de dois minutos entre as passadas teve a finalidade de evitar que a temperatura do material irradiado elevasse demasiadamente.

TABELA 4.4 - Condições de irradiação da matriz A2.

Amostra: A2

\begin{tabular}{ccccc}
\hline $\begin{array}{c}\text { Corrente de } \\
\text { feixe }(\mathrm{mA})\end{array}$ & $\begin{array}{c}\text { Taxa de dose } \\
\left(\mathrm{kGy} . \mathrm{s}^{-1}\right)\end{array}$ & $\begin{array}{c}\text { Dose/passada } \\
(\mathrm{kGy})\end{array}$ & $\begin{array}{c}\text { Número de } \\
\text { passadas }\end{array}$ & $\begin{array}{c}\text { Dose total } \\
(\mathrm{kGy})\end{array}$ \\
\hline 0,4 & 1,82 & 0,803 & 129 & 103,6 \\
0,4 & 1,82 & 0,803 & 193 & 155,0 \\
0,4 & 1,82 & 0,803 & 257 & 206,4 \\
\hline
\end{tabular}

TABELA 4.5 - Condições de irradiação da matriz A2.

\begin{tabular}{ccccc}
\hline \multicolumn{5}{c}{ Amostra: A2 } \\
\hline $\begin{array}{c}\text { Corrente de } \\
\text { feixe }(\mathrm{mA})\end{array}$ & $\begin{array}{c}\text { Taxa de dose } \\
\left(\mathrm{kGy} \cdot \mathrm{s}^{-1}\right)\end{array}$ & $\begin{array}{c}\text { Dose/passada } \\
(\mathrm{kGy})\end{array}$ & $\begin{array}{c}\text { Número de } \\
\text { passadas }\end{array}$ & $\begin{array}{c}\text { Dose } \\
(\mathrm{kGy})\end{array}$ \\
\hline 0,4 & 1,82 & 0,803 & 65 & 52,2 \\
12,7 & 57,6 & 25,7 & $\begin{array}{c}2 \text { (espera de 2min } \\
\text { entre passadas })\end{array}$ & 51,4 \\
\hline \multicolumn{4}{c}{ Dose total $=52,2 \mathrm{kGy}+51,4 \mathrm{kGy}=103,6 \mathrm{kGy}$} \\
\hline
\end{tabular}


TABELA 4.6 - Condições de irradiação da matriz A2.

\begin{tabular}{ccccc}
\hline \multicolumn{5}{c}{ Amostra: A2 } \\
\hline feixe $(\mathrm{mA})$ & $\begin{array}{c}\text { Taxa de dose } \\
\left(\mathrm{kGy} \cdot \mathrm{s}^{-1}\right)\end{array}$ & $\begin{array}{c}\text { Dose/passada } \\
(\mathrm{kG})\end{array}$ & $\begin{array}{c}\text { Número de } \\
\text { passadas }\end{array}$ & $\begin{array}{c}\text { Dose } \\
(\mathrm{kGy})\end{array}$ \\
\hline 0,4 & 1,82 & 0,803 & 65 & 52,2 \\
12,7 & 57,6 & 25,7 & 4 (espera de 2min \\
& & & 102,8 \\
& Dose total = 52,2kGy + 102,8kGy = 155,0kGy & \\
\hline
\end{tabular}

TABELA 4.7 - Condições de irradiação das matrizez A1, A2, A3 e H2.

Amostras: A1, A2, A3 e H2

\begin{tabular}{ccccc}
\hline $\begin{array}{c}\text { Corrente de } \\
\text { feixe }(\mathrm{mA})\end{array}$ & $\begin{array}{c}\text { Taxa de dose } \\
\left(\mathrm{kGy} \cdot \mathrm{s}^{-1}\right)\end{array}$ & $\begin{array}{c}\text { Dose/passada } \\
(\mathrm{kGy})\end{array}$ & $\begin{array}{c}\text { Número de } \\
\text { passadas }\end{array}$ & $\begin{array}{c}\text { Dose } \\
(\mathrm{kGy})\end{array}$ \\
\hline 0,4 & 1,82 & 0,803 & 65 & 52,2 \\
12,7 & 57,6 & 25,7 & $\begin{array}{c}6 \text { (espera de 2min } \\
\text { entre passadas })\end{array}$ & 154,2 \\
\hline \multicolumn{4}{c}{ Dose total = 52,2kGy + 154,2kGy = 206,4kGy } \\
\hline
\end{tabular}

Nas FIG. 4.7 e 4.8 são mostradas, respectivamente, a bandeja com as amostras das matrizes para a irradiação e o corpo-de-prova de DMTA da matriz curada por feixe de elétrons. 


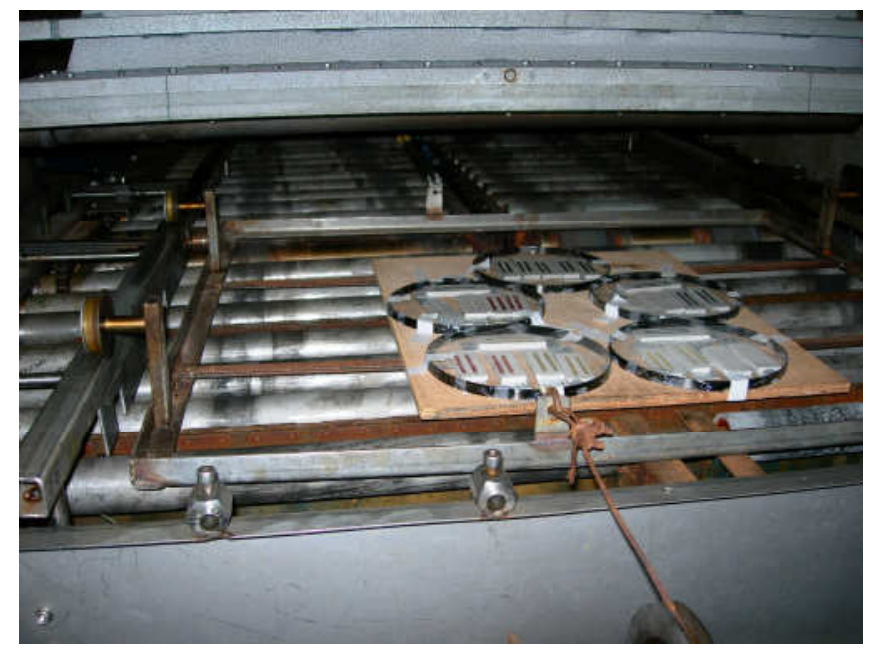

FIGURA 4.7 - Bandeja com as amostras das matrizes.

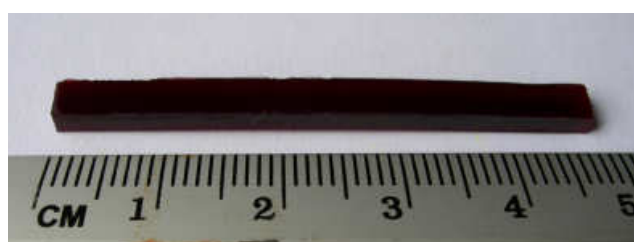

FIGURA 4.8 - Corpo-de-prova de DMTA da matriz curada por feixe de elétrons.

Os corpos-de-prova de tração das matrizes com espessura de 3,5mm foram irradiados com condições de irradiação apresentadas na TAB. 4.8. Estas condições foram diferentes dos corpos-de-prova de DMTA em razão das espessuras dos mesmos. Utilizou-se a velocidade de 3,36 m. $\mathrm{min}^{-1}$ na bandeja onde os corpos-de-prova foram irradiados a temperatura de $25^{\circ} \mathrm{C}$. Na FIG. 4.9 é mostrado o corpo-de-prova de tração da matriz curada por feixe de elétrons. 
TABELA 4.8 - Condições de irradiação do corpo-de-prova de tração da matriz A2.

\begin{tabular}{|c|c|c|c|c|}
\hline \multicolumn{5}{|c|}{ Amostra: A2 } \\
\hline $\begin{array}{l}\text { Corrente de } \\
\text { feixe }(m A)\end{array}$ & $\begin{array}{c}\text { Taxa de dose } \\
\left.\text { (kGy.s }{ }^{-1}\right)\end{array}$ & $\begin{array}{c}\text { Dose/passada } \\
\text { (kGy) }\end{array}$ & $\begin{array}{l}\text { Número de } \\
\text { passadas }\end{array}$ & $\begin{array}{l}\text { Dose } \\
\text { (kGy) }\end{array}$ \\
\hline 0,4 & 1,63 & 0,725 & 69 & 50,0 \\
\hline 12,3 & 50,06 & 22,343 & $\begin{array}{c}7 \text { (espera de } 2 \mathrm{~min} \\
\text { entre passadas) }\end{array}$ & 156,4 \\
\hline
\end{tabular}

FIGURA 4.9 - Corpo-de-prova de tração da matriz curado por feixe de elétrons.

\subsubsection{Preparação dos corpos-de-prova de compósitos}

Os corpos-de-prova de compósitos curados por feixe de elétrons foram preparados pelo processo de enrolamento filamentar. Na FIG. 4.10 é mostrado o molde utilizado, feito de TEFLON, para facilitar a desmoldagem do compósito curado e evitar o aquecimento excessivo durante a irradiação. As dimensões das faces bobinadas foram $2 \mathrm{~mm} \times 24 \mathrm{~mm} \times 60 \mathrm{~mm}$, respectivamente, a espessura, a largura e o comprimento. De um molde foram obtidas duas placas para fabricar os corpos-de-prova para a técnica de DMTA. Estas amostras também foram utilizadas para determinar a temperatura de transição vítrea e quantificar o grau de cura das mesmas por meio da técnica de DSC. 


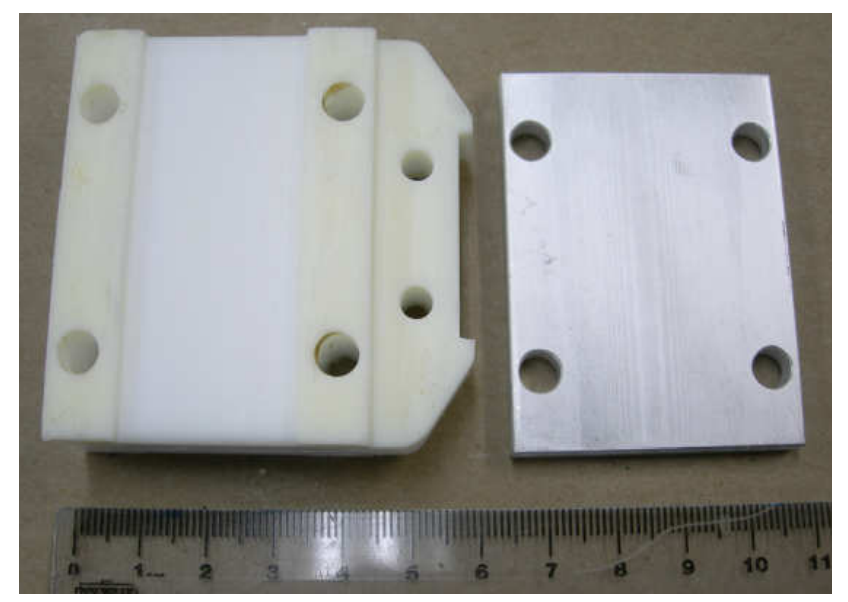

FIGURA 4.10 - Molde para a fabricação de corpos-de-prova de compósito.

Na FIG. 4.11 é mostrado o processo de enrolamento filamentar para a fabricação dos corpos-de-prova. A fibra de carbono foi bobinada com ângulo próximo a 90ำ em relação ao eixo longitudinal do mandril ou molde, com uma velocidade de $4,8 \mathrm{~cm} \cdot \mathrm{s}^{-1}$. Para cada uma das formulações mencionadas na TAB. 4.3, foram depositadas 8 camadas unidirecionais de fibra de carbono, totalizando aproximadamente $2 \mathrm{~mm}$ de espessura.

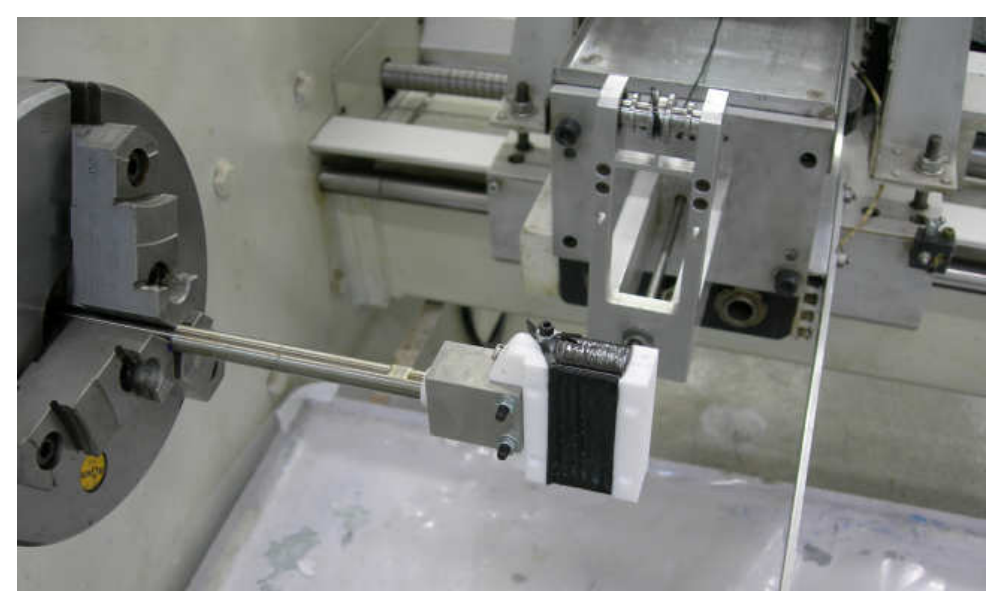

FIGURA 4.11 - Enrolamento filamentar do corpo-de-prova de compósito.

Na FIG. 4.12 é mostrado o banho de impregnação da matriz que foi mantido a $70^{\circ} \mathrm{C}$ durante todo processo de enrolamento. Esta temperatura foi necessária para reduzir a viscosidade da formulação e melhorar sua impregnação na fibra de carbono. 


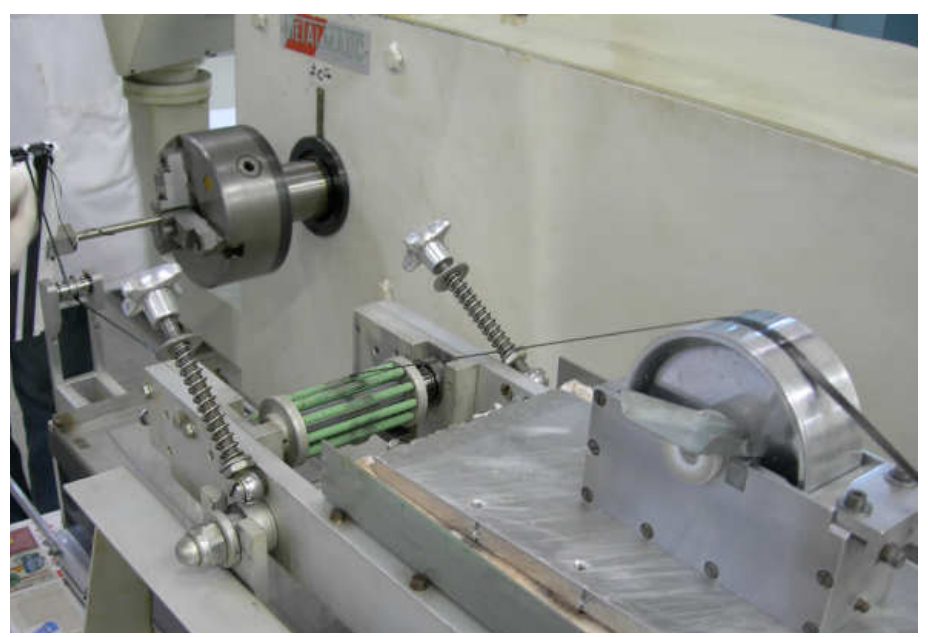

FIGURA 4.12 - Banho de impregnação da matriz.

Após a bobinagem, conforme mostrada na FIG. 4.13, as faces foram prensadas com placas de alumínio e retiradas antes do processo de cura por feixe de elétrons. Este procedimento foi feito para que se obtivesse um corpo-de-prova com boa uniformidade de espessura e com poucos vazios.

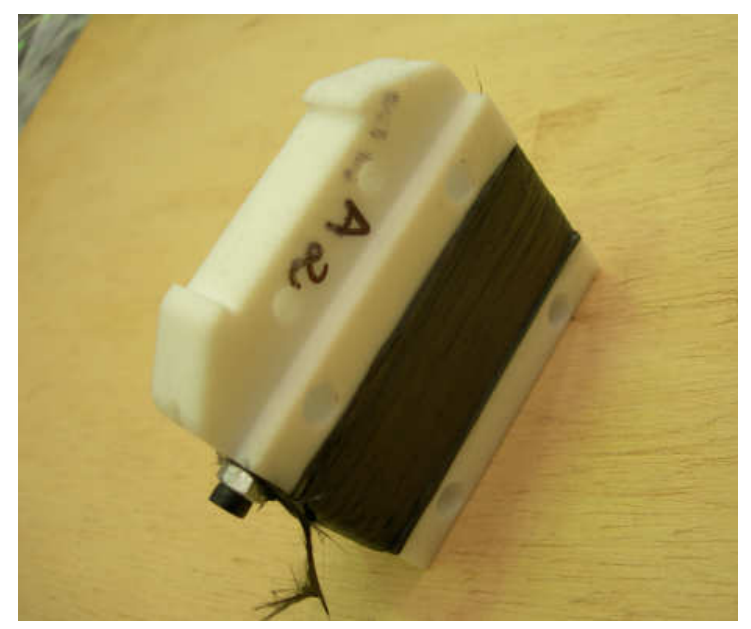

FIGURA 4.13 - Vista geral do molde após o processo de enrolamento filamentar.

Os compósitos foram identificados com o prefixo FC, seguido das matrizes poliméricas identificadas na TAB. 4.3. Foi utilizado o mesmo critério de irradiação das matrizes (item 4.2.2) e apenas a amostra FCA2 foi irradiada com três doses totais e dois processos de irradiação.

Os corpos-de-prova de compósitos foram irradiados em uma face de cada vez e com as condições de irradiação apresentadas nas TAB. 4.9, 
TAB. 4.10, TAB. 4.11, TAB. 4.12. Utilizou-se a velocidade de 3,36 m. $\mathrm{min}^{-1}$ na bandeja onde os corpos-de-prova foram irradiados a temperatura de $25^{\circ} \mathrm{C}$.

O tempo de espera de dois minutos entre as passadas na etapa na qual foi utilizada a taxa de dose de 57,6 kGy.s ${ }^{-1}$, teve a finalidade de evitar o aquecimento excessivo do material irradiado durante o processo de irradiação.

TABELA 4.9 - Condições de irradiação do compósito FCA2.

\begin{tabular}{ccccc}
\hline \multicolumn{5}{c}{ Amostra: FCA2 } \\
\hline feixe $(\mathrm{mA})$ & $\begin{array}{c}\text { Taxa de dose } \\
\left(\mathrm{kGy} \cdot \mathrm{s}^{-1}\right)\end{array}$ & $\begin{array}{c}\text { Dose/passada } \\
(\mathrm{kGy})\end{array}$ & $\begin{array}{c}\text { Número de } \\
\text { passadas }\end{array}$ & $\begin{array}{c}\text { Dose total } \\
(\mathrm{kGy})\end{array}$ \\
\hline 0,4 & 1,82 & 0,803 & 129 & 103,6 \\
0,4 & 1,82 & 0,803 & 193 & 155,0 \\
0,4 & 1,82 & 0,803 & 257 & 206,4 \\
\hline
\end{tabular}

TABELA 4.10 - Condições de irradiação do compósito FCA2.

\begin{tabular}{|c|c|c|c|c|}
\hline \multicolumn{5}{|c|}{ Amostra: FCA2 } \\
\hline $\begin{array}{l}\text { Corrente de } \\
\text { feixe }(m A)\end{array}$ & $\begin{array}{c}\text { Taxa de dose } \\
\left(\mathrm{kGy} . \mathrm{s}^{-1}\right)\end{array}$ & $\begin{array}{c}\text { Dose/passada } \\
\text { (kGy) }\end{array}$ & $\begin{array}{l}\text { Número de } \\
\text { passadas }\end{array}$ & $\begin{array}{l}\text { Dose } \\
\text { (kGy) }\end{array}$ \\
\hline 0,4 & 1,82 & 0,803 & 65 & 52,2 \\
\hline 12,7 & 57,6 & 25,7 & $\begin{array}{c}2 \text { (espera de } 2 \mathrm{~min} \\
\text { entre passadas) }\end{array}$ & 51,4 \\
\hline \multicolumn{5}{|c|}{ Dose total $=52,2 \mathrm{kGy}+51,4 \mathrm{kGy}=103,6 \mathrm{kGy}$} \\
\hline
\end{tabular}


TABELA 4.11 - Condições de irradiação do compósito FCA2.

\begin{tabular}{|c|c|c|c|c|}
\hline \multicolumn{5}{|c|}{ Amostra: FCA2 } \\
\hline $\begin{array}{c}\text { Corrente de } \\
\text { feixe }(m A)\end{array}$ & $\begin{array}{c}\text { Taxa de dose } \\
\left.\text { (kGy.s } \text { s }^{-1}\right)\end{array}$ & $\begin{array}{c}\text { Dose/passada } \\
\text { (kGy) }\end{array}$ & $\begin{array}{l}\text { Número de } \\
\text { passadas }\end{array}$ & $\begin{array}{l}\text { Dose } \\
\text { (kGy) }\end{array}$ \\
\hline 0,4 & 1,82 & 0,803 & 65 & 52,2 \\
\hline 12,7 & 57,6 & 25,7 & $\begin{array}{c}4 \text { (espera de } 2 \mathrm{~min} \\
\text { entre passadas) }\end{array}$ & 102,8 \\
\hline
\end{tabular}

TABELA 4.12 - Condições de irradiação dos compósitos FCA1, FCA2, FCA3 e $\mathrm{FCH} 2$.

Amostras: FCA1, FCA2, FCA3 e FCH2

\begin{tabular}{ccccc}
\hline $\begin{array}{c}\text { Corrente de } \\
\text { feixe }(\mathrm{mA})\end{array}$ & $\begin{array}{c}\text { Taxa de dose } \\
\left(\mathrm{kGy} \cdot \mathrm{s}^{-1}\right)\end{array}$ & $\begin{array}{c}\text { Dose/passada } \\
(\mathrm{kGy})\end{array}$ & $\begin{array}{c}\text { Número de } \\
\text { passadas }\end{array}$ & $\begin{array}{c}\text { Dose } \\
(\mathrm{kGy})\end{array}$ \\
\hline 0,4 & 1,82 & 0,803 & 65 & 52,2 \\
12,7 & 57,6 & 25,7 & $\begin{array}{c}6 \text { (espera de 2min } \\
\text { entre passadas })\end{array}$ & 154,2 \\
\hline \multicolumn{4}{c}{ Dose total = 52,2kGy + 154,2kGy = 206,4kGy } \\
\hline
\end{tabular}

Na FIG. 4.14 é mostrada a bandeja utilizada durante a irradiação dos compósitos e na FIG. 4.15, o compósito curado por feixe de elétrons após a desmoldagem, na qual foram obtidas duas placas para a fabricação dos corpos-de-prova para a técnica de DMTA. Na FIG. 4.16 é mostrada a placa de compósito adequadamente cortada e um corpo-de-prova para a técnica de DMTA. 


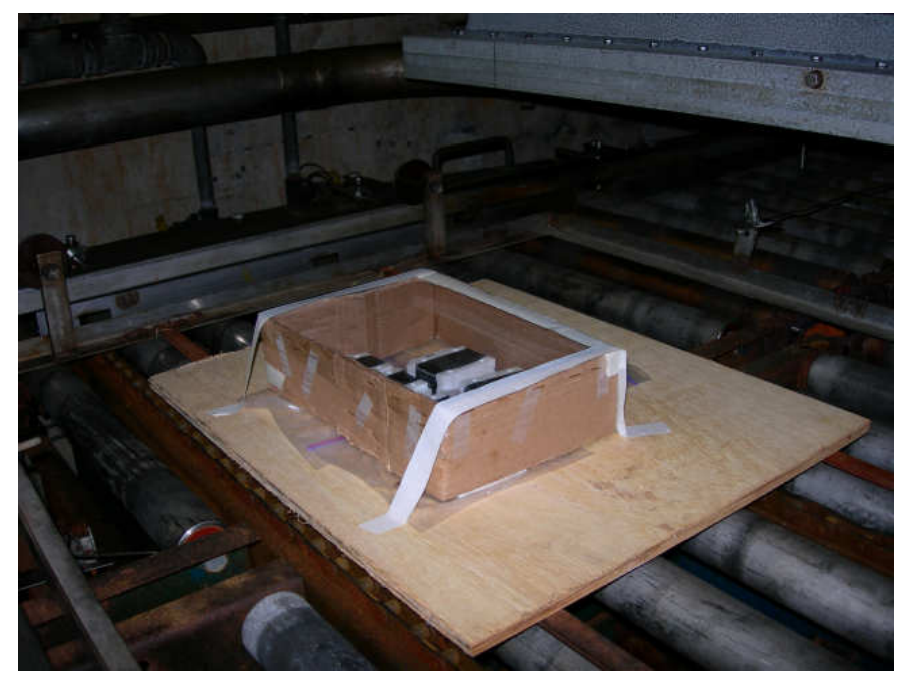

FIGURA 4.14 - Bandeja para irradiação dos compósitos.

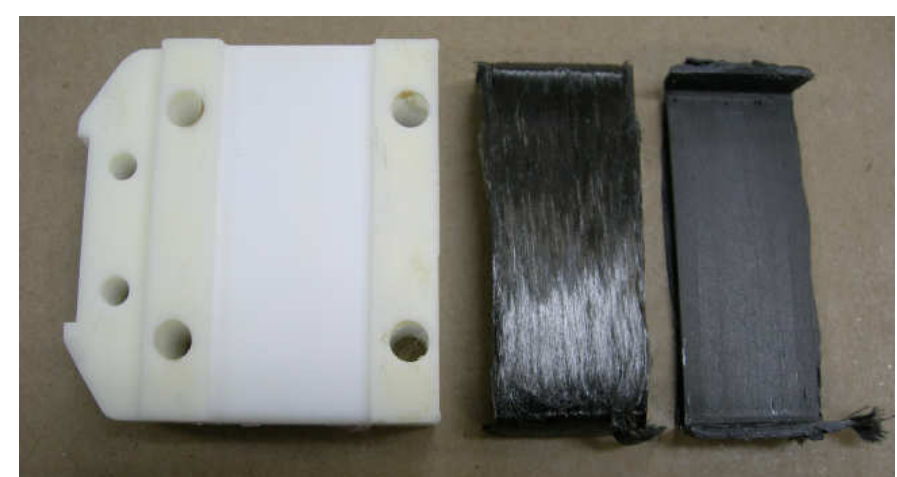

FIGURA 4.15 - Amostras das placas dos compósitos curados por feixe de elétrons.

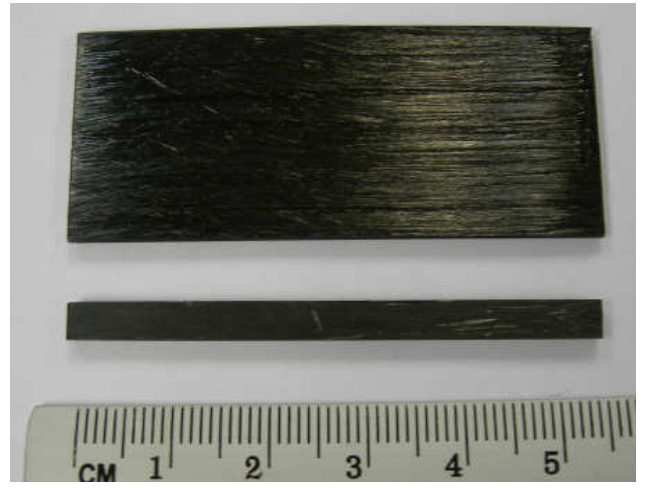

FIGURA 4.16 - Placa de compósito adequadamente cortada e um corpo-de-prova de DMTA. 


\subsection{Cura pelo processo térmico}

\subsubsection{Preparação das formulações das matrizes poliméricas}

Para comparar as propriedades das matrizes poliméricas obtidas pelo processo de feixe de elétrons, foi caracterizada uma matriz de cura térmica utilizando a mesma resina epoxídica TACTIX 123, um endurecedor à base de anidrido metiltetrahidroftálico (HY 917 da Huntsman) e um acelerador de amina terciária benzildimetilamina (DY 062 da Huntsman). As estruturas moleculares do endurecedor e do acelerador são mostradas, respectivamente, nas FIG. 4.17 e 4.18 .

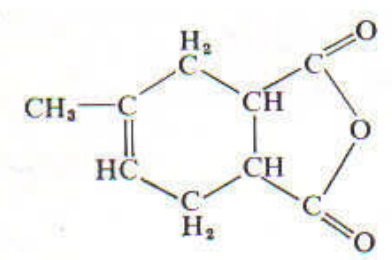

FIGURA 4.17 - Estrutura molecular do anidrido metiltetrahidroftálico.<smiles>CN(C)Cc1ccccc1</smiles>

FIGURA 4.18 - Estrutura molecular do acelerador benzildimetilamina.

As proporções de resina, endurecedor e acelerador para a formulação da matriz foram, respectivamente, de 100, 97 e 0,5 partes em massa. Estes produtos foram homogeneizados a temperatura ambiente e utilizou-se vácuo por 5 minutos para extrair as bolhas de ar oriundas do processo de mistura.

\subsubsection{Preparação dos corpos-de-prova da matriz polimérica}

Os corpos-de-prova de DMTA e de tração curados pelo processo térmico foram preparados com as mesmas dimensões e moldes de silicone utilizados no processo de cura por feixe de elétrons. A matriz foi curada em uma estufa com ar circulante e baseado no catálogo técnico da resina TACTIX 123 (Huntsman,2004), utilizou-se o seguinte ciclo de cura: 
i. $90^{\circ} \mathrm{C}$ por 4 horas;

ii. Incremento da temperatura de $90^{\circ} \mathrm{C}$ a $180^{\circ} \mathrm{C}$ em 4 horas;

iii. Manutenção no patamar de $180^{\circ} \mathrm{C}$ por 8 horas, totalizando 16 horas, mais o tempo de resfriamento.

Nas FIG. 4.19 e 4.20 são mostrados, respectivamente, os corpos-de-prova de DMTA e de tração das matrizes curadas pelo processo térmico.

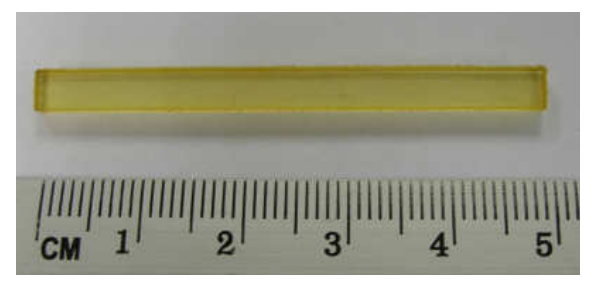

FIGURA 4.19 - Corpo-de-prova de DMTA da matriz curado pelo processo térmico.

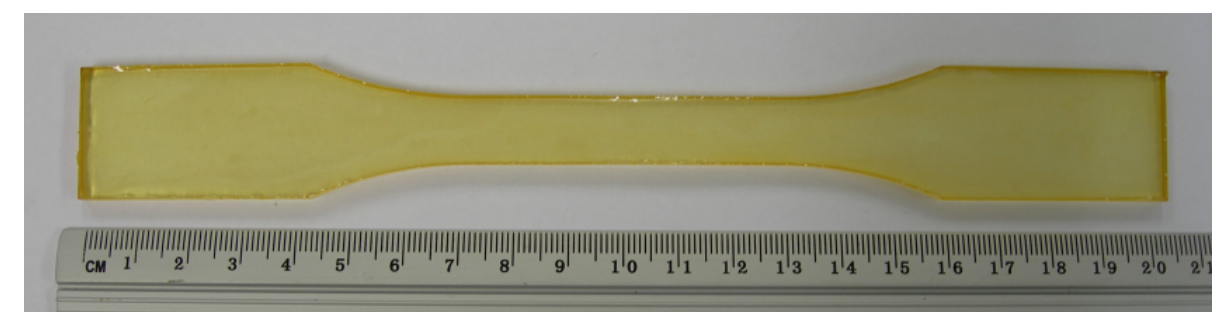

FIGURA 4.20 - Corpo-de-prova de tração da matriz curado pelo processo térmico.

\subsubsection{Preparação dos corpos-de-prova de compósitos poliméricos}

Os corpos-de-prova de compósitos curados pelo processo térmico foram preparados pelo processo de enrolamento filamentar, já descrito no item 4.2.3, e utilizou-se a matriz de cura térmica, citada no item 4.3.1. Na FIG. 4.21 é mostrada a placa de compósito obtida pelo processo térmico e um corpo-de-prova para a técnica de DMTA. O compósito foi curado em uma estufa com ar circulante e com o mesmo ciclo de cura da matriz polimérica. 


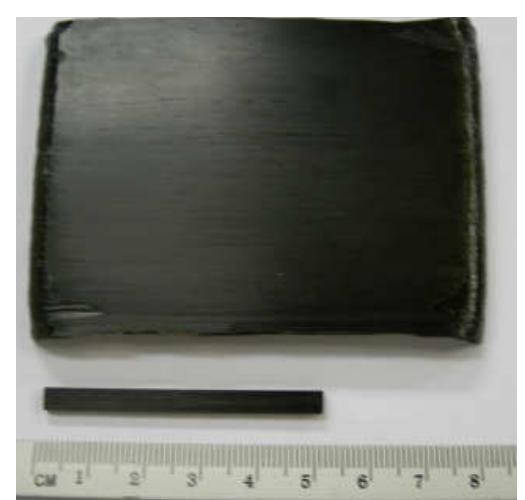

FIGURA 4.21 - Placa do compósito curado pelo processo térmico e um corpo-de-prova de DMTA.

\subsection{Controle da temperatura durante o processo de cura por feixe de elétrons}

A entalpia de reação de cura das resinas epoxídicas curadas por feixe

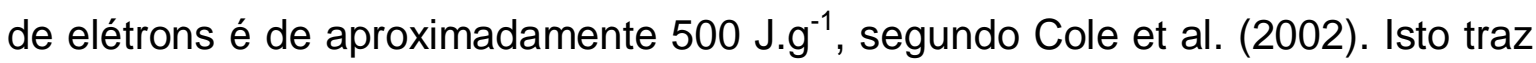
como conseqüência o aumento demasiado da temperatura no material irradiado e dependendo da taxa de dose utilizada pode provocar sua contração.

É desejável que esta temperatura não ultrapasse $90^{\circ} \mathrm{C}$ na etapa inicial da reação de cura (Morgan et. al., 2002 e Wilenski et al., 2002). Utilizando taxa de dose baixa na etapa inicial do processo, pode-se controlar a velocidade da reação de cura e manter uma temperatura abaixo de $90^{\circ} \mathrm{C}$ no material irradiado.

Durante a cura de compósitos poliméricos por feixe de elétrons, 0 aumento de temperatura no material irradiado ocorre em virtude da entalpia de reação de cura elevada, taxa de dose e do material utilizado na fabricação do molde. Os materiais com alto calor específico $\left(C_{p}\right)$ são os mais indicados para serem utilizados na fabricação de moldes de compósitos curados por feixe de elétrons.

O aumento da temperatura $(\Delta \mathrm{T})$ em razão da exposição à irradiação pode ser estimado por meio de uma equação baseada na conservação de energia. Valendo-se da exposição da dose (D) em kGy e o calor específico do material $\left(C_{p}\right)$ em J.g $g^{-1} .{ }^{\circ} \mathrm{C}^{-1}$, determina-se o aumento de temperatura, conforme a equação 4.1 (Morgan et al., 2002).

$$
\Delta \mathrm{T}=\frac{\mathrm{D}}{\mathrm{C}_{\mathrm{p}}}
$$


Esta relação assume que toda radiação é uniformemente e instantaneamente convertida em calor. O aumento instantâneo da temperatura de cada componente do compósito pode ser determinado mediante o respectivo calor específico e utilizando a equação 4.1. Na TAB. 4.13 são apresentados os valores de calor específico dos principais materiais envolvidos no processo de cura de compósitos por feixe de elétrons.

TABELA 4.13 - Calor específico de alguns materiais utilizados no processo de cura por feixe de elétrons.

\begin{tabular}{|c|c|}
\hline Material & Calor específico $\left(\mathrm{J} . \mathrm{g}^{-1} .{ }^{\circ} \mathrm{C}^{-1}\right)$ \\
\hline Alumínio & 0,90 \\
\hline Aço & 0,46 \\
\hline Resina epoxídica & 1,84 \\
\hline Fibra de carbono & 0,71 \\
\hline Espuma de PVC & 0,97 \\
\hline Espuma de poliuretano & 1,67 \\
\hline Fibra de carbono/resina epoxídica & 1,13 \\
\hline Fibra de vidro/resina epoxídica & 0,63 \\
\hline
\end{tabular}

Foi utilizado o equipamento Data Acquisition 34970A da Agilent (FIG. 4.22) para monitorar a temperatura de cura por feixe de elétrons do presente estudo. Uma termorresistência do tipo PT 100 foi colocada no molde para monitorar a temperatura do processo de cura e estão mostradas na FIG. 4.23 e 4.24 .

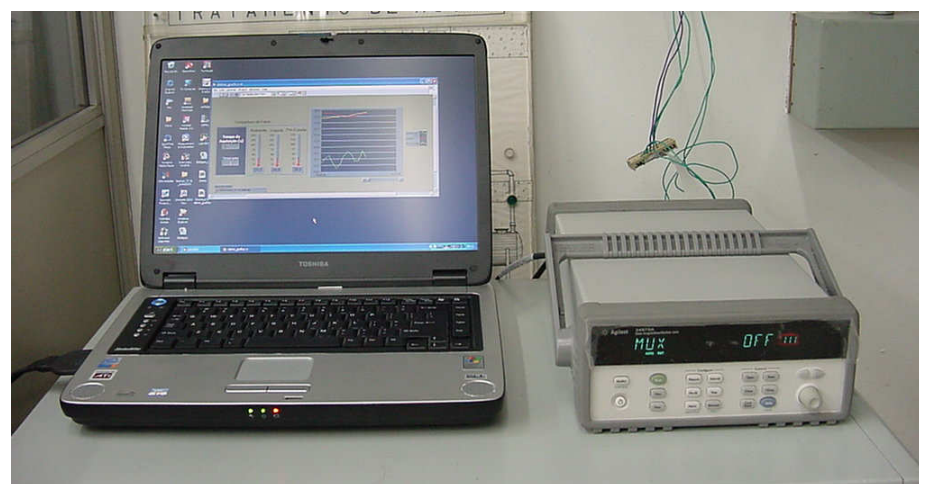

FIGURA 4.22 - Equipamento de monitoração de temperatura. 


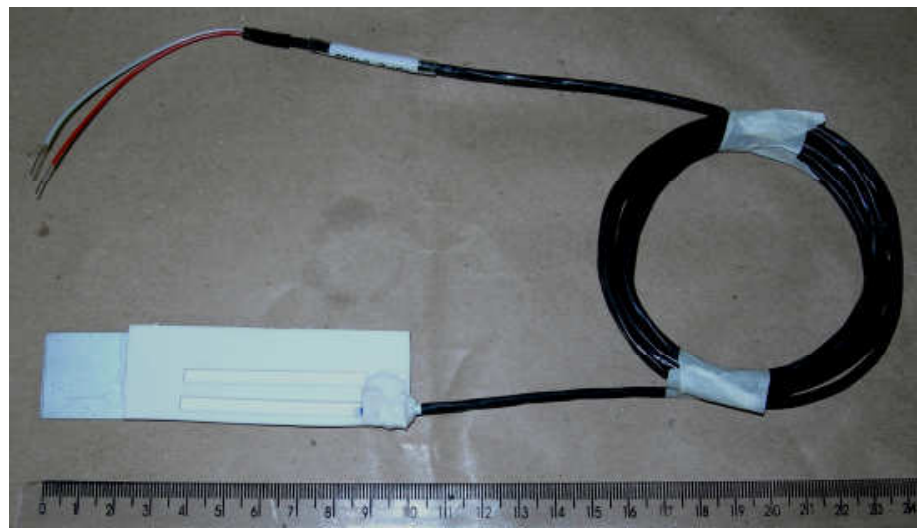

FIGURA 4.23 - Termorresistência PT 100 no molde de matriz.

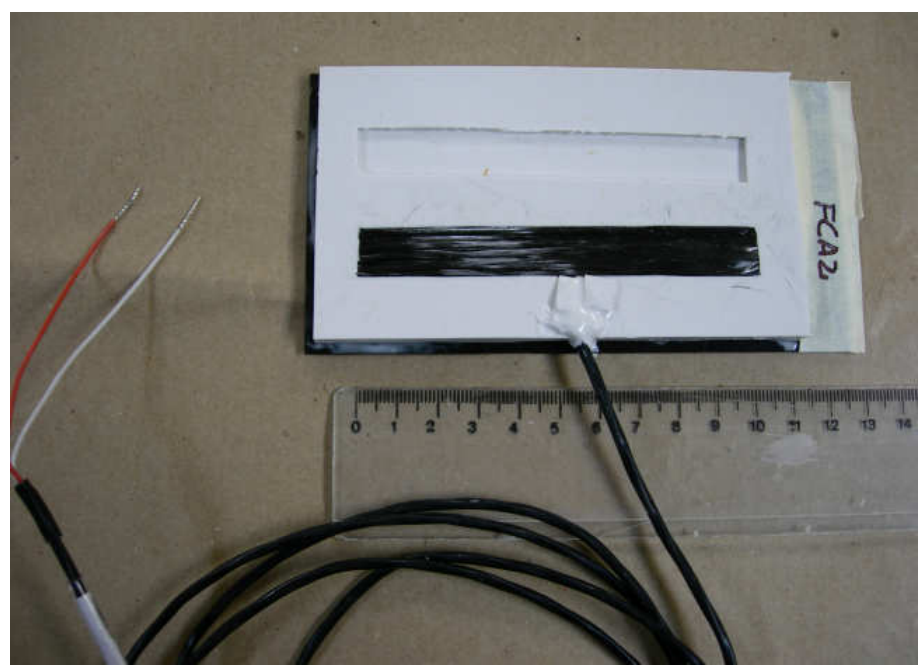

FIGURA 4.24 - Termorresistência PT 100 num molde de compósito.

\subsection{Análise térmica}

\subsubsection{Calorimetria exploratória diferencial (DSC)}

No presente trabalho, a técnica de DSC foi utilizada para determinar a temperatura de transição vítrea das matrizes, transição endotérmica de fusão do iniciador catiônico, transição exotérmica da reação de cura das matrizes epoxídicas e o grau de cura das mesmas. Uma avaliação do grau de cura de uma matriz polimérica pode ser feita pela equação 4.2 que estabelece a relação entre a entalpia da reação de cura residual da amostra $\left(\Delta \mathrm{H}_{\mathrm{a}}\right)$ e a entalpia da mesma matriz polimérica não curada $\left(\Delta \mathrm{H}_{\mathrm{t}}\right)$ determinada quando esta é submetida à técnica de DSC. 


$$
\text { Grau de cura }(\%)=\frac{\Delta H_{t}-\Delta H_{a}}{\Delta H_{t}} \cdot 100
$$

Segundo Raghavan et al. (1998), a entalpia da reação de cura das matrizes que curam pelo processo de feixe de elétrons é a mesma quando curadas pelo processo térmico.

O método da técnica foi baseado nas normas ASTM D 3418-99 e ASTM E 1356-98, utilizando-se amostras de $10 \mathrm{mg}$ a $25 \mathrm{mg}$, com uma razão de aquecimento de $10^{\circ} \mathrm{C} \cdot \mathrm{min}^{-1}$ e submetidas a uma atmosfera de nitrogênio ultrapuro com vazão de $50 \mathrm{~mL} \cdot \mathrm{min}^{-1}$.

\subsubsection{Termodinâmico-mecânica (DMTA)}

A técnica de DMTA permitiu caracterizar as matrizes e compósitos em condições dinâmicas de deformação e determinar suas temperaturas de transição vítrea por meio dos picos do módulo de perda (E”) e tan $\delta$. Neste estudo foi utilizado um equipamento de DMTA com o acessório de flexão em três pontos, seguindo orientações das normas ASTM E 1640-99 e ASTM D 5023-99. Os corpos-de-prova foram analisados com uma razão de aquecimento de $2^{\circ} \mathrm{C} \cdot \mathrm{min}^{-1}$, com freqüência de $1 \mathrm{~Hz}$, amplitude de deslocamento de até $30 \mu \mathrm{m}$, força estática de 1,5 vezes a força dinâmica e força dinâmica máxima de $6 \mathrm{~N}$.

\subsubsection{Termogravimetria (TG)}

Nas análises, as amostras de $10 \mathrm{mg}$ a $20 \mathrm{mg}$ foram aquecidas até $625^{\circ} \mathrm{C}$ com uma razão de aquecimento de $20^{\circ} \mathrm{C} \cdot \mathrm{min}^{-1}$ sob atmosfera de nitrogênio ultrapuro com vazão de $50 \mathrm{~mL} \cdot \mathrm{min}^{-1}$, as quais permaneceram nesta temperatura por um período de 40 minutos. Nestas condições, as fibras de carbono não perdem massa, portanto, foi possível determinar a massa de reforço (\%FC) contido nas amostras de compósitos valendo-se da perda de massa do compósito $\left(\Delta \mathrm{m}_{\mathrm{c}}\right)$ e da perda de massa da matriz $\left(\Delta \mathrm{m}_{\mathrm{m}}\right)$ por meio da equação 4.3 .

$$
\% \mathrm{FC}=100-\left(\frac{\Delta \mathrm{m}_{\mathrm{c}}}{\Delta \mathrm{m}_{\mathrm{m}}}\right) \cdot 100
$$




\subsection{Determinação das frações volumétricas}

Para determinação das frações de massa de fibra e matriz dos corpos-de-prova de compósitos curados por feixe de elétrons e pelo processo térmico foi utilizada a técnica termogravimétrica, descrita no item 4.5.3. A densidade dos corpos-de-prova foi determinada de acordo com a norma ASTM D 792-98. Para cada amostra foram realizadas três determinações utilizando os aparatos mostrados nas FIG. 4.25 e 4.26.

A técnica para determinar a densidade utiliza o princípio de Arquimedes, que se baseia no fato de que um fluído em equilíbrio age sobre um corpo sólido nele imerso parcialmente ou totalmente, exercendo uma força vertical orientada de baixo para cima, denominada empuxo. Esta força é aplicada no centro de gravidade do volume de fluído deslocado, cuja intensidade é proporcional à massa do volume de fluído deslocado.

A equação 4.4 é utilizada para a determinação da densidade de um corpo sólido $\left(\mathrm{d}_{\mathrm{a}}\right)$, na qual $\mathrm{m}_{\mathrm{a}}$ e $\mathrm{m}_{\mathrm{ap}}$ são, respectivamente, a massa da amostra ao ar e a massa aparente da amostra, ou seja, a massa da amostra quando imersa. Neste estudo, foi utilizada a água como líquido de imersão da amostra e sua densidade $\left(d_{l}\right)$ em função da temperatura.

$$
\mathrm{d}_{\mathrm{a}}=\left(\frac{\mathrm{m}_{\mathrm{a}}}{\mathrm{m}_{\mathrm{a}}-\mathrm{m}_{\mathrm{ap}}}\right) \cdot \mathrm{d}_{\mathrm{l}}
$$

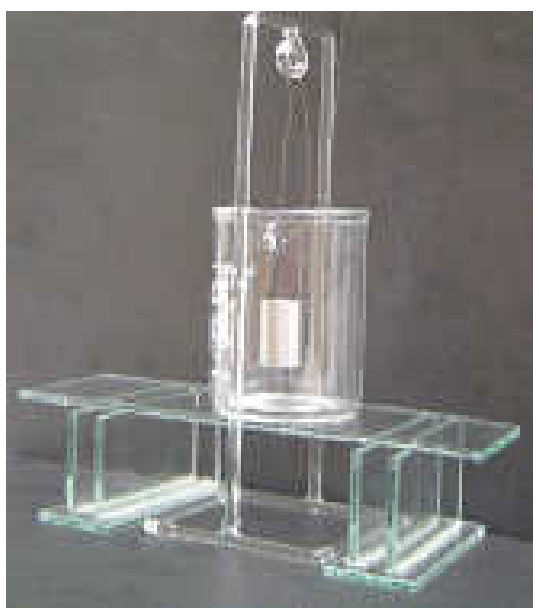

FIGURA 4.25 - Aparato para a determinação da densidade (LQES). 


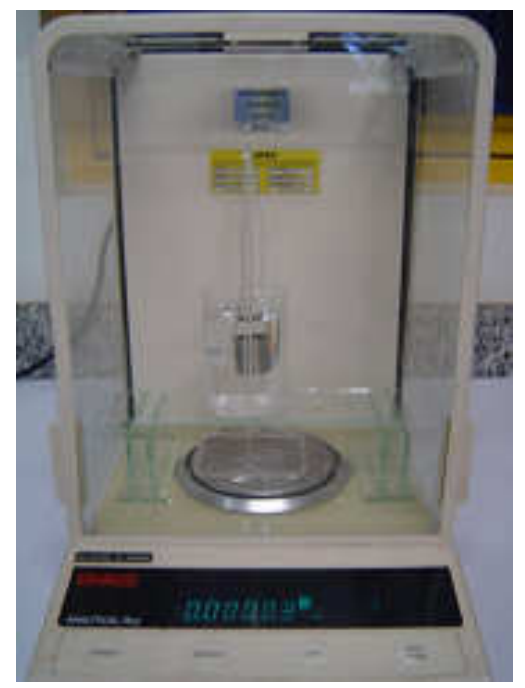

FIGURA 4.26 - Balança com o aparato para determinação da densidade (LQES).

As frações volumétricas de fibra de carbono $\left(\mathrm{v}_{\mathrm{f}}\right)$, de matriz $\left(\mathrm{v}_{\mathrm{m}}\right)$ e de vazio ( $\left.v_{v}\right)$ são obtidos pelas equações $4.5,4.6$ e 4.7. As frações em massa de fibra e matriz são respectivamente, $\mathrm{m}_{\mathrm{f}}$ e $\mathrm{m}_{\mathrm{m}}$. As densidades da fibra de carbono, de matriz e do compósito são, respectivamente, $d_{f}, d_{m}$ e $d_{c}$.

$$
\begin{aligned}
& v_{f}=m_{f} \cdot \frac{d_{c}}{d_{f}} \\
& v_{m}=m_{m} \cdot \frac{d_{c}}{d_{m}} \\
& v_{v}=1-\left(v_{f}+v_{m}\right)
\end{aligned}
$$

As frações volumétricas de reforço e matriz estão intimamente ligadas ao desempenho mecânico de um compósito. A fração volumétrica ideal de fibra de carbono num compósito é aproximadamente de $65 \%$ e a fração de vazios inferior a $\%$ (ASM, 2001).

\subsection{Ensaio de tração}

Para a determinação das propriedades mecânicas das matrizes, como o limite de resistência à tração, módulo de elasticidade e alongamento na ruptura, foi utilizada uma máquina universal de ensaios. Os corpos-de-prova foram ensaiados com uma velocidade da ponte de $5,0 \mathrm{~mm} \cdot \mathrm{min}^{-1}$, seguindo as 
orientações da norma ASTM D 638-99. Na FIG. 4.27 é mostrado um corpo-de-prova de matriz durante o ensaio de tração.

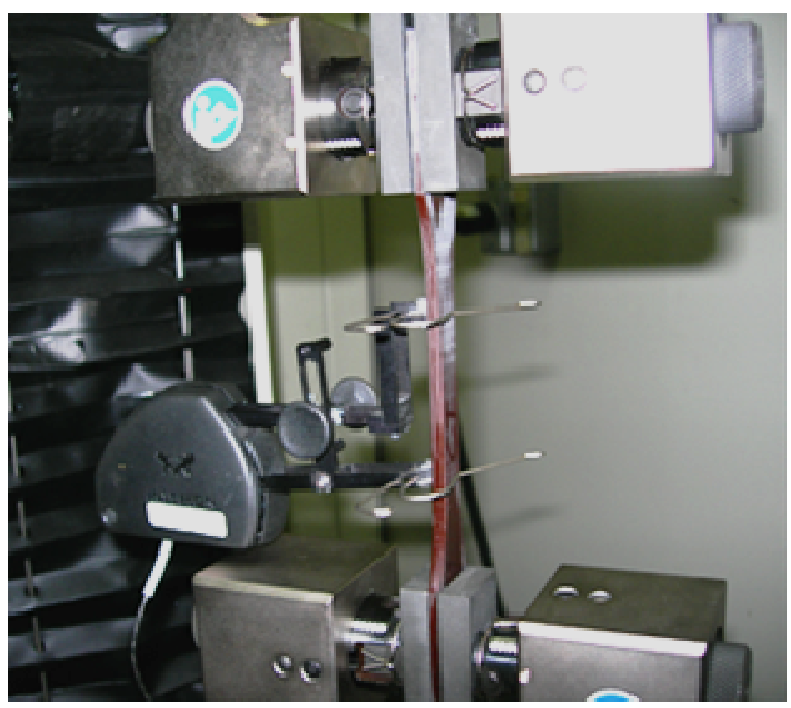

FIGURA 4.27 - Ensaio de tração do corpo-de-prova da matriz com extensômetro. 


\section{RESULTADOS E DISCUSSÃO}

Para avaliar as matrizes formuladas para cura por feixe de elétrons e 0 estudo dos parâmetros de irradiação, foi necessário realizar o controle de temperatura durante o processo de cura, determinar o grau de cura e temperatura de transição vítrea, assim como determinar as propriedades mecânicas em tração das matrizes.

\subsection{Controle de temperatura durante o processo de cura por feixe de elétrons}

No item 4.4 foi destacada a importância do controle de temperatura durante o processo de cura por feixe de elétrons, sobretudo na etapa inicial da polimerização. Para evitar uma contração indesejável do material irradiado em virtude da entalpia da reação de cura elevada, foi utilizada taxa de dose baixa no início do processo de irradiação. Caso fosse empregada taxa de dose alta nesta etapa do processo, isto provocaria um aumento da velocidade da reação de cura e, conseqüentemente, uma maior exotermia.

Para determinar a temperatura sob o feixe de elétrons com as taxas de doses utilizadas neste trabalho, foram realizadas medidas de temperatura sem a presença de material a ser irradiado, apenas com a termorresistência do tipo PT100. Foram realizadas medidas de temperatura em função do tempo de irradiação, mostradas na FIG. 5.1, com as taxas de doses de 1,82 kGy.s ${ }^{-1}$ e $57,6 \mathrm{kGy} . \mathrm{s}^{-1}$ empregadas no processo de cura das matrizes e compósitos poliméricos mencionados respectivamente nos itens 4.2.2 e 4.2.3. Cada pico corresponde a uma passada da termorresistência PT 100 sob o feixe de elétrons, que estava fixada sobre o sistema de transporte de material. As máximas temperaturas nas taxas de doses de 1,82 kGy.s. ${ }^{-1}$ e 57,6 kGy.s ${ }^{-1}$ foram, respectivamente, $30^{\circ} \mathrm{C}$ e $70^{\circ} \mathrm{C}$. Pelo resultado obtido, constatou-se que a taxa de dose de $1,82 \mathrm{kGy} \cdot \mathrm{s}^{-1}$ não proporcionou aumento significativo de temperatura no local da irradiação. 


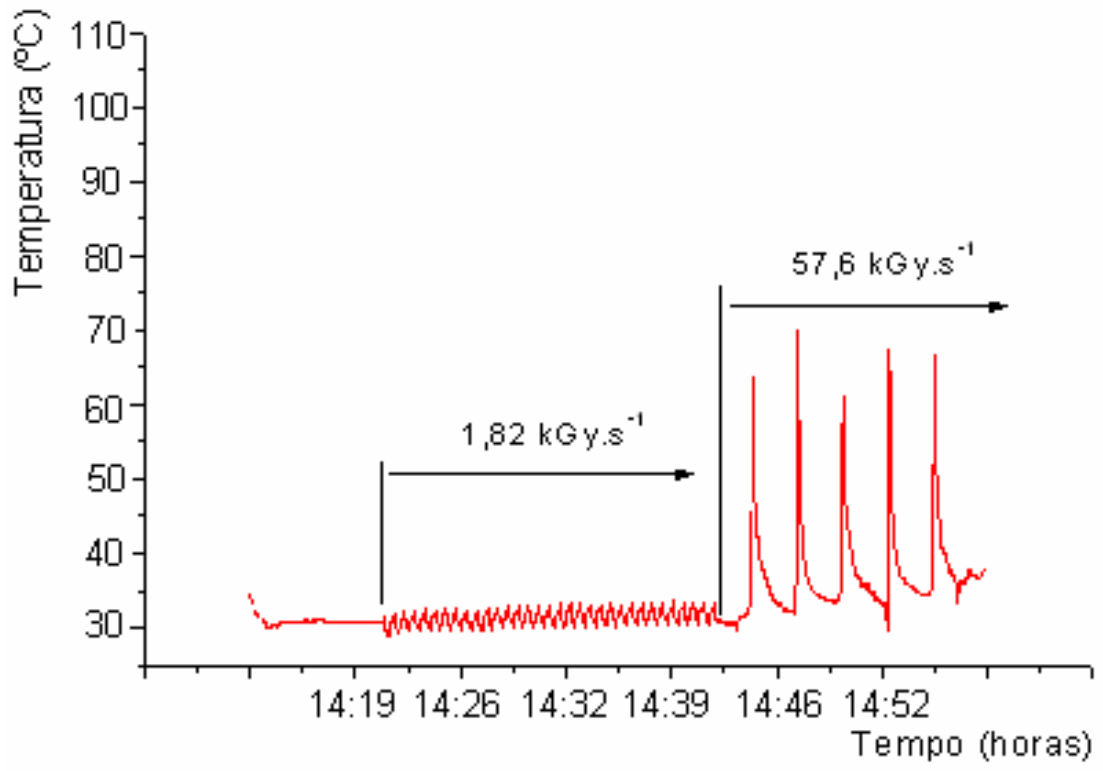

FIGURA 5.1 - Temperatura sob o feixe de elétrons durante a irradiação.

Também foram realizadas medidas de temperatura durante o processo de irradiação das matrizes e compósitos poliméricos para determinar as temperaturas durante a reação de cura do material irradiado.

As temperaturas durante o processo de irradiação nas matrizes $A 1, A 2$ e A3 com taxa de dose de 1,82 kGy.s ${ }^{-1}$ até completar a dose parcial de 52,2kGy e $57,6 \mathrm{kGy} . \mathrm{s}^{-1}$ até completar a dose total de 206,4kGy foram monitoradas e seus registros são mostrados na FIG. 5.2. No primeiro minuto de irradiação indicado entre os pontos $\mathrm{P} 0$ e $\mathrm{P} 1$, as matrizes $\mathrm{A} 2$ e A3 atingiram uma temperatura de $113^{\circ} \mathrm{C}$ e no minuto seguinte, de P1 a P2, a matriz A1 atingiu 102ํ․ Após estes minutos iniciais, as temperaturas estabilizaram em torno de $45^{\circ} \mathrm{C}$ até a dose parcial de 52,2kGy ter sido completada. 


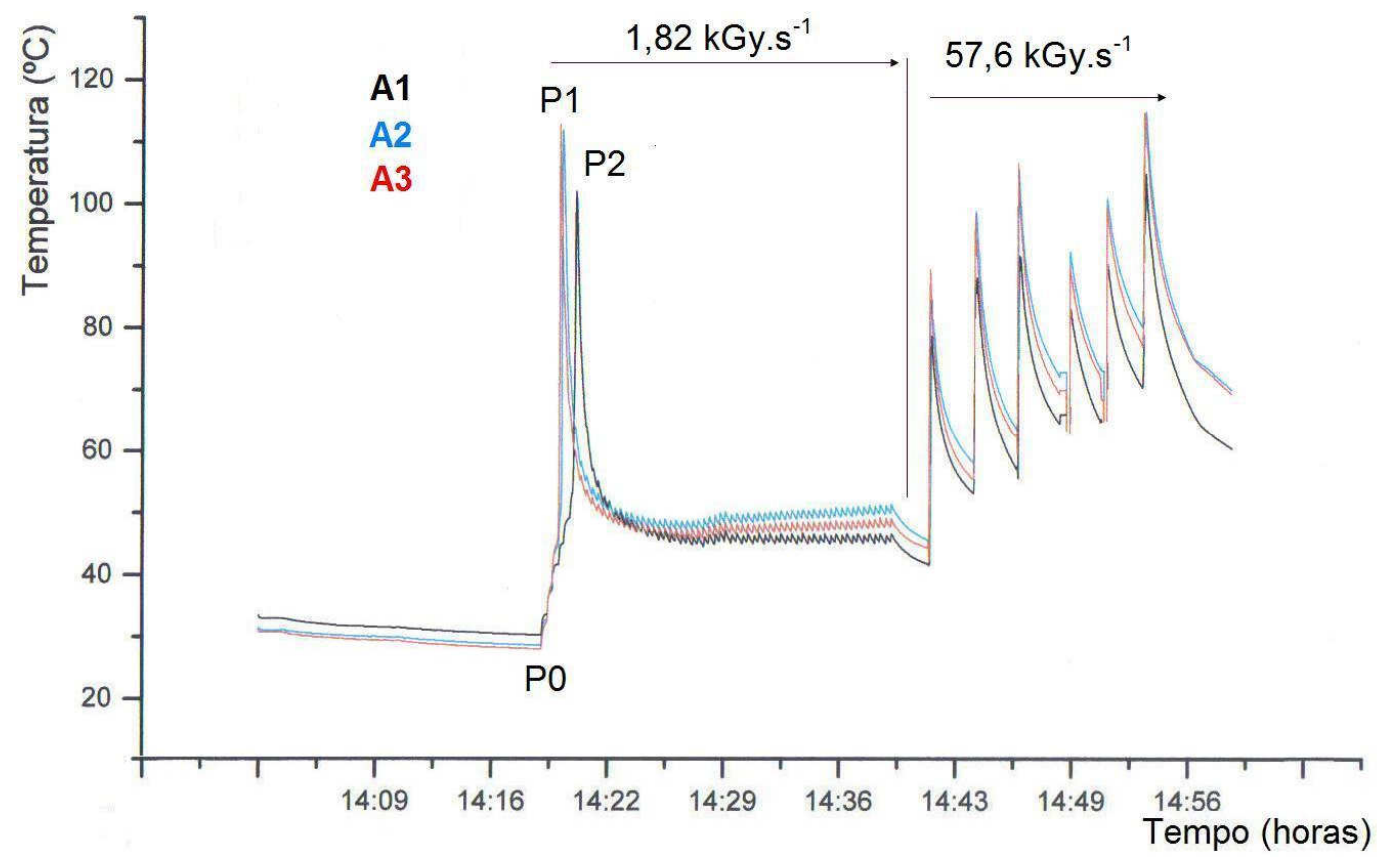

FIGURA 5.2 - Temperaturas das matrizes A1, A2 e A3 durante a cura por feixe de elétrons com taxa de dose de 1,82 kGy.s ${ }^{-1}$ até completar a dose parcial de $52,2 \mathrm{kGy}$ e 57,6 kGy.s.-1 até completar a dose total de 206,4kGy.

O aumento súbito da temperatura nos minutos iniciais da irradiação foi em virtude da reação de cura ser muito exotérmica, sobretudo, com concentrações acima de $2 \%$ de iniciador catiônico (PC 2506). Na etapa do processo na qual foi utilizada a taxa de dose de 57,6 kGy.s ${ }^{-1}$, a temperatura atingiu o valor máximo de $114^{\circ} \mathrm{C}$ na sexta e última passada da bandeja sob 0 feixe de elétrons. $O$ aumento de temperatura em cada passada foi em razão da taxa de dose alta, mostrada na FIG. 5.1, já que a maior parte do calor de reação de cura foi liberada no início da irradiação. O tempo total de irradiação foi de, aproximadamente, 40 minutos.

Na FIG. 5.3 são mostrados os registros das temperaturas durante 0 processo de cura por feixe de elétrons dos compósitos FCA1, FCA2 e FCA3. Foram utilizados os mesmos parâmetros de irradiação das matrizes $A 1, A 2$, e A3, exceto as espessuras das amostras que foram de $2,0 \mathrm{~mm}$ em vez de $2,5 \mathrm{~mm}$ das matrizes.

Na etapa inicial com taxa de dose de 1,82 kGy.s ${ }^{-1}$ até completar a dose parcial de 52,2kGy, verificou-se que as temperaturas dos compósitos atingiram no máximo $50^{\circ} \mathrm{C}$. Não foi observada nenhuma elevação brusca de temperatura nos 
minutos iniciais da irradiação como nas matrizes. Isto se deve em razão da dissipação de calor por meio das fibras de carbono e também pelo de fato que no compósito a matriz está distribuída em finas camadas, favorecendo a redução da exotermia.

$\mathrm{Na}$ etapa seguinte do processo em que foi utilizado a taxa de dose de $57,6 \mathrm{kGy} \cdot \mathrm{s}^{-1}$, a temperatura atingiu o valor máximo de $112^{\circ} \mathrm{C}$ na última passada da bandeja sob o feixe de elétrons até que se completasse a dose total de 206,4kGy. Não foram realizados os registros das temperaturas do processo de irradiação da matriz $\mathrm{H} 2$ e do compósito $\mathrm{FCH} 2$ em razão destes possuírem a mesma concentração do iniciador catiônico das amostras A2 e FCA2.

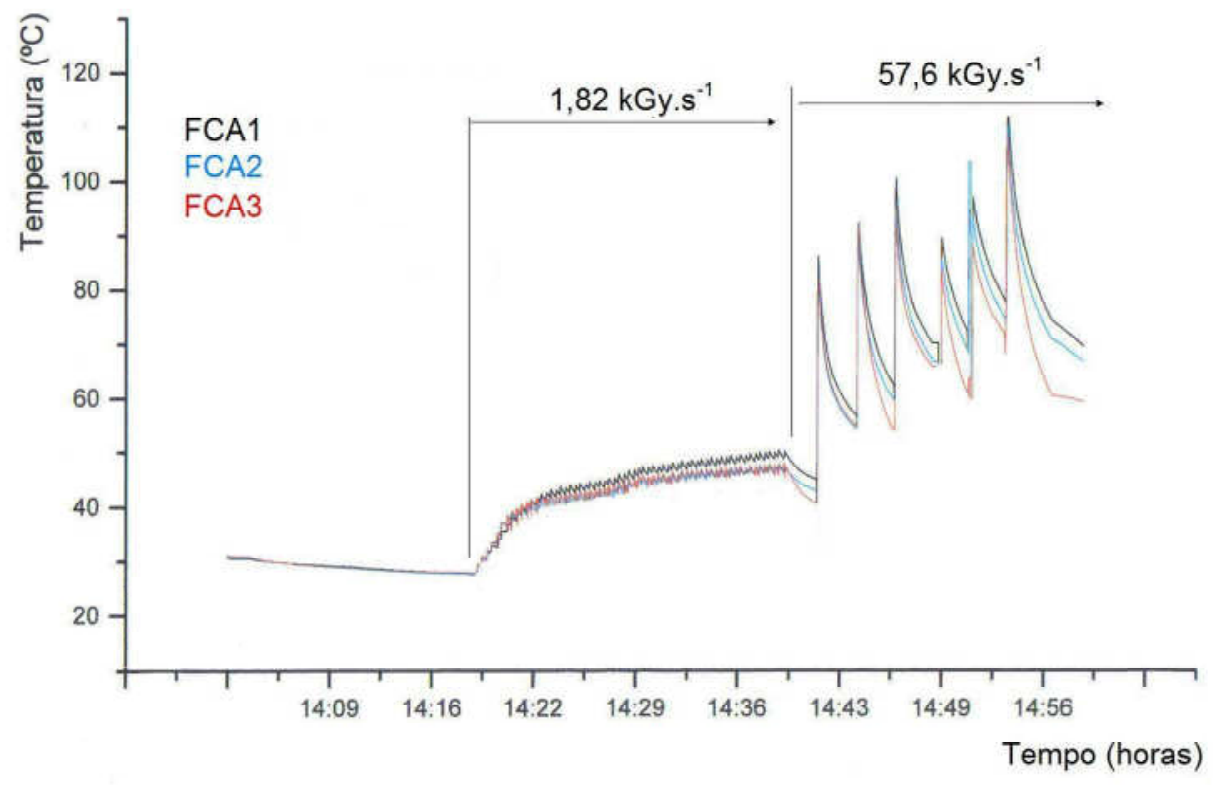

FIGURA 5.3 - Temperatura dos compósitos FCA1, FCA2 e FCA3 durante a cura por feixe de elétrons com taxa de dose de 1,82 kGy.s ${ }^{-1}$ até completar a dose parcial de 52,2kGy e 57,6 kGy.s ${ }^{-1}$ até completar a dose total de 206,4kGy.

No processo de cura em que foi utilizado apenas a taxa de dose de 1,82 kGy.s ${ }^{-1}$ até completar a dose total de 206,4kGy (FIG. 5.4), verificou-se que o compósito $\mathrm{FCA} 2$ atingiu a temperatura máxima de $48^{\circ} \mathrm{C}$, ao passo que a matriz A2 atingiu $116^{\circ} \mathrm{C}$ no primeiro minuto de irradiação. Em seguida, as temperaturas estabilizaram em torno de $50^{\circ} \mathrm{C}$, para ambos os materiais, até o término da irradiação. O tempo total do processo de cura foi de 70 minutos, ou seja, 30 minutos a mais que o processo em que foram utilizadas as taxas de doses de $1,82 \mathrm{kGy} \cdot \mathrm{s}^{-1}$ e $57,6 \mathrm{kGy} \cdot \mathrm{s}^{-1}$. 
Em virtude da limitação do acelerador de elétrons, a menor taxa de dose utilizada $\left(1,82 \mathrm{kGy} . \mathrm{s}^{-1}\right)$ foi considerada alta para a cura de matrizes poliméricas, pois a temperatura do processo atingiu temperaturas acima de $110^{\circ} \mathrm{C}$ no início da reação de cura, o que pode provocar uma contração indesejável no material irradiado. No processo de cura das matrizes quando combinadas com um elemento de reforço (fibras de carbono), a temperatura aumentou da ambiente para $50^{\circ} \mathrm{C}$. Nesta temperatura, a reação de cura iniciou de maneira gradual sem proporcionar uma contração no material irradiado.

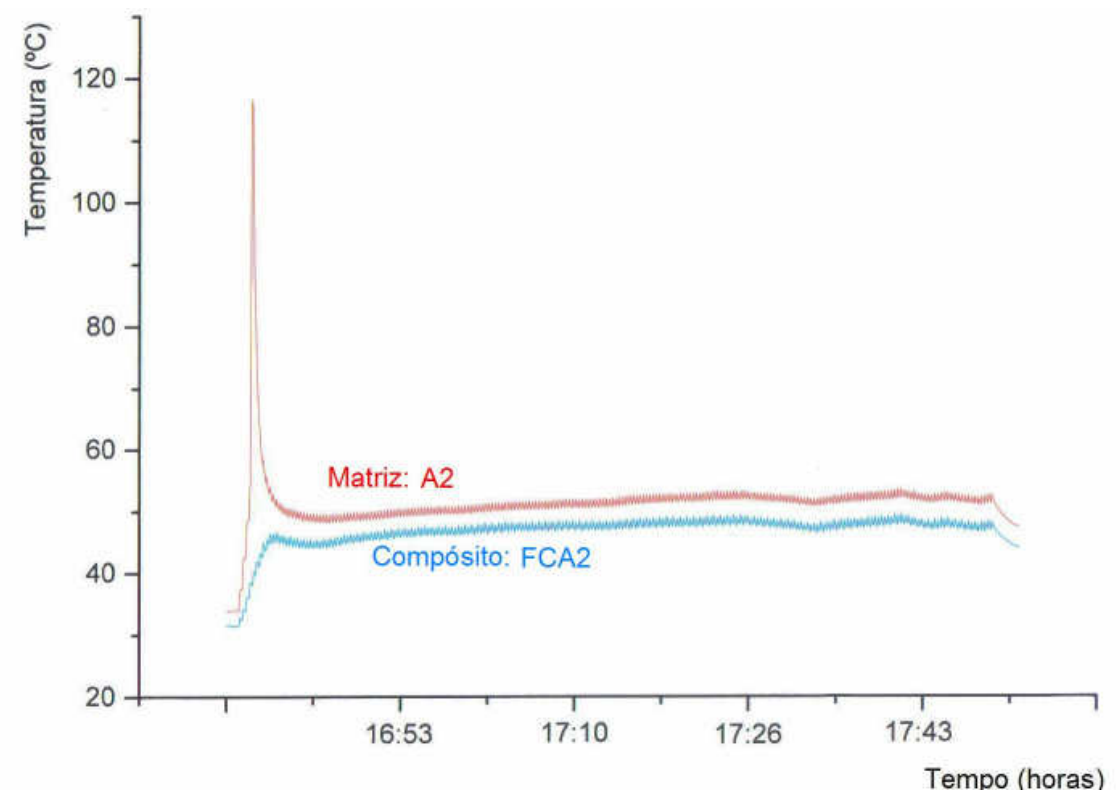

FIGURA 5.4 - Temperaturas da matriz A2 e do compósito FCA2 durante a cura por feixe de elétrons com taxa de dose de 1,82 kGy.s ${ }^{-1}$ até completar 206,4kGy.

\subsection{Análise térmica}

\subsubsection{Calorimetria exploratória diferencial (DSC)}

Com a técnica de DSC foi possível comparar e determinar o grau de cura e a temperatura de transição vítrea das matrizes e compósitos curados pelo processo térmico e por feixe de elétrons. Para isto, foi utilizada a mesma resina epoxídica nas amostras estudadas em ambos os processos de cura. 


\subsubsection{Cura térmica}

Foram analisadas as amostras de cura térmica da matriz TACTIX 123/HY 917/DY 062 e do compósito com esta mesma matriz polimérica. As temperaturas de transição vítrea são apresentadas na TAB. 5.1 e nas FIG. 5.5 e 5.6 são mostradas as respectivas curvas DSC. Neste trabalho é mostrada apenas uma curva representativa de DSC das três análises que foram realizadas para cada amostra.

TABELA 5.1. - As temperaturas de transição vítrea pela técnica de DSC da matriz TACTIX 123/HY 917/DY 062 e do compósito de mesma matriz curados pelo processo térmico.

\begin{tabular}{cc}
\hline Amostra & $\mathrm{T}_{\mathrm{g}}\left(^{\circ} \mathrm{C}\right)$ \\
\hline Matriz (TACTIX 123/HY 917/DY 062) & $116 \pm 3$ \\
Compósito & $117 \pm 3$ \\
\hline
\end{tabular}

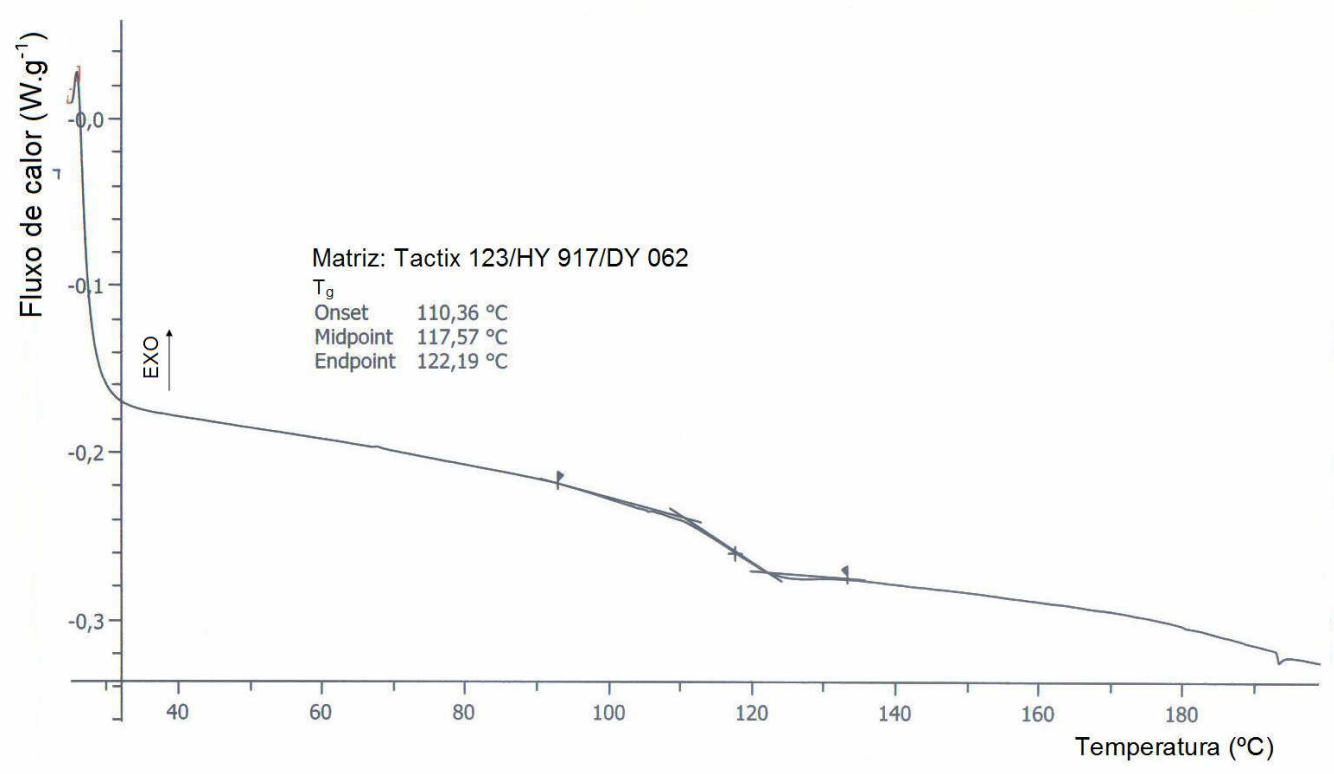

FIGURA 5.5 - Curva DSC da matriz curada pelo processo térmico. 


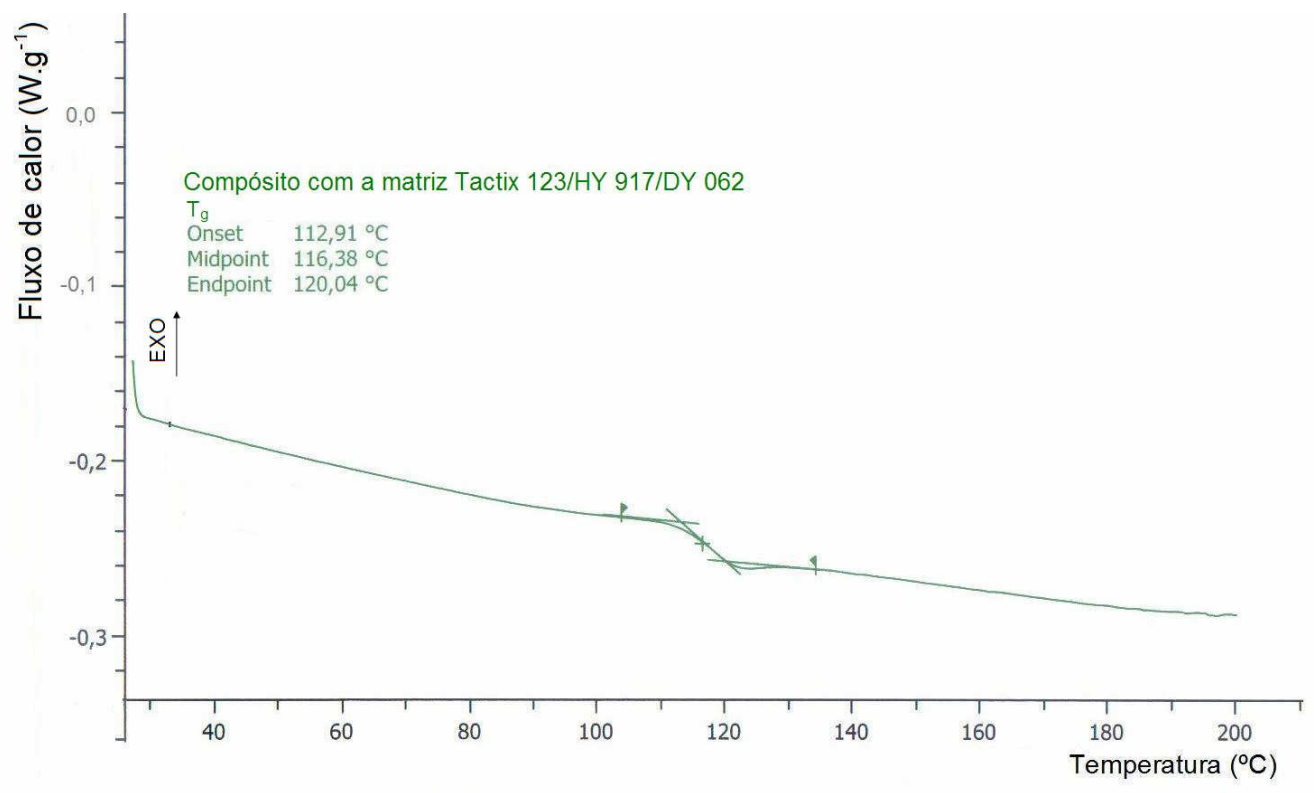

FIGURA 5.6 - Curva DSC do compósito curado pelo processo térmico.

\subsubsection{Cura por feixe de elétrons}

Os resultados de DSC constataram que não houve uma cura total das matrizes curadas por feixe de elétrons. A cura incompleta nas matrizes foi observada tanto no processo de irradiação em que se utilizou a taxa de dose de $1,82 \mathrm{kGy} . \mathrm{s}^{-1}$, quanto no processo em que foram empregadas as taxas de doses de 1,82 kGy.s ${ }^{-1}$ e 57,6 kGy.s ${ }^{-1}$. Nas FIG. 5.7, 5.8 e 5.9 são mostradas as curvas DSC com as entalpias residuais das matrizes A1, A2, A3 e H2. A liberação de calor constatou a entalpia residual da cura incompleta destas matrizes e como conseqüência não foi possível determinar a $T_{g}$ pela técnica de DSC. 


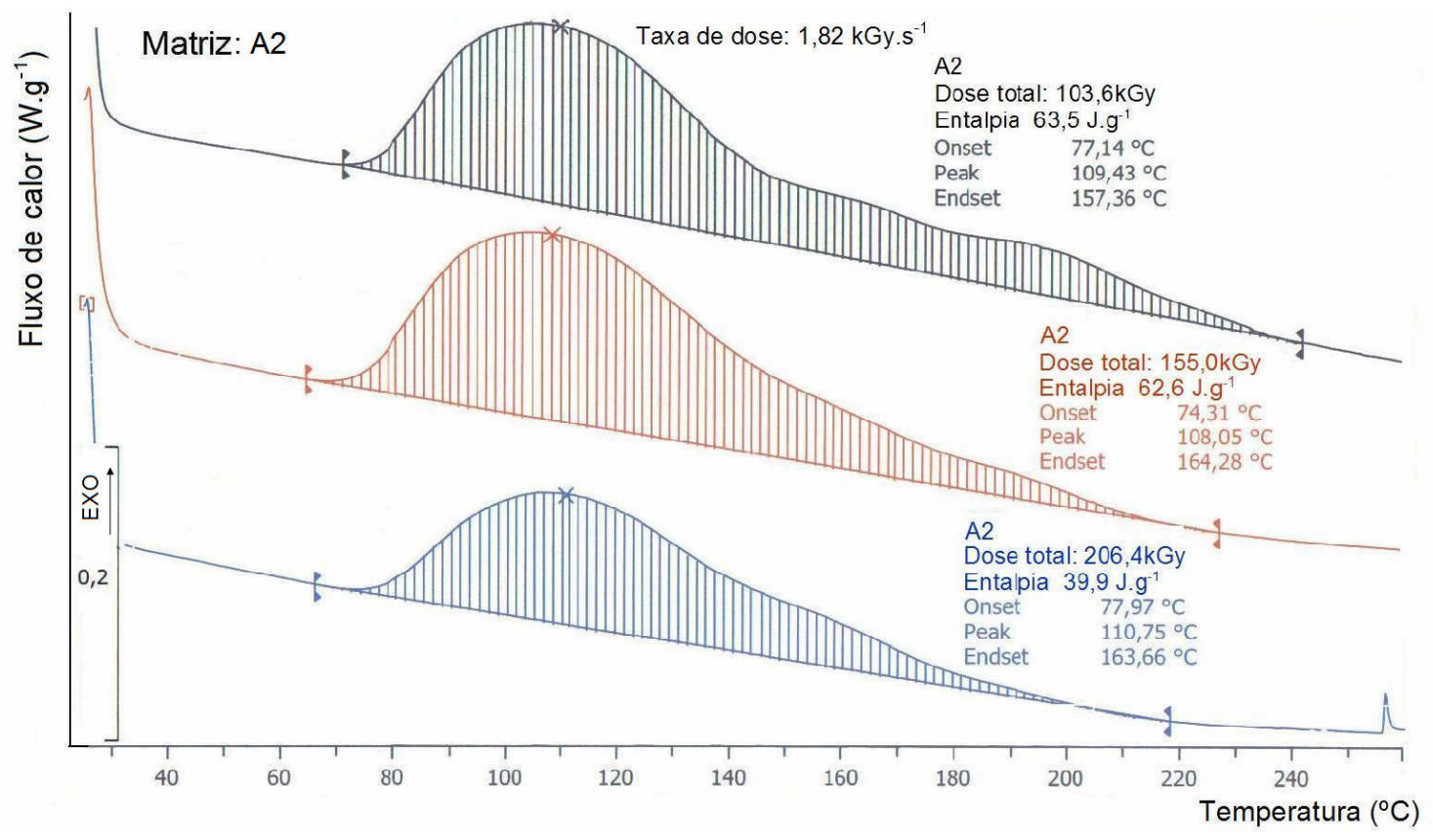

FIGURA 5.7 - Curvas DSC da entalpia residual da reação de cura da matriz A2 curada por feixe de elétrons com taxa de dose de 1,82 kGy.s ${ }^{-1}$ e doses totais de 103,6 kGy, 155,0 kGy e 206,4kGy.

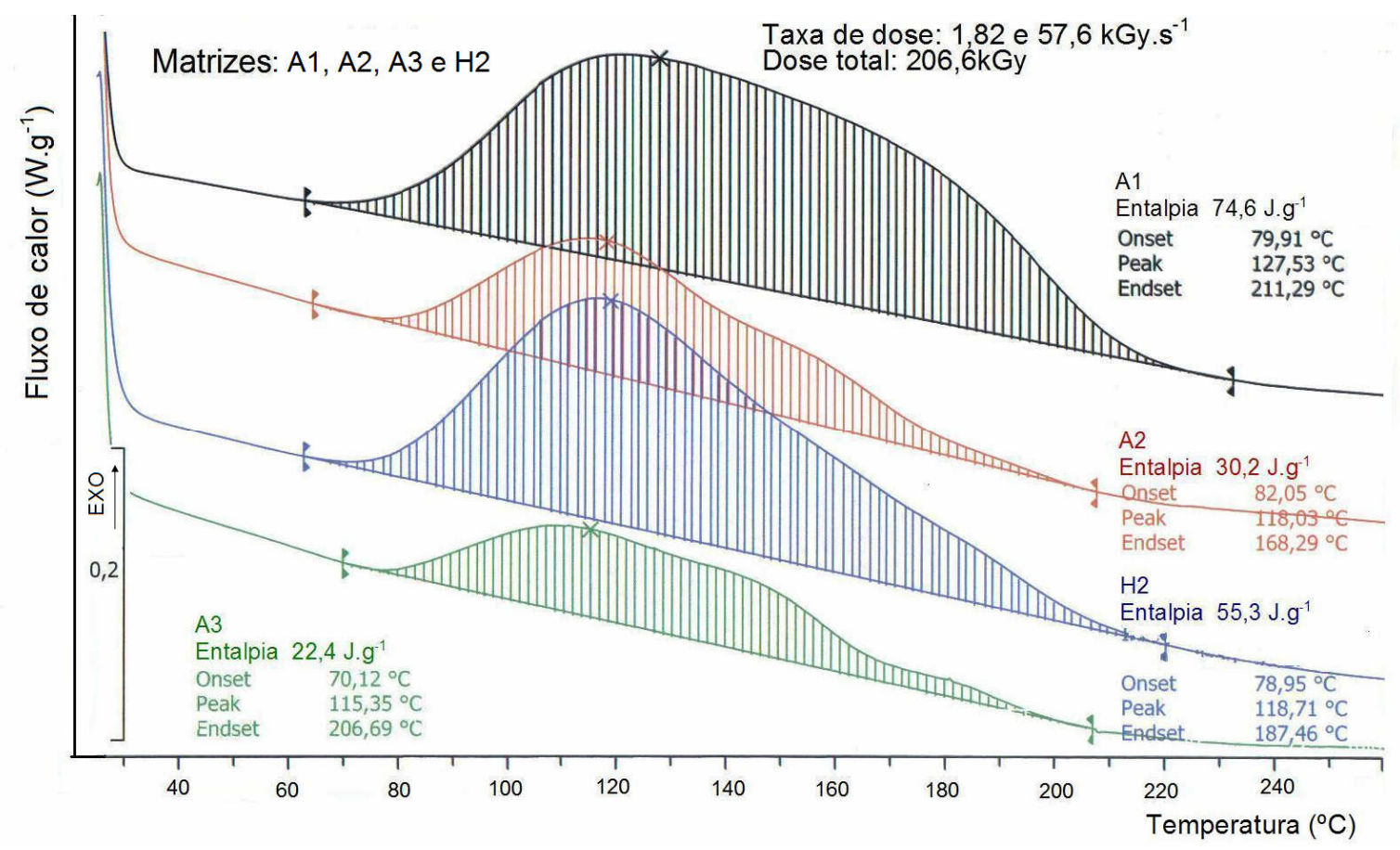

FIGURA 5.8 - Curvas DSC da entalpia residual da reação de cura das matrizes $\mathrm{A} 1, \mathrm{~A} 2, \mathrm{~A} 3$ e $\mathrm{H} 2$ curadas por feixe de elétrons com taxas de doses de 1,82 kGy.s $\mathrm{s}^{-1}$ e $57,6 \mathrm{kGy} \cdot \mathrm{s}^{-1}$ e dose total de $206,4 \mathrm{kG}$. 


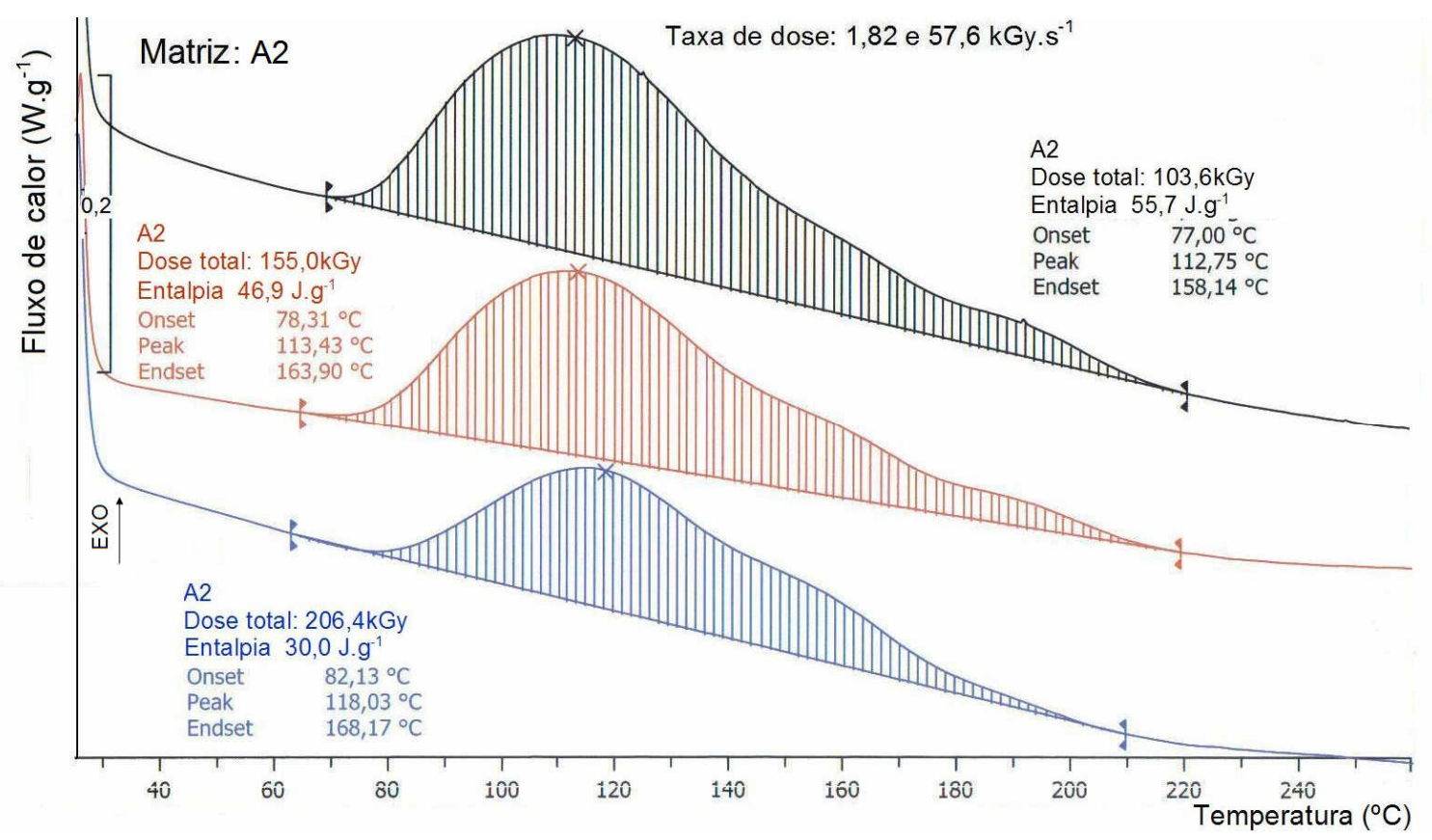

FIGURA 5.9 - Curvas DSC da entalpia residual da reação de cura da matriz A2 curada por feixe de elétrons com taxas de doses de 1,82 kGy.s ${ }^{-1}$ e 57,6 kGy.s ${ }^{-1} \mathrm{e}$ doses totais de 103,6kGy, 155,0kGy e 206,4kGy.

Assim como nas matrizes, os compósitos curados por feixe de elétrons, também não obtiveram um grau de cura total. Nas FIG. 5.10, 5.11 e 5.12 são mostradas as curvas DSC com as entalpias residuais das matrizes utilizadas nos compósitos FCA1, FCA2, FCA3 e FCH2. Observou-se que as entalpias residuais dos compósitos foram menores que das respectivas matrizes, pelo fato de que as entalpias de cura destes compósitos também foram menores que as das respectivas matrizes. Os fatores que contribuíram para esta ocorrência foram a menor quantidade de massa da matriz contida no compósito e a dissipação de calor gerado pela reação de cura por meio das fibras de carbono. 


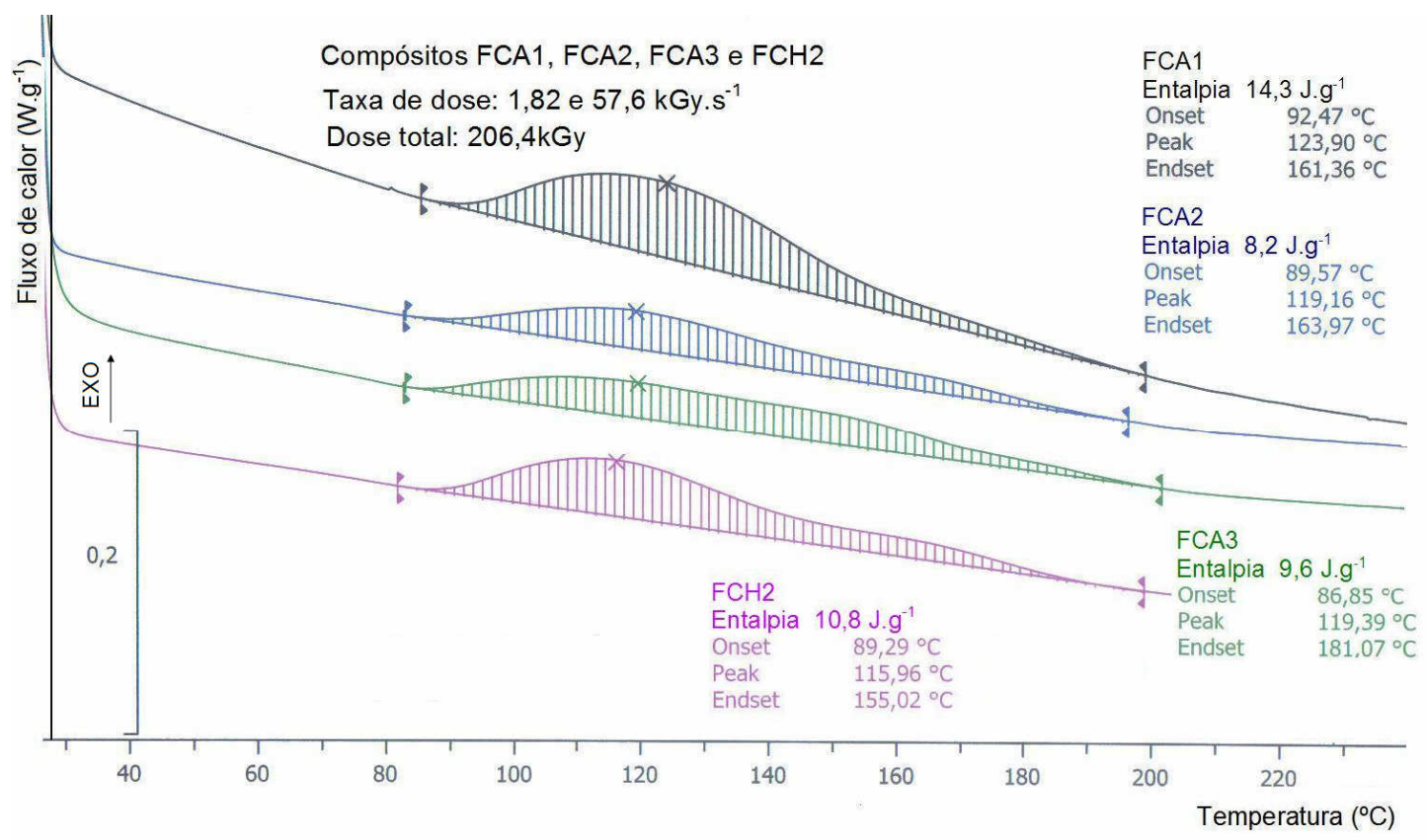

FIGURA 5.10 - Curvas DSC da entalpia residual da reação de cura dos compósitos FCA1, FCA2, FCA3 e FCH2 curados por feixe de elétrons com taxas de doses de $1,82 \mathrm{kGy} \cdot \mathrm{s}^{-1}$ e $57,6 \mathrm{kGy} \cdot \mathrm{s}^{-1}$ e dose total de $206,4 \mathrm{kGy}$.

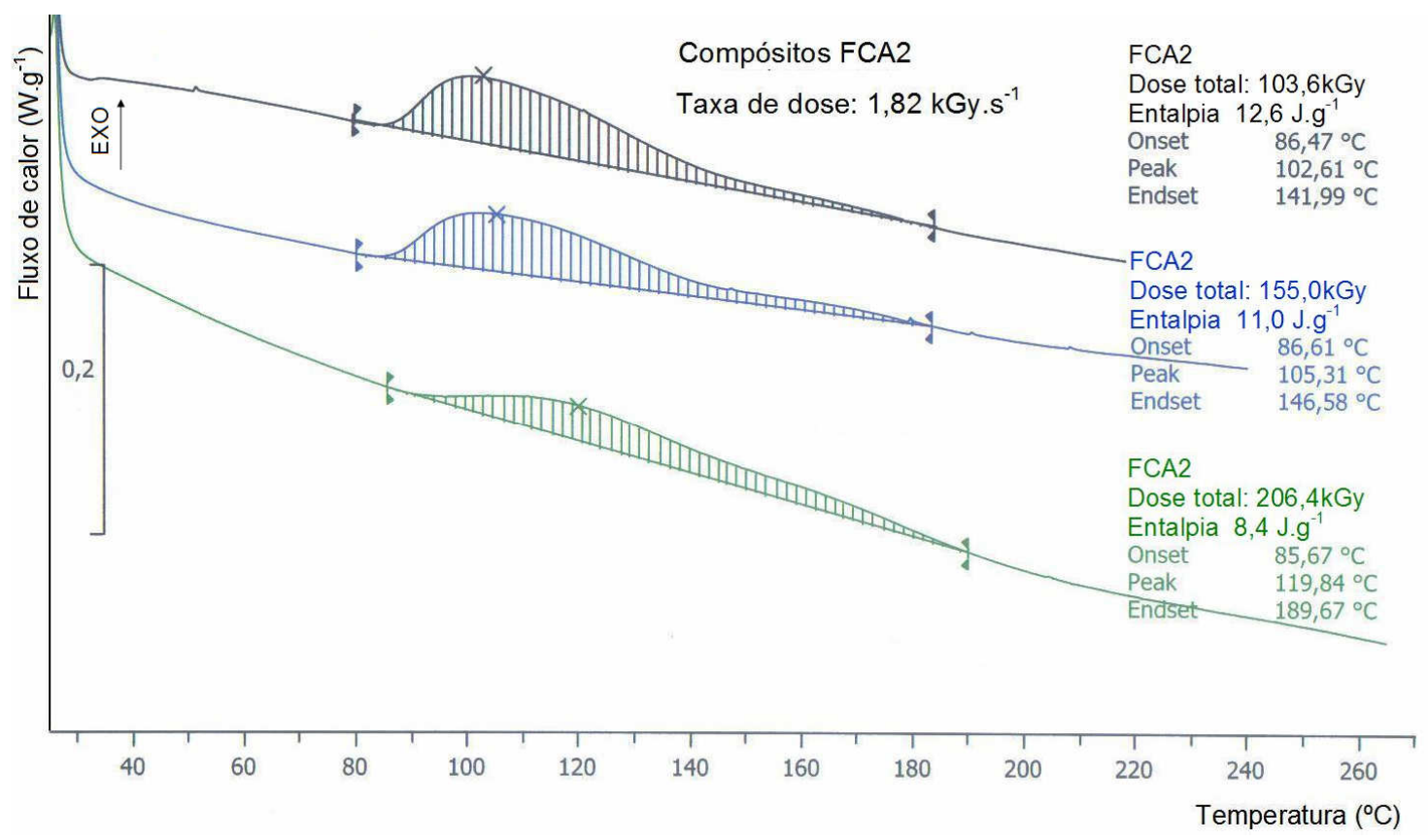

FIGURA 5.11 - Curvas DSC da entalpia residual da reação de cura dos compósitos FCA2 curados por feixe de elétrons com taxa de dose de 1,82 kGy.s ${ }^{-1}$ e dose total de 103,6kGy, 155,0kGy e 206,4kGy. 


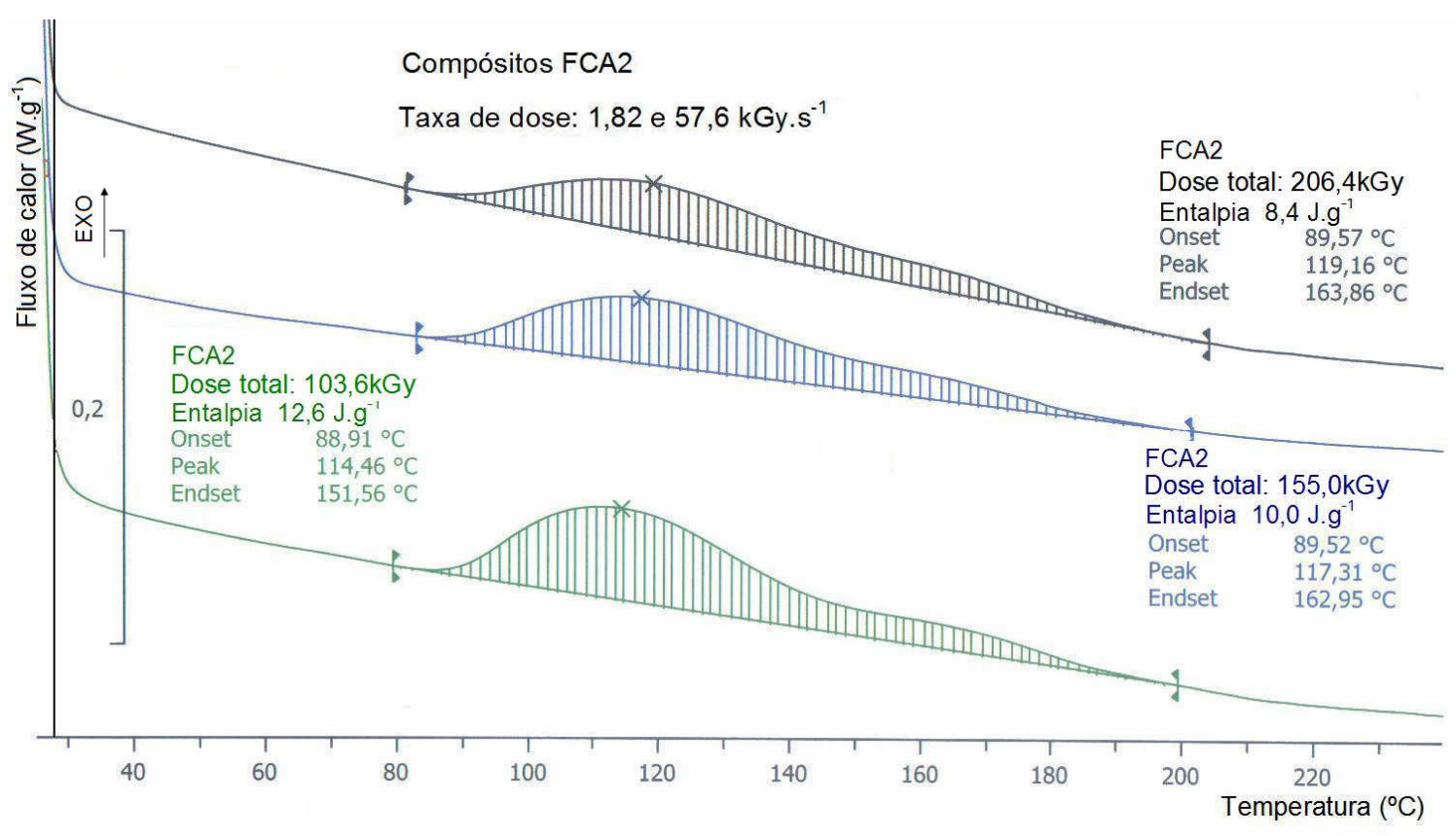

FIGURA 5.12 - Curvas DSC da entalpia residual da reação de cura dos compósitos FCA2 curados por feixe de elétrons com taxas de doses de $1,82 \mathrm{kGy} . \mathrm{s}^{-1}$ e 57,6 kGy.s ${ }^{-1}$ e doses totais de 103,6kGy, 155,0kGy e 206,4kGy.

Para calcular o grau de cura das matrizes e compósitos curados por feixe de elétrons, por intermédio da equação 4.2, foi preciso determinar as entalpias de reação de cura das amostras não curadas $\left(\Delta H_{t}\right)$ das matrizes poliméricas $\mathrm{A} 1, \mathrm{~A} 2, \mathrm{~A} 3$ e $\mathrm{H} 2$ e dos compósitos FCA1, FCA2, FCA3 e FCH2, apresentadas, respectivamente, nas TAB. 5.2 e TAB. 5.3. Nas FIG. 5.13 e 5.14 são mostradas as curvas DSC de cura obtidas quando estas amostras não curadas foram submetidas à técnica. Se a cura de uma amostra estiver incompleta, a entalpia residual da amostra $\left(\Delta \mathrm{H}_{\mathrm{a}}\right)$ é proporcional a fração da amostra não curada, o que permite calcular o grau de cura. A relação entre $\Delta \mathrm{H}_{\mathrm{a}} \mathrm{e}$ $\Delta \mathrm{H}_{\mathrm{t}}$ resulta diretamente na fração não reagida. Apenas uma curva representativa de DSC é mostrada das três análises que foram realizadas para cada amostra.

Na TAB. 5.2 é apresentada também a entalpia de reação de cura da matriz utilizada no processo de cura térmica (Tactix 123/HY 917/DY 062) e a respectiva curva DSC é mostrada na FIG. 5.13.

Dentre as matrizes contendo o iniciador catiônico, a amostra A3, apresentou a entalpia de reação de cura maior, por causa da maior concentração de PC 2506. 
TABELA 5.2 - Entalpias de reação de cura das matrizes de cura térmica e por feixe de elétrons obtido pelo DSC.

\begin{tabular}{cc}
\hline Matriz & $\Delta \mathrm{H}_{\mathrm{t}}\left(\mathrm{J} . \mathrm{g}^{-1}\right)$ \\
\hline TACTIX 123/HY 917/DY 062 & $212 \pm 13$ \\
A1 & $320 \pm 5$ \\
A2 & $502 \pm 7$ \\
A3 & $525 \pm 5$ \\
H2 & $502 \pm 6$ \\
\hline
\end{tabular}

TABELA 5.3. - Entalpias de reação de cura dos compósitos de cura por feixe de elétrons obtido pelo DSC.

\begin{tabular}{cc}
\hline Compósito & $\Delta \mathrm{H}_{\mathrm{t}}\left(\mathrm{J} . \mathrm{g}^{-1}\right)$ \\
\hline FCA1 & $120 \pm 3$ \\
FCA2 & $196 \pm 3$ \\
FCA3 & $223 \pm 5$ \\
FCH2 & $196 \pm 3$ \\
\hline
\end{tabular}

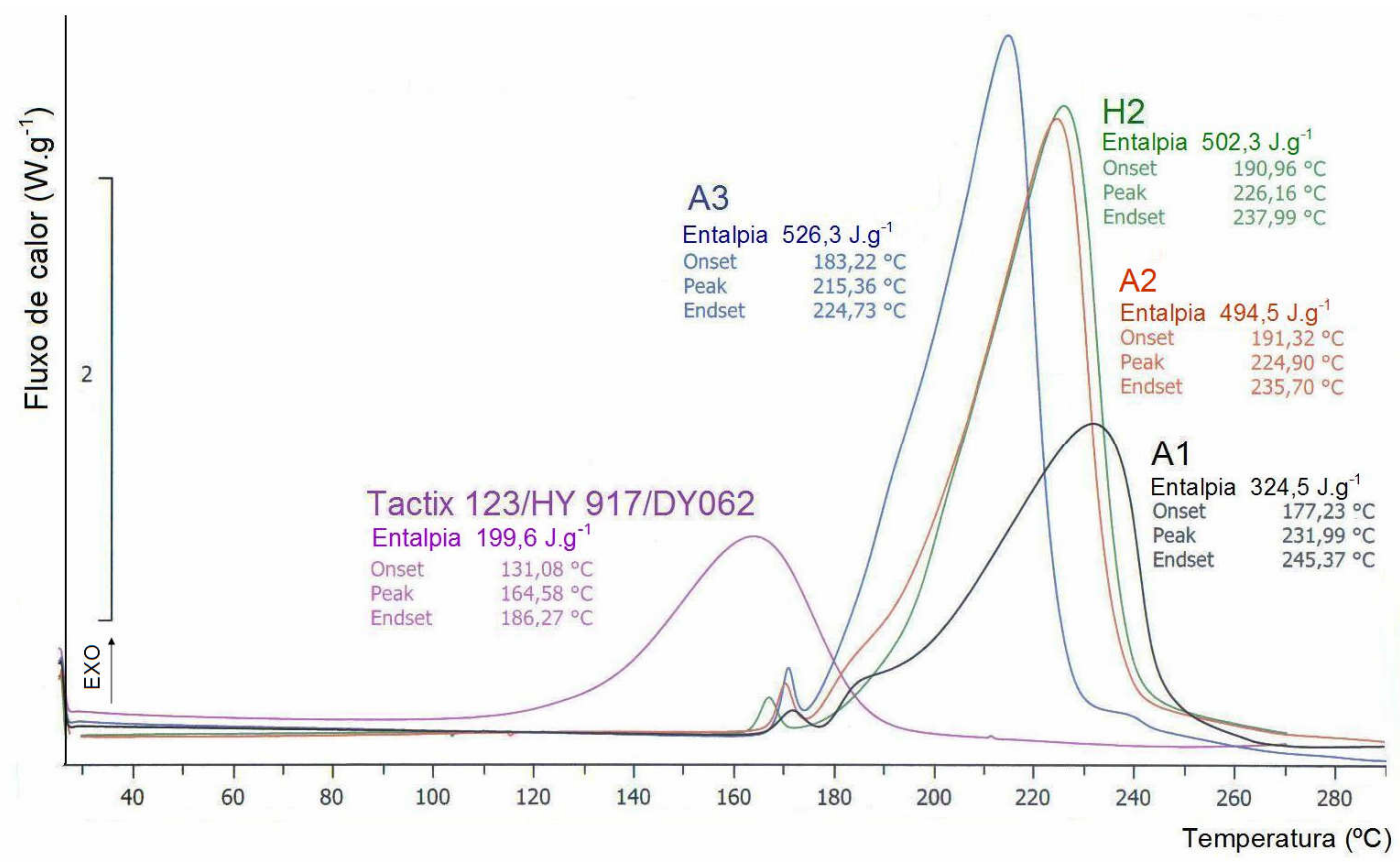

FIGURA 5.13 - Curvas DSC da entalpia de reação de cura das matrizes A1, A2, A3 e H2 de cura por feixe de elétrons e da matriz de cura térmica (Tactix 123/HY 917/DY 062). 


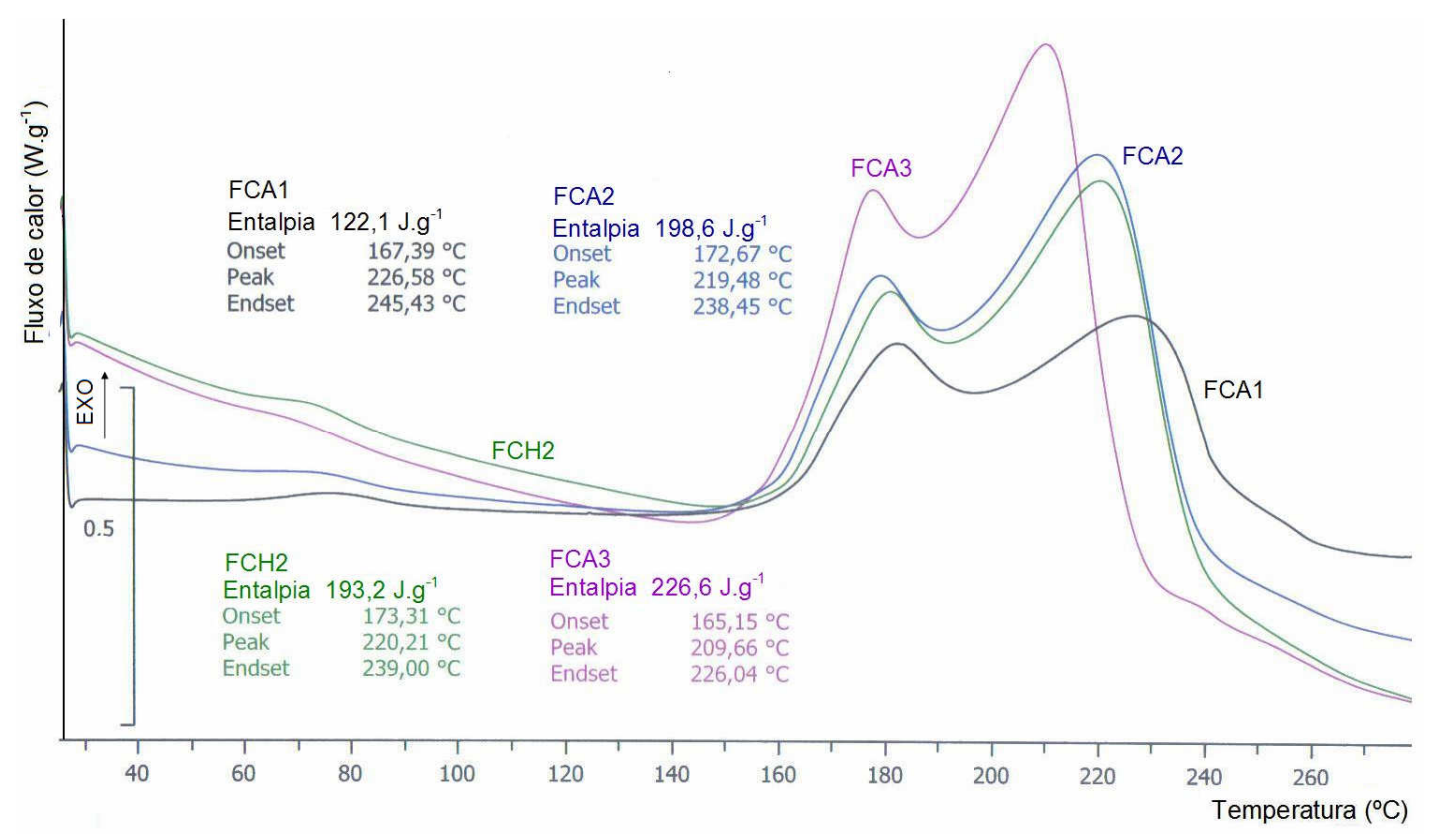

FIGURA 5.14 - Curvas DSC da entalpia da reação de cura dos compósitos FCA1, FCA2, FCA3 e FCH2 de cura por feixe de elétrons.

O grau de cura das matrizes e compósitos curados por feixe de elétrons foi determinado pela equação 4.2 e é apresentado, respectivamente, nas TAB. 5.4 e TAB. 5.5.

TABELA 5.4 - Grau de cura das matrizes curadas por feixe de elétrons.

\begin{tabular}{ccccc}
\hline \multicolumn{5}{c}{ Condição de cura } \\
Matriz & Taxa de dose $\left(\mathrm{kGy} . \mathrm{s}^{-1}\right)$ & Dose total (kGy) & $\Delta \mathrm{H}_{\mathrm{a}}\left(\mathrm{J} \cdot \mathrm{g}^{-1}\right)$ & $\begin{array}{c}\text { Grau de cura } \\
(\%)\end{array}$ \\
\hline A1 & 1,82 e 57,6 & 206,4 & $67 \pm 6$ & 79 \\
A2 & 1,82 & 103,6 & $65 \pm 4$ & 87 \\
A2 & 1,82 & 155,0 & $55 \pm 8$ & 89 \\
A2 & 1,82 & 206,4 & $41 \pm 6$ & 92 \\
A2 & 1,82 e 57,6 & 103,6 & $52 \pm 4$ & 90 \\
A2 & 1,82 e 57,6 & 155,0 & $51 \pm 4$ & 90 \\
A2 & 1,82 e 57,6 & 206,4 & $37 \pm 5$ & 93 \\
A3 & 1,82 e 57,6 & 206,4 & $28 \pm 6$ & 95 \\
H2 & 1,82 e 57,6 & 206,4 & $58 \pm 4$ & 88 \\
\hline
\end{tabular}


TABELA 5.5 - Grau de cura dos compósitos curados por feixe de elétrons.

\begin{tabular}{ccccc}
\hline Compósito & \multicolumn{2}{c}{ Condição de cura } & $\begin{array}{c}\text { Grau de } \\
\text { cura (\%) }\end{array}$ \\
& Taxa de dose $\left(\mathrm{kGy} . \mathrm{s}^{-1}\right)$ & Dose total (kGy) & $\Delta \mathrm{H}_{\mathrm{a}}\left(\mathrm{J} \cdot \mathrm{g}^{-1}\right)$ & \\
\hline FCA1 & 1,82 e 57,6 & 206,4 & $16 \pm 2$ & 87 \\
FCA2 & 1,82 & 103,6 & $14 \pm 1$ & 93 \\
FCA2 & 1,82 & 155,0 & $12 \pm 1$ & 94 \\
FCA2 & 1,82 & 206,4 & $9 \pm 1$ & 95 \\
FCA2 & 1,82 e 57,6 & 103,6 & $13 \pm 1$ & 93 \\
FCA2 & 1,82 e 57,6 & 155,0 & $10 \pm 1$ & 95 \\
FCA2 & 1,82 e 57,6 & 206,4 & $8 \pm 1$ & 96 \\
FCA3 & 1,82 e 57,6 & 206,4 & $10 \pm 1$ & 96 \\
FCH2 & 1,82 e 57,6 & 206,4 & $12 \pm 1$ & 94 \\
\hline
\end{tabular}

Como pode ser observado nas TAB. 5.4 e TAB. 5.5, no processo de cura por feixe de elétrons os compósitos obtiveram grau de cura maior que as matrizes correspondentes.

A matriz A3 obteve $95 \%$ de grau de cura, o maior dentre as matrizes irradiadas e os compósitos FCA2 e FCA3 curados com taxas de doses de 1,82 kGy.s. ${ }^{-1}$ e 57,6 kGy.s ${ }^{-1}$ e dose total de 206,4kGy atingiram o mesmo grau de cura de $96 \%$. Para o compósito FCA2, a concentração de $2 \%$ do iniciador catiônico na formulação da matriz foi o suficiente para se obter o maior grau de cura com estas condições de irradiação. Em um estudo desenvolvido por Cole et al. (2002), foi obtida uma matriz curada por feixe de elétrons com um grau de cura de $94 \%$.

O aumento súbito de temperatura nos minutos iniciais do processo da reação de cura das matrizes quando comparado com os respectivos compósitos, conforme mostrado nas FIG. 5.2 e 5.3, proporcionou como conseqüência a redução do grau de cura. Embora tivesse utilizado as mesmas taxas de doses de $1,82 \mathrm{kGy} \cdot \mathrm{s}^{-1}$ e $57,6 \mathrm{kGy} \cdot \mathrm{s}^{-1}$ e dose total de $206,4 \mathrm{kGy}$ no processo de irradiação, os compósitos curaram de maneira mais lenta e atingiram um maior grau de cura.

A ausência do produto molecular sieves na matriz $\mathrm{H} 2$ não interferiu na cura do compósito, visto que as amostras FCH2 e FCA2 (dose total de 206,4kGy) obtiveram graus de cura aproximadamente iguais, respectivamente, 94\% e 96\%. 
Isto mostra que a resina utilizada não continha água suficiente para inibir a reação de cura por feixe de elétrons.

O iniciador catiônico (PC 2506) dissocia-se em baixas temperaturas quando irradiadas por feixe de elétrons, visto que o processo de cura por irradiação foi realizado a $25^{\circ} \mathrm{C}$. Quando este é aquecido a uma temperatura acima de $170^{\circ} \mathrm{C}$ observa-se este mesmo fenômeno. Por meio da técnica de DSC foi observado que o iniciador catiônico no intervalo de temperatura entre $75^{\circ} \mathrm{C}$ e

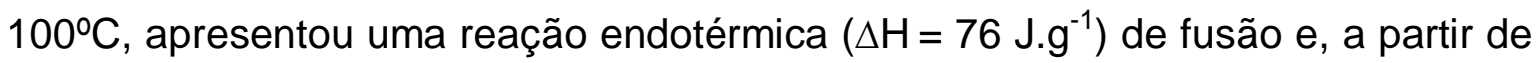
$170^{\circ} \mathrm{C}$, a dissociação térmica em ácido $\mathrm{H}^{+} \mathrm{SbF}_{6}{ }^{-}$(ácido forte de Bronsted), que propicia a iniciação da polimerização catiônica da resina epoxídica. Na FIG. 5.15 são mostradas as curvas DSC da dissociação térmica do iniciador catiônico e da matriz A2, na qual pode ser observada a presença de um pequeno pico localizado na temperatura de $170^{\circ} \mathrm{C}$ que corresponde a formação do ácido $\mathrm{H}^{+} \mathrm{SbF}_{6}{ }^{-}$.

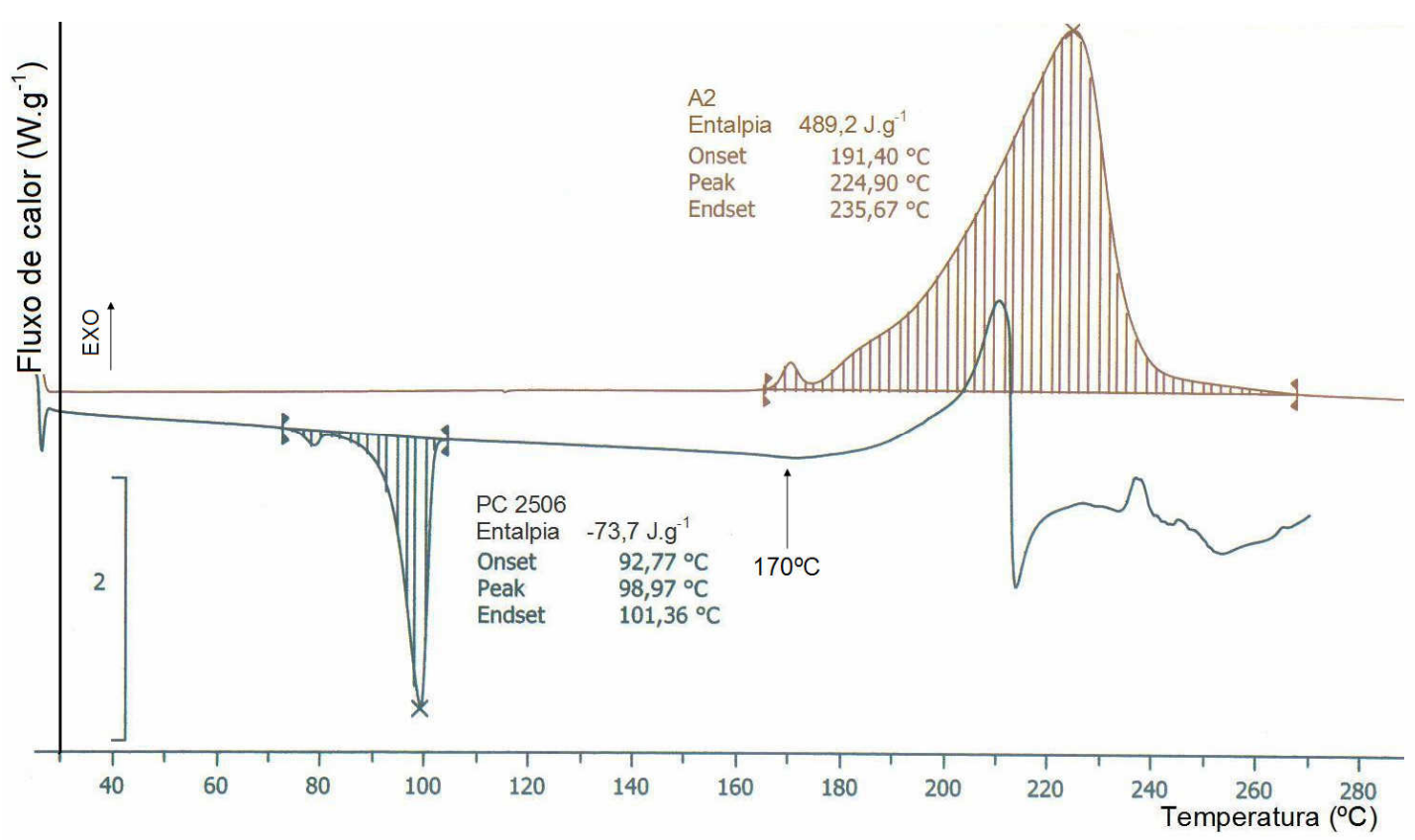

FIGURA 5.15 - Curvas DSC do iniciador catiônico e da formulação da matriz A2.

\subsubsection{Pós-cura térmica}

Para aumentar o grau de cura das matrizes e compósitos curados por feixe de elétrons, foi realizado um estudo de pós-cura nas matrizes A2 e nos compósitos FCA2 curados com a dose total de 206,4kGy. Esta escolha foi em razão destes compósitos terem apresentados graus de cura elevados, com a menor quantidade de iniciador catiônico e, conseqüentemente, redução de custo. 
Estas amostras foram pós-curadas termicamente a $180^{\circ} \mathrm{C}$ por um período de 60 minutos, conforme o trabalho de Defoort e Drzal, (2001). Segundo Berejka (2007), para se obter uma matriz epoxídica totalmente curada é necessário executar uma pós-cura térmica nos materiais irradiados.

As amostras pós-curadas termicamente atingiram a cura total, indicada pela presença da variação das curvas na região de transição vítrea, que permitiu a determinação apresentadas na TAB. 5.6. O estudo indica que a temperatura elevada ativou o iniciador catiônico residual contido na matriz ou facilitou a difusão das espécies aprisionadas, mas ainda ativas. Na reação de cura pelo processo por feixe de elétrons, a matriz solidifica de maneira muita rápida, impedindo uma eficiência total do iniciador catiônico.

TABELA 5.6 - Temperaturas de transição vítrea pela técnica de DSC das matrizes e compósitos curados por feixe de elétrons e pós-curados termicamente.

$$
\text { Condição de cura } \quad \mathrm{T}_{\mathrm{g}}\left({ }^{\circ} \mathrm{C}\right)
$$

Amostra

\begin{tabular}{cccc} 
Amostra & $\begin{array}{c}\text { Taxa de dose } \\
\left(\mathrm{kGy} \cdot \mathrm{s}^{-1}\right)\end{array}$ & $\begin{array}{c}\text { Dose total } \\
(\mathrm{kGy})\end{array}$ & $\begin{array}{c}\text { (Pós-cura térmica de } \\
180^{\circ} \mathrm{C} \text { por } 1 \text { hora) }\end{array}$ \\
\hline A2 & 1,82 & 206,4 & $152 \pm 2$ \\
A2 & 1,82 e 57,6 & 206,4 & $152 \pm 2$ \\
FCA2 & 1,82 & 206,4 & $153 \pm 3$ \\
FCA2 & 1,82 e 57,6 & 206,4 & $158 \pm 3$ \\
\hline
\end{tabular}

As curvas de DSC das amostras de matrizes A2 e compósitos FCA2 curados por feixe de elétrons com dose total de 206,4kGy e pós-curados termicamente são mostradas nas FIG. 5.16, 5.17, 5.18 e 5.19. Nestas figuras são mostradas as curvas DSC das amostras antes da pós-cura térmica, na qual pode ser observada a entalpia residual da reação de cura, e a curva DSC correspondente a amostra pós-curada, que evidenciou a variação correspondente à transição vítrea e a ausência da entalpia residual. 


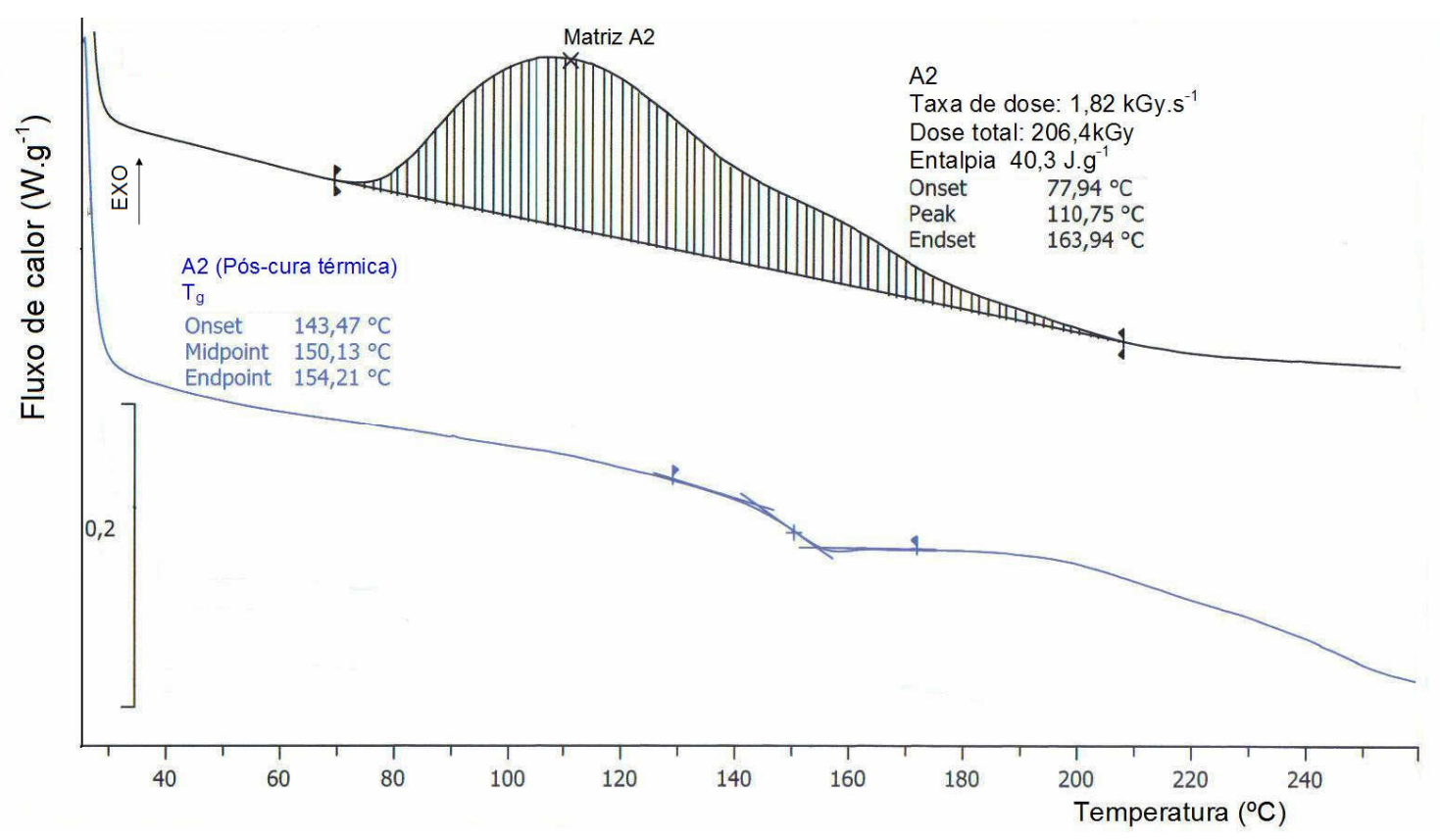

FIGURA 5.16 - Curvas DSC da matriz A2 curada por feixe de elétrons com taxa de dose de $1,82 \mathrm{kGy} \cdot \mathrm{s}^{-1}$, dose total de 206,4kGy e pós-curada termicamente.

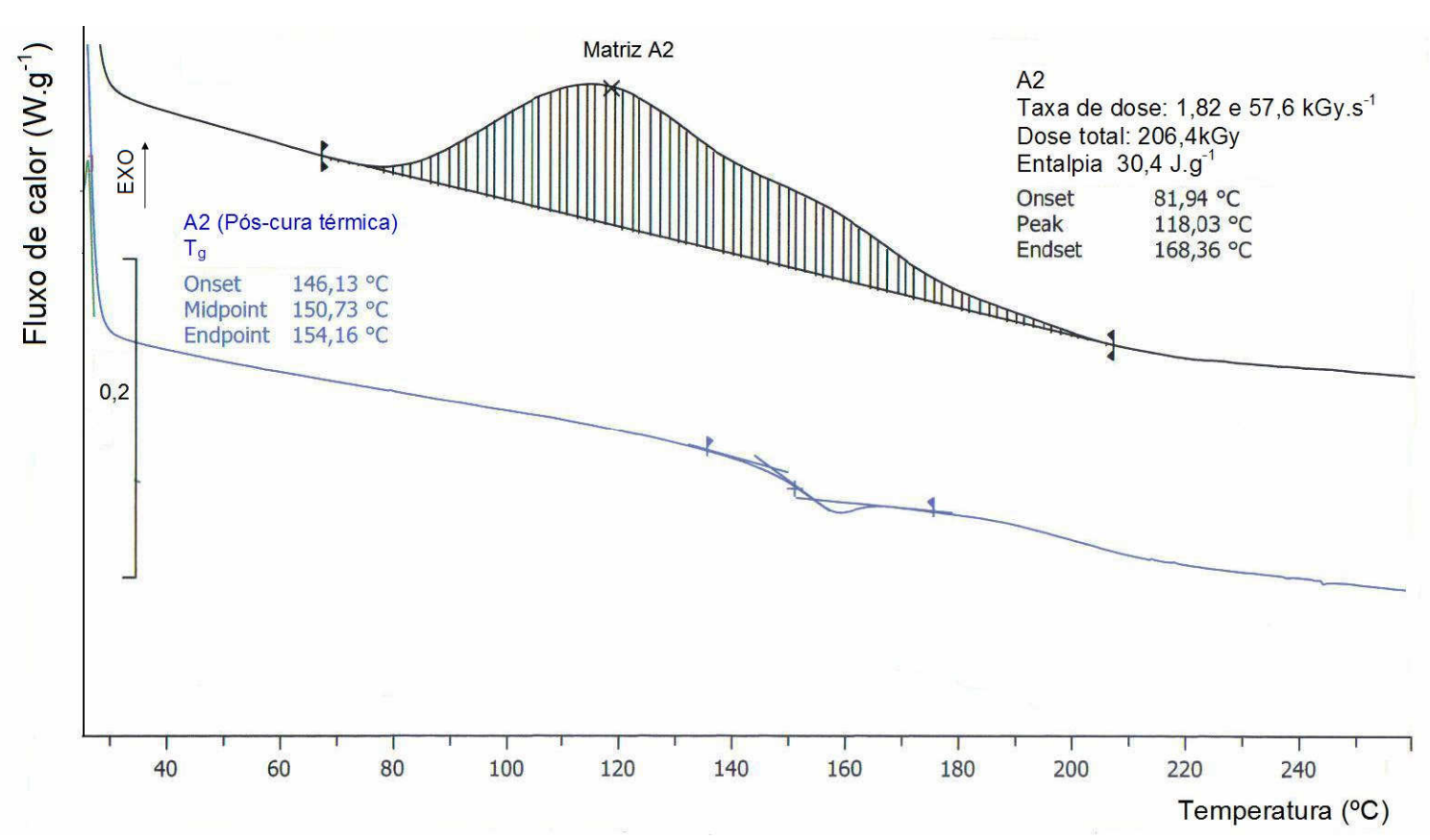

FIGURA 5.17 - Curvas DSC da matriz A2 curada por feixe de elétrons com taxas de doses de 1,82 kGy.s ${ }^{-1}$ e $57,6 \mathrm{kGy} . \mathrm{s}^{-1}$, dose total de $206,4 \mathrm{kGy}$ e pós-curada termicamente. 


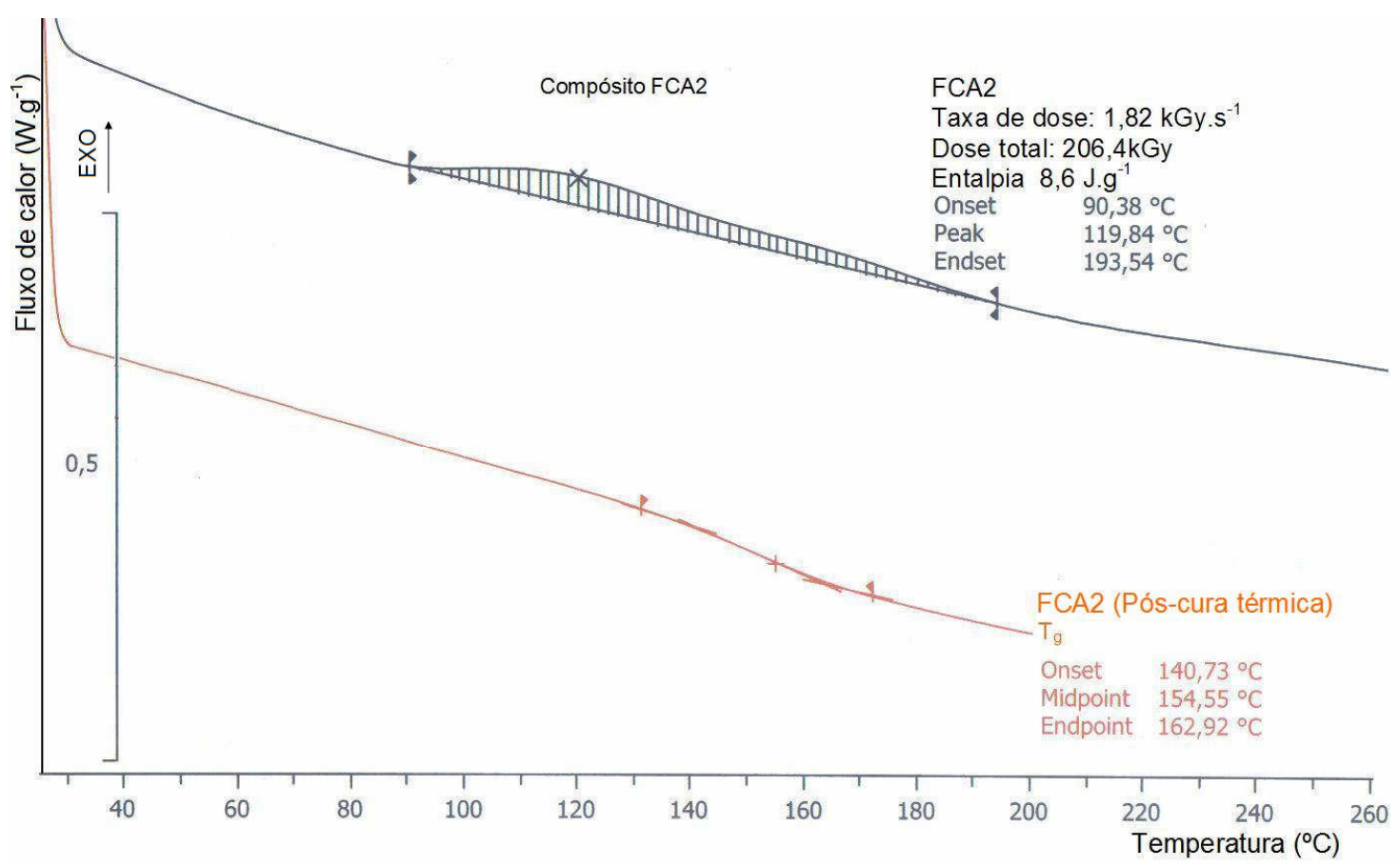

FIGURA 5.18 - Curvas DSC do compósito FCA2 curado por feixe de elétrons com taxa de dose de $1,82 \mathrm{kGy} \cdot \mathrm{s}^{-1}$, dose total de 206,4kGy e pós-curado termicamente.

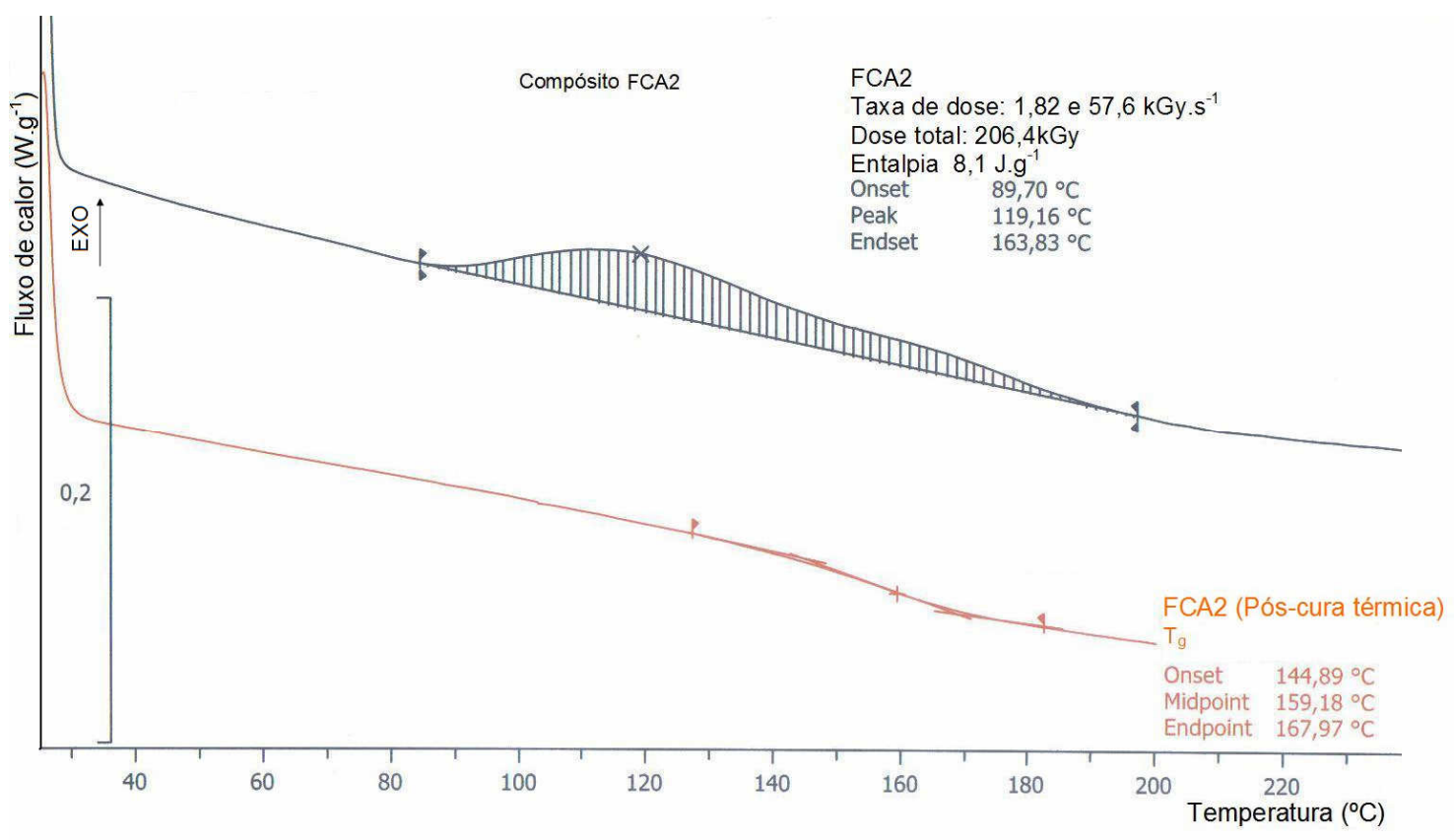

FIGURA 5.19 - Curvas DSC do compósito FCA2 curado por feixe de elétrons com taxas de doses de 1,82 kGy.s ${ }^{-1}$ e $57,6 \mathrm{kGy}^{-1} \mathrm{~s}^{-1}$, dose total de 206,4kGy e pós-curado termicamente. 
O compósito FCA2 curado com as taxas de doses de 1,82 kGy.s ${ }^{-1} \mathrm{e}$ 57,6 kGy. $^{-1}$ e dose total de 206,4kGy obteve uma $T_{g}$ mais elevada (FIG.5.19) quando comparado com outros materiais pós-curados termicamente.

\subsubsection{Termodinâmico-mecânica (DMTA)}

A técnica de DMTA tem como um dos principais objetivos relacionar as propriedades macroscópicas, tais como as propriedades mecânicas, com as relaxações moleculares associadas às mudanças conformacionais e às deformações microscópicas geradas a partir de rearranjos moleculares.

$\mathrm{Na}$ região da temperatura de transição vítrea ocorre uma maior mobilidade das cadeias poliméricas proporcionando uma redução acentuada de E', aumentando a dissipação de energia em função da temperatura até um máximo de $E "$ " e de $\tan \delta$. Como a tan $\delta$ é a razão entre os módulos de perda e armazenamento, esta atingirá valores máximos em regiões próximas aos máximos observados para o E”, porém em temperaturas maiores. A temperatura de transição vítrea pode ser associada com o onset do módulo de armazenamento (E'), com o pico do módulo de perda (E”) ou com o pico de amortecimento $(\tan \delta)$.

A temperatura de transição vítrea é acompanhada por uma variação do

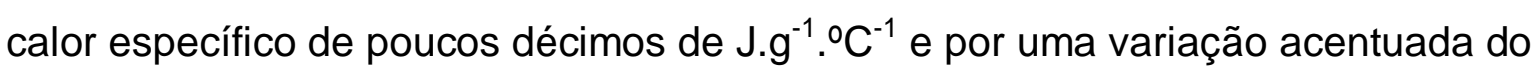
módulo de armazenamento, da ordem de $10^{3} \mathrm{~Pa}$ no caso de polímeros amorfos. Estas características tornam a técnica de DMTA especialmente sensível para a sua detecção em comparação com a técnica calorimétrica.

\subsubsection{Cura térmica}

$\mathrm{Na}$ TAB. 5.7 são apresentadas as temperaturas de transição vítrea determinadas pelos picos das curvas do módulo E" e tan $\delta$ da matriz e do compósito curados pelo processo térmico. Nas FIG. 5.20 e 5.21 são mostradas, respectivamente, as curvas DMTA da matriz e do compósito. Foi observado que ambas as amostras exibiram comportamento dinâmico-mecânico de um material totalmente curado em razão da ausência de pico secundário nas suas respectivas

curvas $\tan \delta$. Ressalta-se que apenas uma curva representativa de DMTA é mostrada, de duas análises realizadas para cada amostra. 
Pelo resultado obtido verificou-se que para os compósitos, os valores de $T_{g}$ dependem da técnica empregada para a análise, conforme as TAB. $5.1 \mathrm{e}$ TAB. 5.7, respectivamente, DSC e DMTA. A temperatura de transição vítrea determinada pelo DSC foi de $117^{\circ} \mathrm{C}$ e pelo DMTA atingiu $129^{\circ} \mathrm{C}$ (pico de E") e $136^{\circ} \mathrm{C}$ (pico de $\tan \delta$ ), portanto, um aumento de até $16 \%$ de um equipamento para o outro. Na matriz, a temperatura de transição vítrea pelo DSC, coincidiu com o pico de E" que foi de $116^{\circ} \mathrm{C}$.

Embora a $T_{g}$ esteja associada ao comportamento térmico da matriz polimérica, houve evidência de que quando combinada com um material de reforço esta propriedade sofre uma alteração. Neste trabalho, as amostras analisadas foram de um compósito com as fibras de carbono na direção longitudinal ou 0 . Nesta direção, o compósito tem a maior resistência à tração e flexão e maior módulo de elasticidade, justificando o aumento de $T_{g}$ pelo DMTA. Um compósito com os elementos de reforços na direção transversal ou $90^{\circ}$ tem uma $T_{g}$ próxima da matriz sem reforço.

TABELA 5.7 - Temperatura de transição vítrea pela técnica de DMTA da matriz TACTIX 123/HY 917/DY 062 e do compósito de mesma matriz curados pelo processo térmico.

\begin{tabular}{ccc}
\hline Amostra & $\mathrm{T}_{\mathrm{g}}\left({ }^{\circ} \mathrm{C}\right), \mathrm{E}^{\prime \prime}$ & $\mathrm{T}_{\mathrm{g}}\left({ }^{\circ} \mathrm{C}\right), \tan \delta$ \\
\hline Matriz (TACTIX 123/HY 917/DY 062) & $116 \pm 3$ & $125 \pm 3$ \\
Compósito & $129 \pm 4$ & $136 \pm 4$ \\
\hline
\end{tabular}




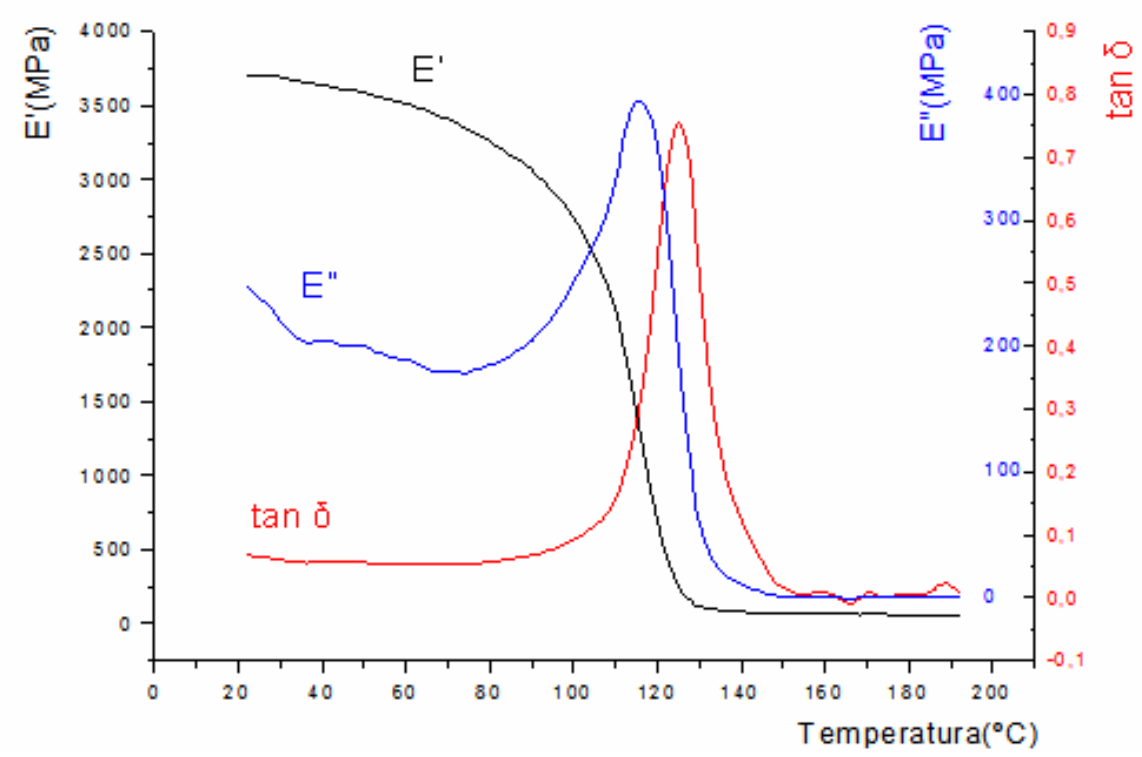

FIGURA 5.20 - Curvas DMTA da matriz curada pelo processo térmico.

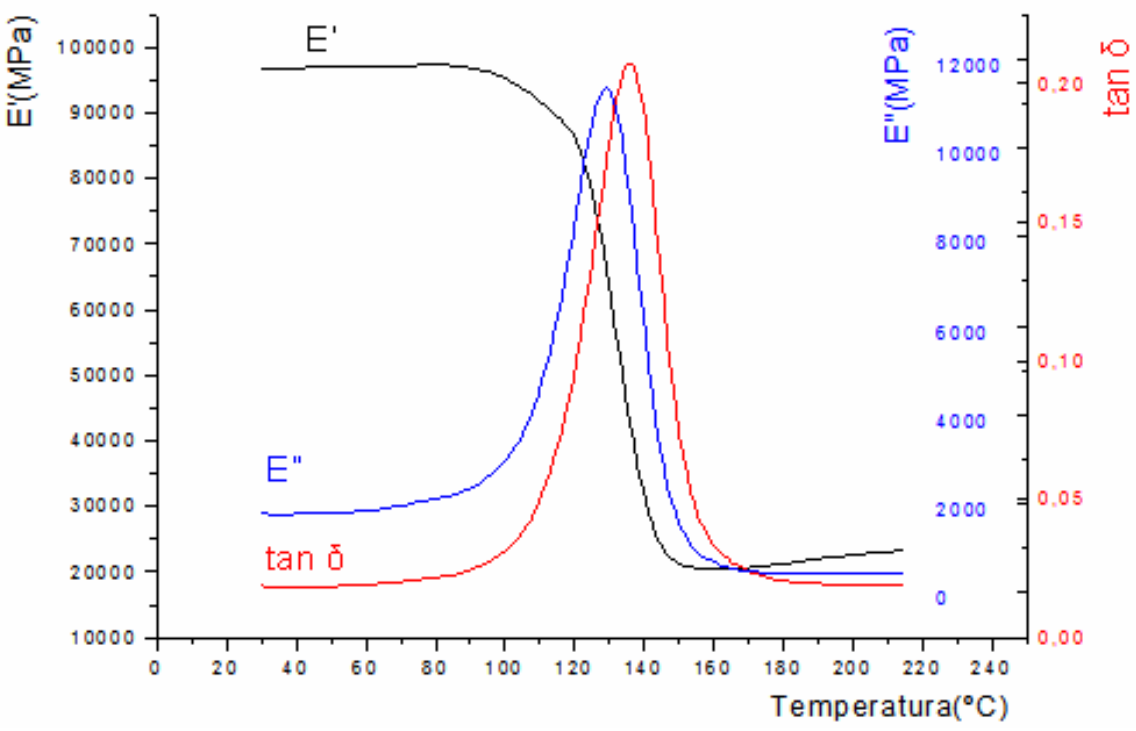

FIGURA 5.21 - Curvas DMTA do compósito curado pelo processo térmico.

\subsubsection{Cura por feixe de elétrons}

As temperaturas de transição vítrea determinadas pelo pico da curva do módulo E" e tan $\delta$ das matrizes curadas por feixe de elétrons são apresentadas na TAB. 5.8. Por meio da técnica de DSC não foi possível determinar a temperatura de transição vítrea das matrizes irradiadas, pois estas apresentaram entalpia residual de cura. A técnica de DMTA foi sensível o suficiente para 
determinar o comportamento dinâmico-mecânico em função da temperatura, indicando a temperatura transição do material, mesmo nas amostras parcialmente curadas.

TABELA 5.8 - Temperaturas de transição vítrea pela técnica de DMTA das matrizes curadas por feixe de elétrons.

\section{Condição de cura}

Amostra Taxa de dose $\left(k G y . s^{-1}\right)$ Dose total (kGy) $\quad T_{g}\left({ }^{\circ} \mathrm{C}\right), \mathrm{E}^{\prime \prime} \quad \mathrm{T}_{\mathrm{g}}\left({ }^{\circ} \mathrm{C}\right)$, $\tan \delta$

\begin{tabular}{lcccc}
\hline A1 & 1,82 e 57,6 & 206,4 & $149 \pm 3$ & $165 \pm 3$ \\
A2 & 1,82 & 103,6 & $136 \pm 3$ & $153 \pm 3$ \\
A2 & 1,82 & 155,0 & $141 \pm 3$ & $159 \pm 3$ \\
A2 & 1,82 & 206,4 & $142 \pm 3$ & $159 \pm 3$ \\
A2 & 1,82 e 57,6 & 103,6 & $141 \pm 3$ & $159 \pm 3$ \\
A2 & 1,82 e 57,6 & 155,0 & $144 \pm 3$ & $159 \pm 3$ \\
A2 & 1,82 e 57,6 & 206,4 & $150 \pm 3$ & $167 \pm 3$ \\
A3 & 1,82 e 57,6 & 206,4 & $145 \pm 3$ & $165 \pm 3$ \\
H2 & 1,82 e 57,6 & 206,4 & $149 \pm 3$ & $167 \pm 3$ \\
\hline
\end{tabular}

Nas FIG. 5.22, 5.23 e 5.24 são mostradas as curvas DMTA de tan $\delta$ das matrizes A1, A2, A3 e H2 curadas por feixe elétrons, conforme as condições de cura apresentadas na TAB. 5.8. A presença de pico secundário nas curvas de $\tan \delta$ confirma que as matrizes não estão totalmente curadas. Para melhor compreensão estas regiões foram indicadas por setas nas respectivas curvas. Estes picos secundários correspondem à presença de entalpia residual nas matrizes analisadas e que foi apresentada na TAB. 5.4.

As curvas DMTA individuais contendo o módulo E', módulo E" e tan $\delta$ das matrizes $\mathrm{A} 1, \mathrm{~A} 2, \mathrm{~A} 3$ e $\mathrm{H} 2$ curadas por feixe de elétrons são mostradas no APÊNDICE A e correspondem a uma das duas análises realizadas para cada amostra. 


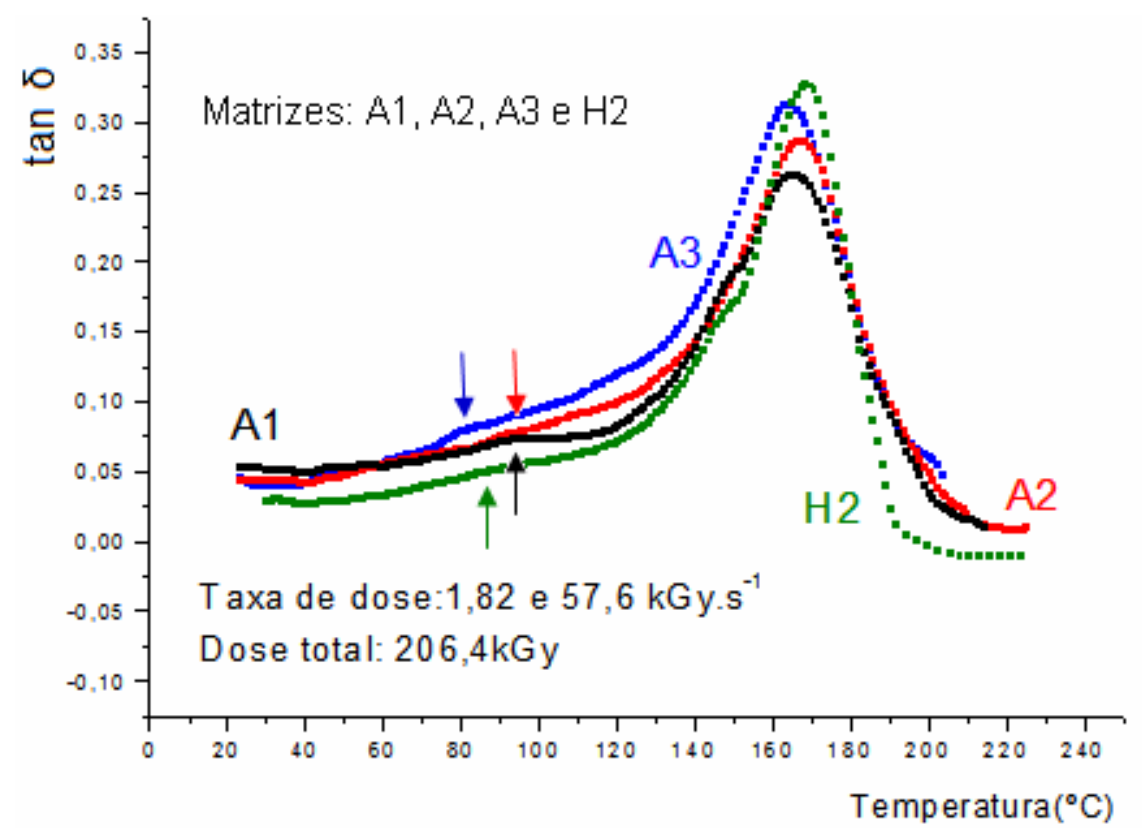

FIGURA 5.22 - Curvas DMTA de tan $\delta$ das matrizes A1, A2, A3 e H2 curadas por feixe elétrons com taxas de doses de 1,82 kGy.s ${ }^{-1}$ e $57,6 \mathrm{kGy} \cdot \mathrm{s}^{-1}$ e dose total de 206,4kGy.

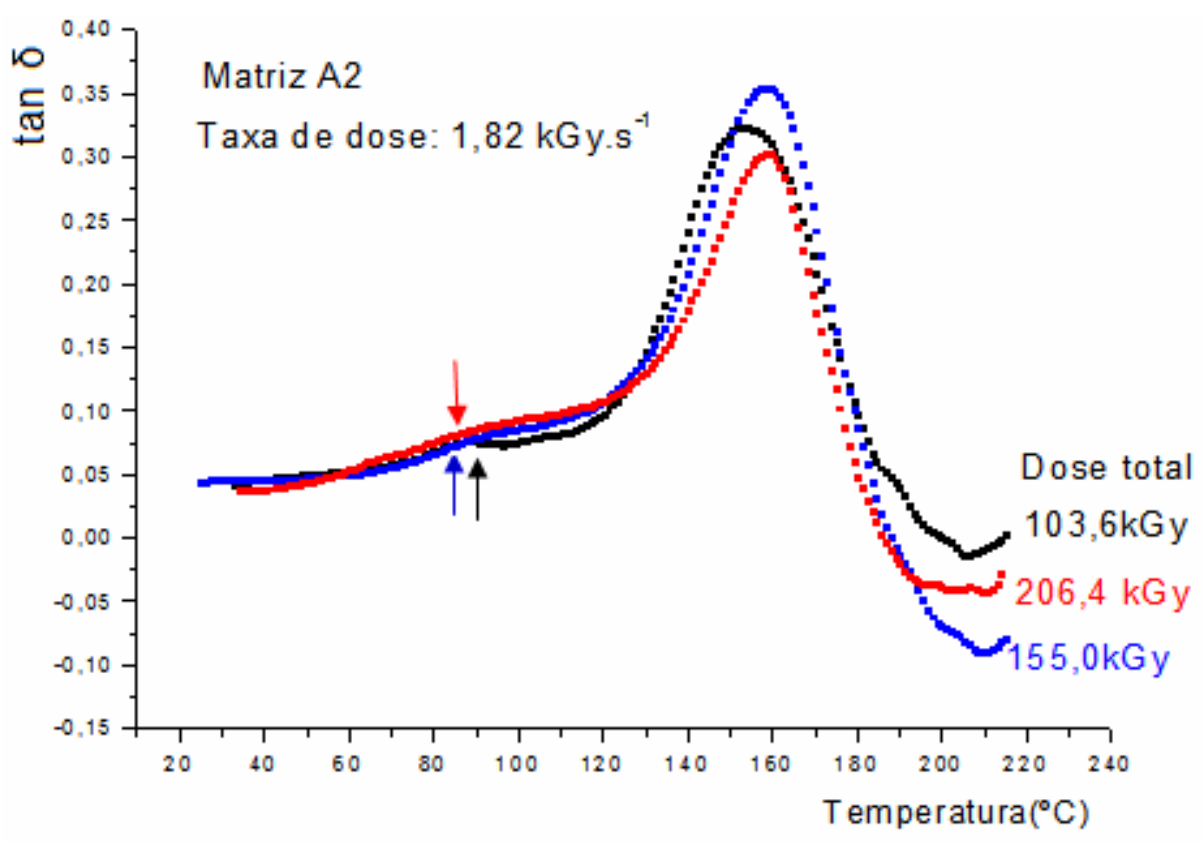

FIGURA 5.23 - Curvas DMTA de tan $\delta$ das matrizes A2 curadas por feixe de elétrons com taxa de dose de 1,82 kGy.s ${ }^{-1}$ e doses totais de 103,6kGy, 155,0kGy e 206,4kGy. 


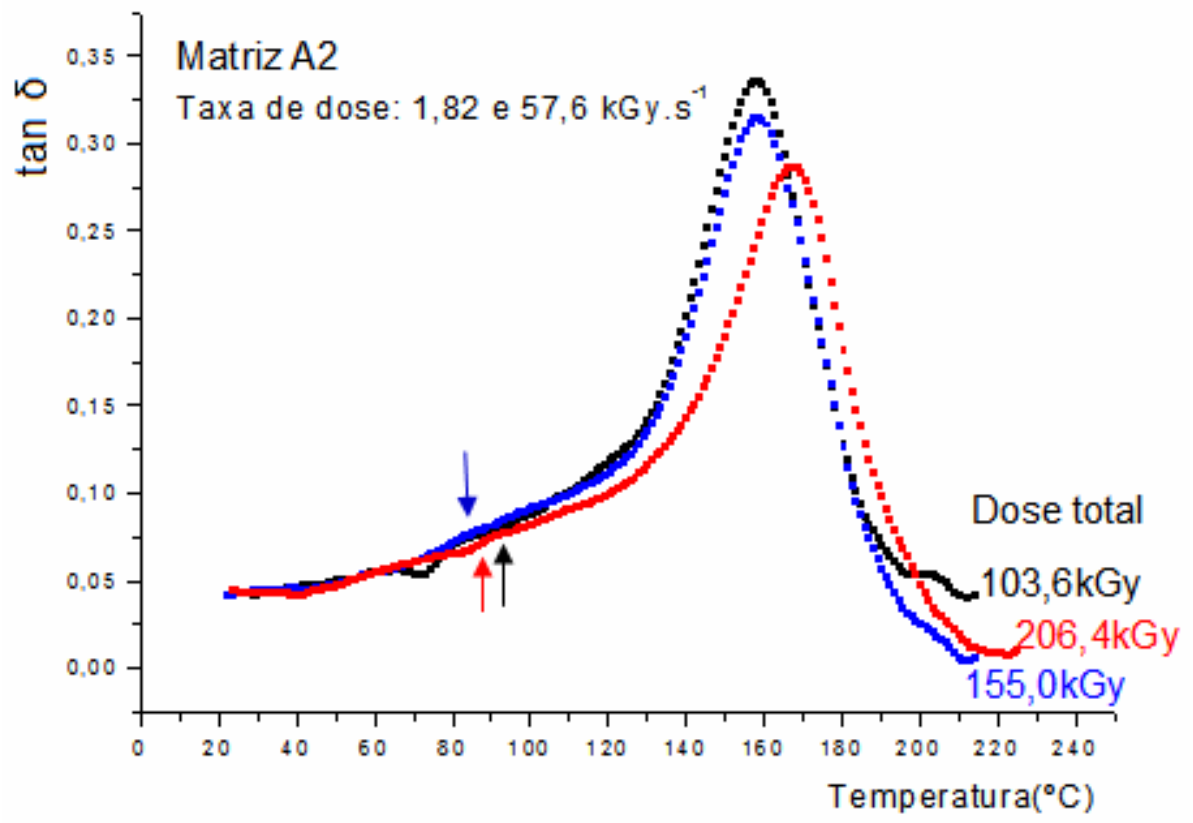

FIGURA 5.24 - Curvas DMTA de tan $\delta$ das matrizes A2 curadas por feixe de elétrons com taxas de doses de 1,82 kGy.s ${ }^{-1}$ e 57,6 kGy.s ${ }^{-1}$ e doses totais de 103,6kGy, 155,0kGy e 206,4kGy.

Observou-se que o módulo de armazenamento E' das matrizes curadas por feixe de elétrons (FIG. A1 do APÊNDICE A) diminuiu mais acentuadamente em função do aumento de temperatura que as matrizes curadas pelo processo térmico, conforme mostrado na FIG. 5.20. Este fenômeno já havia sido constatado por Palmese et al. (2000), entretanto, estes autores não relataram uma explicação para o evento.

Na TAB. 5.9 são apresentadas as temperaturas de transição vítrea dos compósitos curados por feixe de elétrons e nas FIG. 5.25 a 5.27 são mostradas as curvas DMTA de tan $\delta$. O compósito FCA2 curado com taxa de dose de $1,82 \mathrm{kGy} . \mathrm{s}^{-1}$ e dose total de 206,4kGy, mostrado na FIG. 5.25, e os compósitos FCA2, FCA3 e FCH2 curados com taxas de doses de 1,82 kGy.s ${ }^{-1}$ e 57,6 kGy.s ${ }^{-1}$ e dose total de 206,4kGy mostrados nas FIG. 5.26 e 5.27 obtiveram um comportamento dinâmico-mecânico correspondente ao de um compósito curado, como aquele obtido pelo processo térmico mostrado na FIG. 5.21. Nestas curvas de tan $\delta$ não houve a presença de pico secundário, embora na técnica de DSC se tenha verificado que estes compósitos curados por feixe de elétrons não obtiveram cura total e foram apresentados na TAB. 5.5 . 
Os demais compósitos analisados não obtiveram comportamento dinâmico-mecânico característico de um material curado, pois apresentaram picos secundários na curva tan $\delta$. Para melhor compreensão, estes picos são indicados por uma seta nas FIG. 5.25 a 5.27. Os compósitos FCA2 curados com dose total de 155,0kGy, embora tenham atingido o grau de cura de 94\% (taxa de dose de $1,82 \mathrm{kGy} . \mathrm{s}^{-1}$ ) e 95\% (taxas de doses de 1,82 kGy.s ${ }^{-1}$ e 57,6 kGy.s $\mathrm{s}^{-1}$ ), não obtiveram o comportamento dinâmico-mecânico característico de um material curado, conforme as curvas mostradas no APÊNDICE $B$, respectivamente, FIG. B3 e B6.

As curvas DMTA individuais contendo o módulo E', módulo E" e tan $\delta$ dos compósitos FCA1, FCA2, FCA3 e FCH2 curados por feixe de elétrons são mostradas no APÊNDICE B e correspondem a uma das duas análises realizadas para cada amostra.

TABELA 5.9 - Temperaturas de transição vítrea pela técnica de DMTA dos compósitos curados por feixe de elétrons.

\section{Condição de cura}

Amostra Taxa de dose $\left(k G y \cdot s^{-1}\right)$ Dose total (kGy) $\quad T_{g}\left({ }^{\circ} \mathrm{C}\right), E^{\prime \prime} \quad T_{g}\left({ }^{\circ} \mathrm{C}\right)$, $\tan \delta$

\begin{tabular}{lcccc}
\hline FCA1 & 1,82 e 57,6 & 206,4 & $161 \pm 3$ & $165 \pm 3$ \\
FCA2 & 1,82 & 103,6 & $152 \pm 3$ & $158 \pm 3$ \\
FCA2 & 1,82 & 155,0 & $153 \pm 3$ & $158 \pm 3$ \\
FCA2 & 1,82 & 206,4 & $151 \pm 3$ & $157 \pm 3$ \\
FCA2 & 1,82 e 57,6 & 103,6 & $154 \pm 3$ & $159 \pm 3$ \\
FCA2 & 1,82 e 57,6 & 155,0 & $159 \pm 3$ & $163 \pm 3$ \\
FCA2 & 1,82 e 57,6 & 206,4 & $162 \pm 3$ & $167 \pm 3$ \\
FCA3 & 1,82 e 57,6 & 206,4 & $156 \pm 3$ & $162 \pm 3$ \\
FCH2 & 1,82 e 57,6 & 206,4 & $161 \pm 3$ & $167 \pm 3$ \\
\hline
\end{tabular}




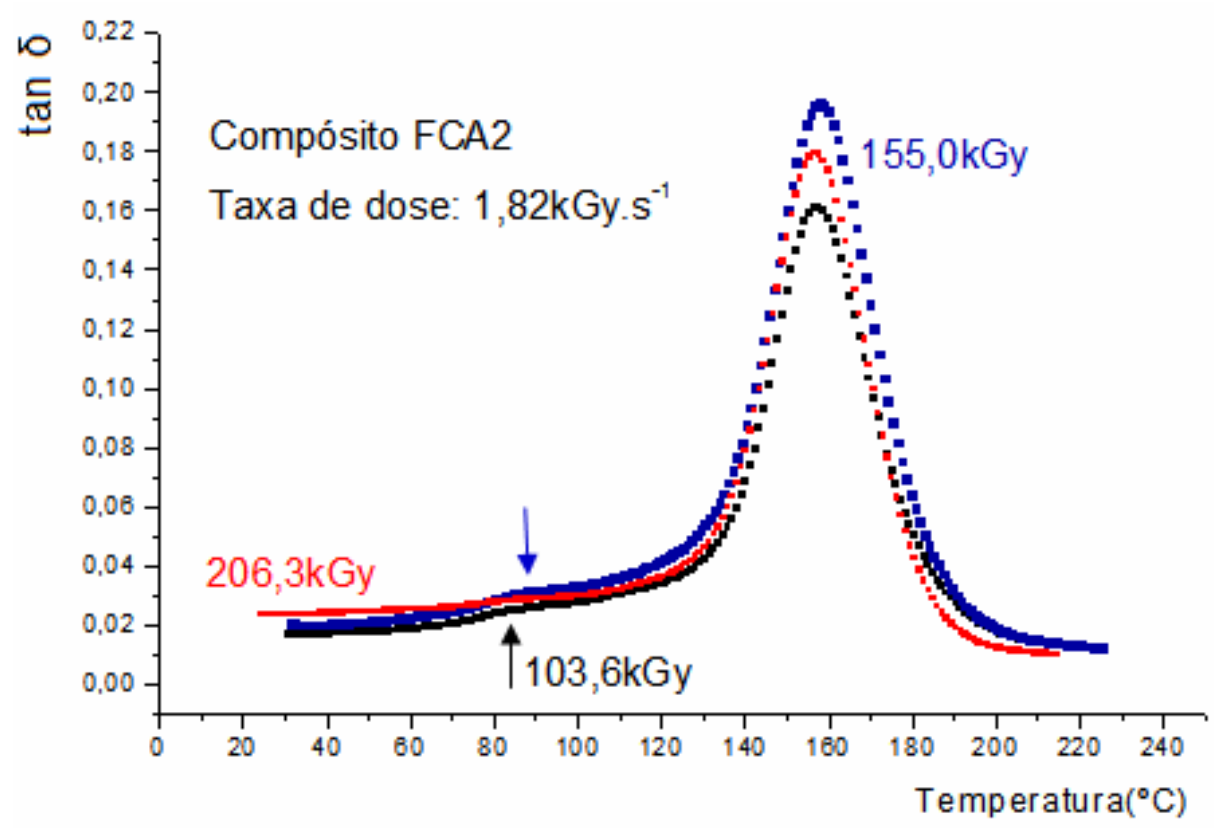

FIGURA 5.25 - Curvas DMTA de tan $\delta$ dos compósitos FCA2 curado por feixe de elétrons com taxa de dose de 1,82 kGy.s ${ }^{-1}$ e doses totais de 103,6kGy, 155,0kGy e 206,4kGy.

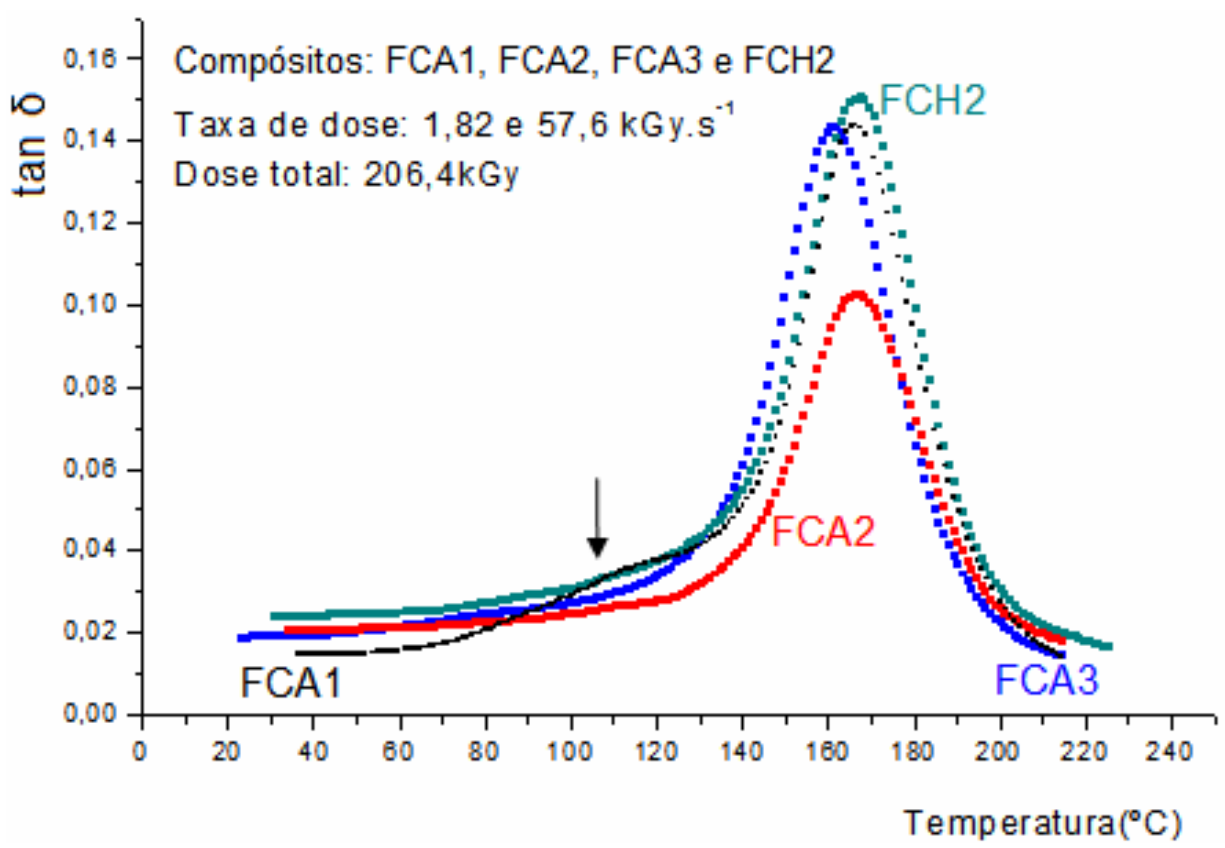

FIGURA 5.26 - Curvas DMTA de tan $\delta$ dos compósitos FCA1, FCA2, FCA3 e $\mathrm{FCH} 2$ curados por feixe elétrons com taxas de doses de $1,82 \mathrm{kGy} \cdot \mathrm{s}^{-1} \mathrm{e}$ $57,6 \mathrm{kGy} \cdot \mathrm{s}^{-1}$ e dose total de $206,4 \mathrm{kGy}$. 


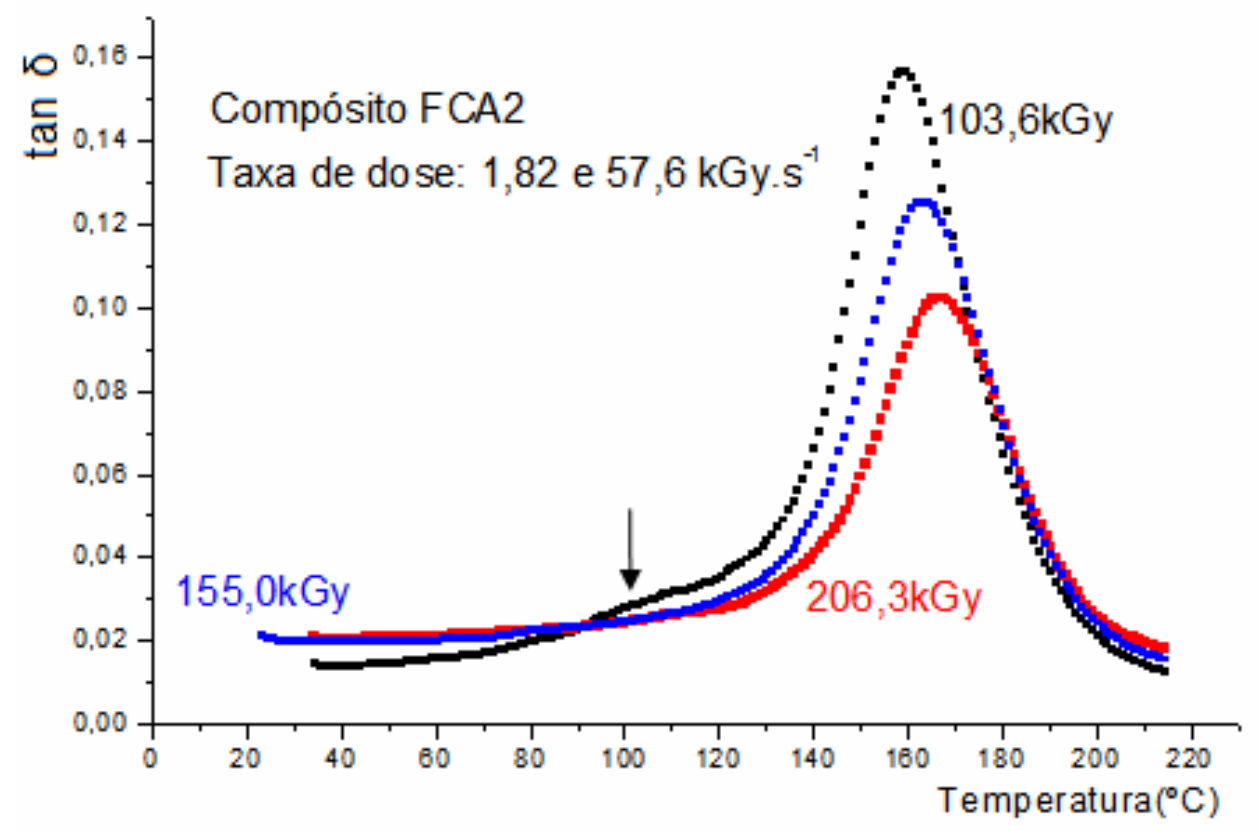

FIGURA 5.27 - Curvas DMTA de tan $\delta$ compósitos FCA2 curados por feixe de elétrons com taxas de doses de 1,82 kGy.s ${ }^{-1}$ e 57,6 kGy.s ${ }^{-1}$ e doses totais de 103,6kGy, 155,0kGy e 206,4kGy.

Os compósitos FCA2 e FCH2 curados com taxas de doses de $1,82 \mathrm{kGy} . \mathrm{s}^{-1}$ e 57,6 kGy.s ${ }^{-1}$ e dose total de 206,4kGy, ou seja, taxa de dose alta na etapa final do processo de cura, atingiram, respectivamente, o grau de cura de 96\% e 94\% pela técnica de DSC, conforme a TAB. 5.5. Pelo DMTA indicou um aumento de $10^{\circ} \mathrm{C}$ na $\mathrm{T}_{\mathrm{g}}$ determinada pelo pico de tan $\delta$, quando comparado com 0 compósito FCA2 curado com a taxa de dose de 1,82 kGy.s ${ }^{-1}$ e dose total de 206,4kGy, conforme TAB. 5.9.

O ciclo de cura dos compósitos curados com taxas de doses de $1,82 \mathrm{kGy} . \mathrm{s}^{-1}$ e $57,6 \mathrm{kGy} . \mathrm{s}^{-1}$, totalizou 40 minutos. No processo no qual foi utilizado somente a taxa de dose de $1,82 \mathrm{kGy} . \mathrm{s}^{-1}$, foram necessários 70 minutos para completar a dose total de 206,4kGy. O primeiro ciclo de cura que utilizou duas taxas de doses proporcionou um ganho de 30 minutos e teve um aumento na temperatura de transição vítrea (tan $\delta)$ do compósito.

A melhor concentração do iniciador catiônico (PC 2506) foi de $2 \%$ em massa em relação à resina. Os compósitos $\mathrm{FCA} 2$ e $\mathrm{FCH} 2$ proporcionaram uma $\mathrm{T}_{\mathrm{g}}$ (pico de tan $\delta$ ) maior que o compósito FCA3, embora este também tenha atingido um grau de cura de $96 \%$. Para cada iniciador cationico, deve-se fazer um estudo 
para definir a melhor concentração a ser utilizada (Lopata e Janke, 1999). Para as matrizes A2 também foi observado que a concentração de $2 \%$ em massa do iniciador catiônico proporcionou uma $T_{g}$ (pico de tan $\delta$ ) superior com as mesmas condições de irradiação da TAB. 5.8, embora 0 comportamento dinâmico-mecânico não tenha sido semelhante ao de uma matriz totalmente curada.

\subsubsection{Pós-cura térmica}

Pelo mesmo motivo que foi realizado a pós-cura térmica nas amostras curadas por feixe de elétrons e analisadas pela técnica de DSC, realizou-se o mesmo procedimento nas amostras das matrizes A2 e compósitos FCA2 curados por feixe de elétrons com dose total de 206,4kGy. Estas amostras foram pós-curadas termicamente por um período de 60 minutos a $180^{\circ} \mathrm{C}$ e analisadas pelo DMTA. As curvas DMTA contendo o módulo E', módulo E" e tan $\delta$ das matrizes A2 e dos compósitos FCA2 pós-curados termicamente são mostradas no APÊNDICE C e correspondem a uma das duas análises realizadas para cada amostra.

Na TAB. 5.10 são apresentadas as temperaturas de transição vítrea determinadas pelo DMTA das matrizes e compósitos pós-curados com as curvas correspondentes nas FIG. 5.28 e 5.29 para as matrizes e FIG. 5.30 e 5.31 para os compósitos. A matriz A2 curada com taxa de dose de 1,82 kGy.s ${ }^{-1}$, dose total de 206,4kGy e pós-curada não alterou o comportamento dinâmico-mecânico de modo significativo, como ocorreu com a matriz A2 curada com taxas de doses de 1,82 kGy.s ${ }^{-1}$ e 57,6 kGy.s $\mathrm{s}^{-1}$ e dose total de 206,4kGy. Esta última não apresentou pico secundário na curva de tan $\delta$ após a pós-cura (FIG. 5.29), indicando uma cura completa e similar com a curva de tan $\delta$ e mostrada no trabalho de Cole et al. (2002).

Os compósitos FCA2 curados com taxa de dose de 1,82 kGy.s ${ }^{-1}$ e dose total de 206,4kGy e com taxas de doses de 1,82 kGy.s ${ }^{-1}$ e 57,6 kGy.s ${ }^{-1}$ e dose total de 206,4kGy, ambos pós-curados termicamente, não tiveram o comportamento dinâmico-mecânico muito alterado (FIG. 5.30 e 5.31), em razão do alto grau de cura antes da pós-cura térmica, respectivamente, 95\% e 96\%. As temperaturas de transição vítrea pela curva de tan $\delta$ de ambas as amostras tiveram um aumento de apenas $5^{\circ} \mathrm{C}$. 
Segundo Lopata e Janke (1999), as propriedades reológicas finais da matriz com grau de cura alto não são afetadas com uma pós-cura térmica. $A$ mesma conclusão é atribuída a Menard (1999), porém com a condição de que algumas matrizes epoxídicas com grau de cura a partir de $94 \%$, não tenham a $\mathrm{T}_{\mathrm{g}}$ e o módulo E' aumentados de modo significativo com uma pós-cura térmica.

Tomando-se por base estes resultados obtidos, o compósito FCA2 curado com taxa de dose de $1,82 \mathrm{kGy} \cdot \mathrm{s}^{-1}$ e dose total de 206,4kGy e os compósitos FCA2, FCA3 e FCH2 curados com taxas de doses de 1,82 kGy.s ${ }^{-1}$ e 57,6 kGy.s ${ }^{-1}$ e dose total de 206,4kGy podem ser utilizados sem serem submetidos ao processo de pós-cura térmica.

TABELA 5.10 - Temperaturas de transição vítrea das matrizes e compósitos curados por feixe de elétrons e pós-curados termicamente.

Pós-cura térmica de

Amostra Condição de cura $\quad 180^{\circ} \mathrm{C}$ por 1 hora

Taxa de dose (kGy.s $\left.{ }^{-1}\right) \quad$ Dose total (kGy) $\quad \mathrm{T}_{\mathrm{g}}\left({ }^{\circ} \mathrm{C}\right), \mathrm{E}^{\prime \prime} \quad \mathrm{T}_{\mathrm{g}}\left({ }^{\circ} \mathrm{C}\right)$, $\tan \delta$

\begin{tabular}{ccccc}
\hline A2 & 1,82 & 206,4 & $150 \pm 3$ & $162 \pm 3$ \\
A2 & 1,82 e 57,6 & 206,4 & $152 \pm 3$ & $168 \pm 3$ \\
FCA2 & 1,82 & 206,4 & $158 \pm 3$ & $163 \pm 3$ \\
FCA2 & 1,82 e 57,6 & 206,4 & $168 \pm 3$ & $172 \pm 3$ \\
\hline
\end{tabular}




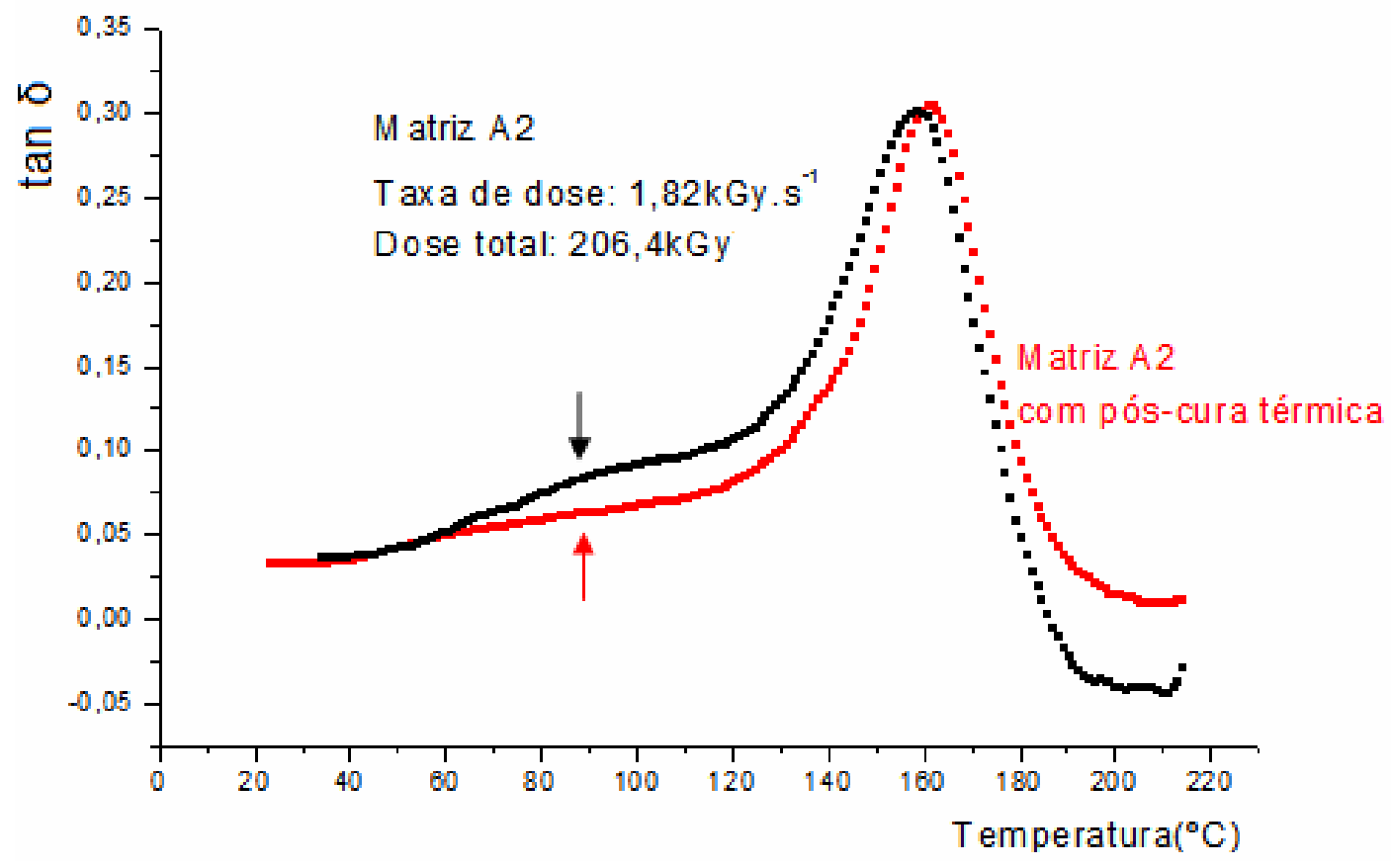

FIGURA 5.28 - Curvas DMTA de tan $\delta$ da matriz A2 curada por feixe de elétrons com taxa de dose de 1,82 kGy.s. ${ }^{-1}$, dose total de 206,4kGy e da amostra pós-curada termicamente.

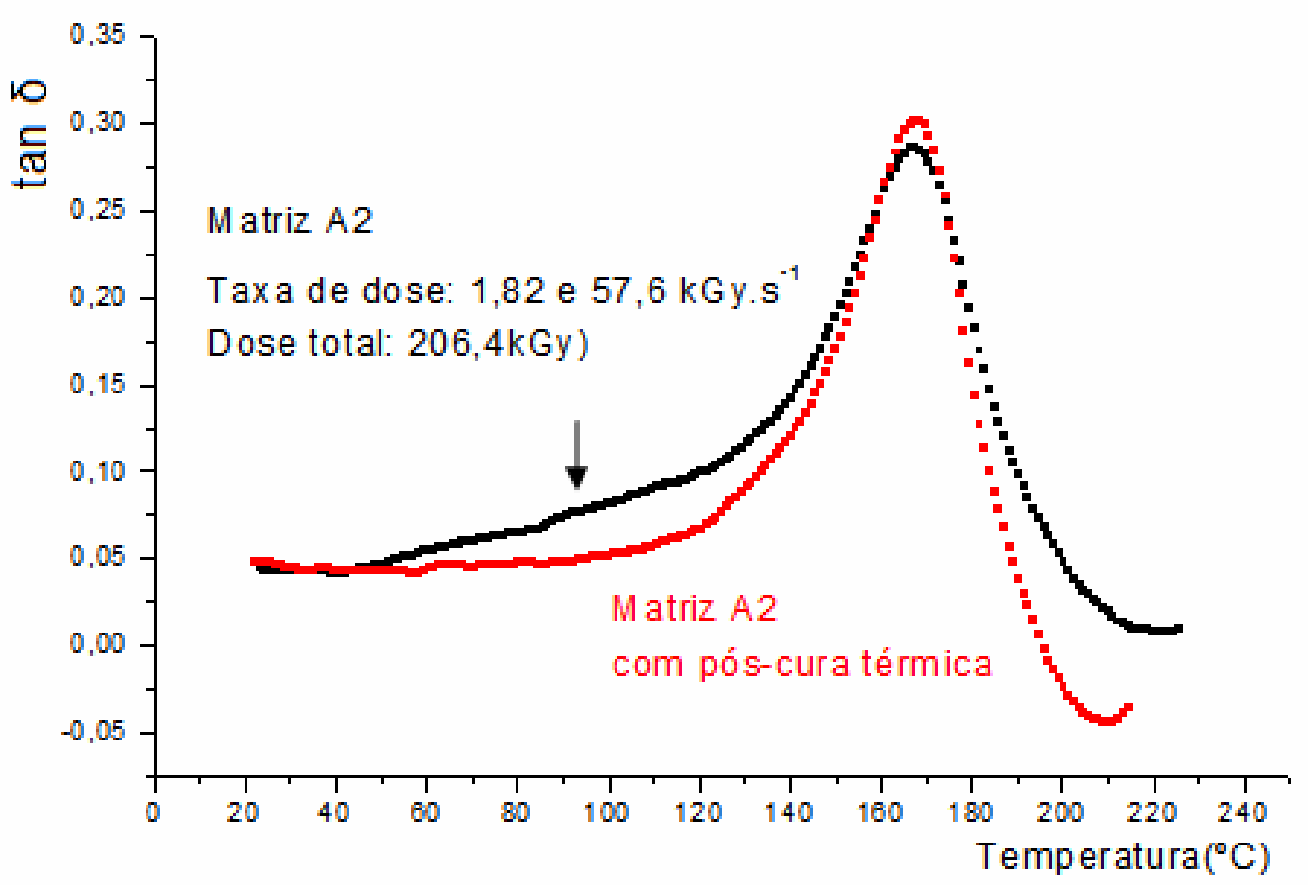

FIGURA 5.29 - Curvas DMTA de tan $\delta$ da matriz A2 curada por feixe de elétrons com taxas de doses de 1,82 kGy.s ${ }^{-1}$ e 57,6 kGy.s ${ }^{-1}$, dose total de 206,4kGy e da amostra pós-curada termicamente. 


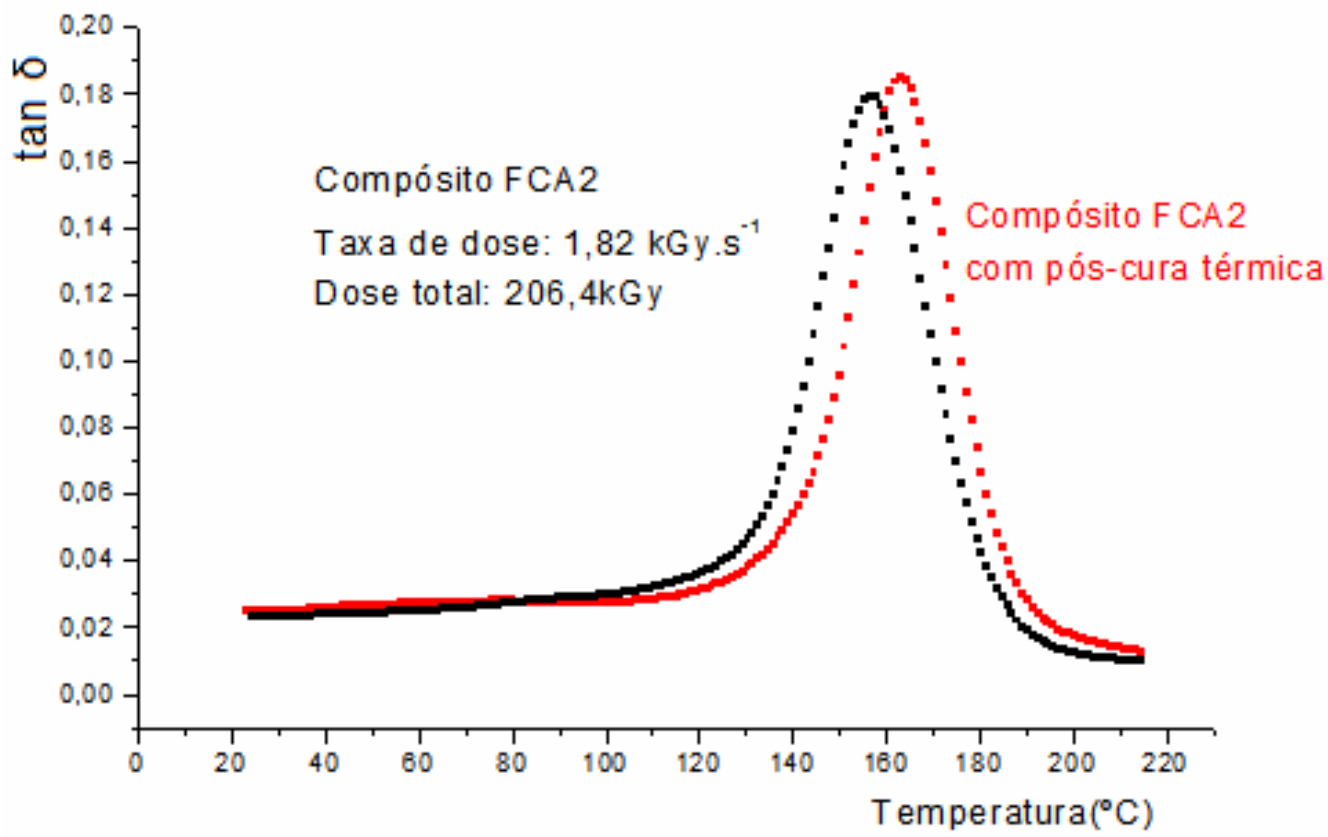

FIGURA 5.30 - Curvas DMTA de tan $\delta$ do compósito FCA2 curado por feixe de elétrons com taxa de dose de 1,82 kGy.s ${ }^{-1}$, dose total de 206,4kGy e da amostra pós-curada termicamente.

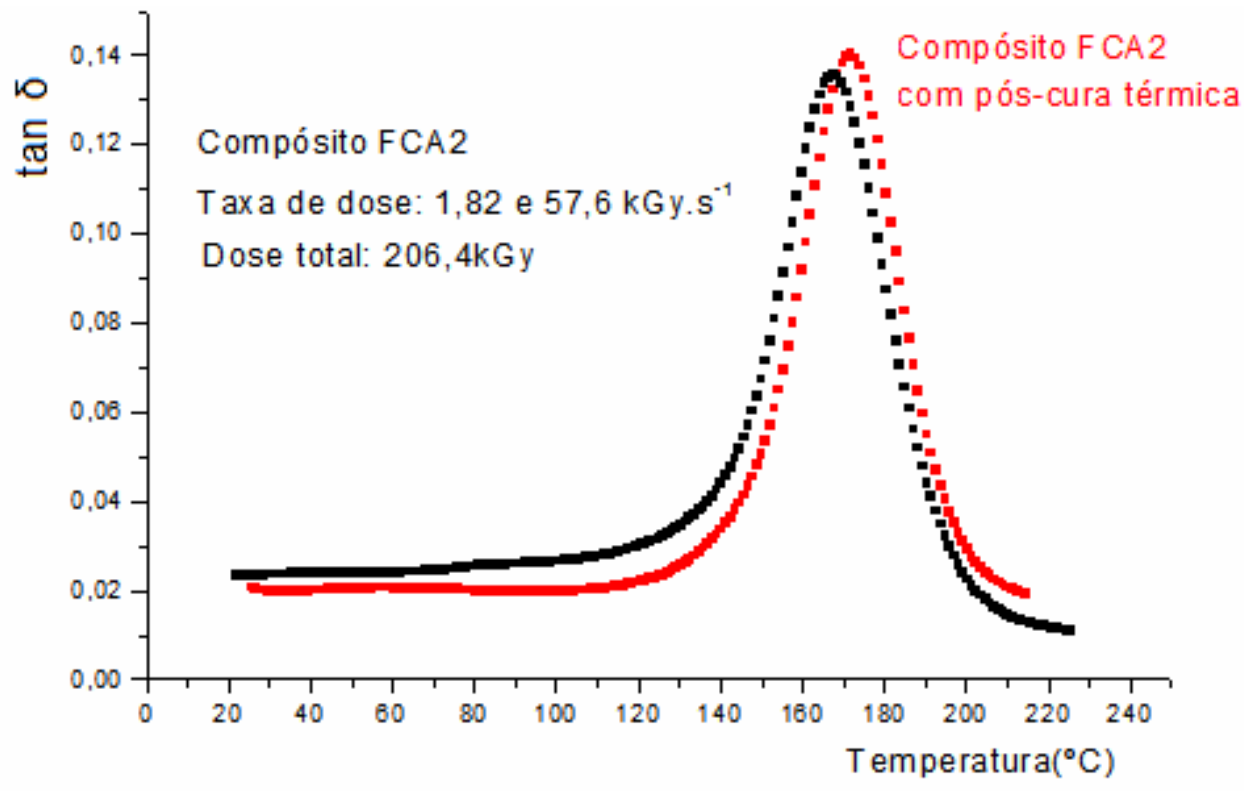

FIGURA 5.31 - Curvas DMTA de tan $\delta$ do compósito FCA2 curado por feixe de elétrons com taxas de doses de 1,82 kGy.s ${ }^{-1}$ e 57,6 kGy.s ${ }^{-1}$, dose total de 206,4kGy e da amostra pós-curada termicamente. 


\subsubsection{Termogravimetria (TG)}

A técnica de cura por feixe de elétrons proporcionou redução do tempo de cura de matrizes epoxídicas e aumentou a temperatura de transição vítrea em relação à curada pelo processo térmico. Na FIG. 5.32 foi possível identificar o resultado da maior densidade de ligações cruzadas obtidas pelo processo de cura por feixe de elétrons, uma vez que a temperatura de início da perda de massa de $360^{\circ} \mathrm{C}$ foi bem superior à temperatura de $280^{\circ} \mathrm{C}$ obtida pela matriz de cura térmica. Isto ocorre em razão da ausência de um endurecedor ou agente de cura na formulação da matriz que cura por feixe de elétrons, pois estas moléculas reagem com o oligômero epoxídico, flexibilizando o material.

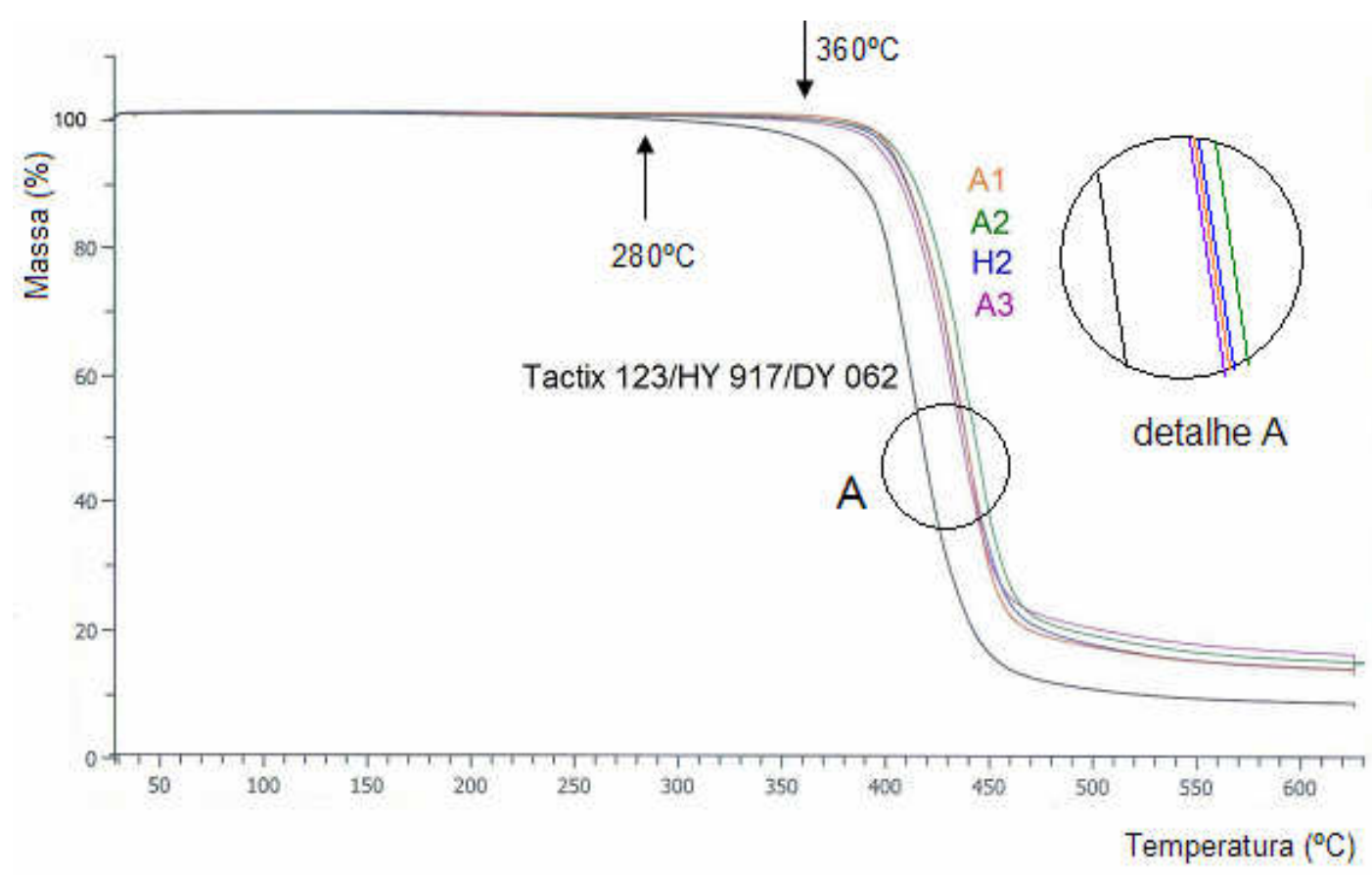

FIGURA 5.32 - Curvas TG das matrizes A1, A2, A3 e H2 curadas por feixe de elétrons e da matriz Tactix123/HY915/DY062 curada pelo processo térmico.

Nas TAB. 5.11 e TAB. 5.12 são apresentadas, respectivamente, as porcentagens em massa de resíduos das matrizes curadas pelo processo térmico e por feixe de elétrons. Nas matrizes curadas por feixe de elétrons a quantidade de resíduo após a queima é aproximadamente $80 \%$ maior que a matriz curada pelo processo térmico, confirmando a maior densidade de ligações cruzadas existentes no primeiro processo. 
TABELA 5.11 - Resíduo da matriz curada pelo processo térmico.

\begin{tabular}{cc}
\hline Matriz & Resíduo (\%) \\
\hline TACTIX 123/HY 917/DY 062 & $8 \pm 1$ \\
\hline
\end{tabular}

TABELA 5.12 - Resíduos das matrizes curadas por feixe de elétrons.

\begin{tabular}{cccc}
\hline \multicolumn{4}{c}{ Condição de cura } \\
Matriz & Taxa de dose $\left(\mathrm{kGy} \cdot \mathrm{s}^{-1}\right)$ & Dose total (kGy) & Resíduo (\%) \\
\hline A1 & 1,82 e 57,6 & 206,4 & $14 \pm 1$ \\
A2 & 1,82 & 103,6 & $14 \pm 1$ \\
A2 & 1,82 & 155,0 & $14 \pm 1$ \\
A2 & 1,82 & 206,4 & $14 \pm 1$ \\
A2 & 1,82 e 57,6 & 103,6 & $14 \pm 1$ \\
A2 & 1,82 e 57,6 & 155,0 & $14 \pm 1$ \\
A2 & 1,82 e 57,6 & 206,4 & $15 \pm 1$ \\
A3 & 1,82 e 57,6 & 206,4 & $15 \pm 1$ \\
H2 & 1,82 e 57,6 & 206,4 & $13 \pm 1$ \\
\hline
\end{tabular}

Nas TAB. 5.13 e TAB. 5.14 são apresentadas as frações mássicas em porcentagem de fibra de carbono e da matriz dos compósitos estudados e que foram calculadas por meio da equação 4.3. Esta equação fez o desconto do resíduo da matriz no compósito após a queima. A porcentagem baixa de massa de reforço nos compósitos curados por feixe de elétrons não interferiu no objetivo deste trabalho, que foi desenvolver as matrizes poliméricas e estudar os parâmetros de irradiação adequados à cura de compósitos. Convém destacar que este estudo não teve como objetivo obter propriedades mecânicas elevadas dos compósitos.

TABELA 5.13 - Frações mássicas de fibra de carbono e de matriz do compósito curado pelo processo térmico.

\begin{tabular}{ccc}
\hline Amostra & $\begin{array}{c}\text { Fração mássica de fibra de } \\
\text { carbono }(\%)\end{array}$ & $\begin{array}{c}\text { Fração mássica de } \\
\text { matriz (\%) }\end{array}$ \\
\hline Compósito & $74 \pm 1$ & $26 \pm 1$ \\
\hline
\end{tabular}


TABELA 5.14 - Frações mássicas de fibra de carbono e de matriz dos compósitos curados por feixe de elétrons.

\begin{tabular}{ccccc}
\hline Compósito & \multicolumn{2}{c}{ Condição de cura } & $\begin{array}{c}\text { Fração } \\
\text { mássica de } \\
\text { fibra de } \\
\left(\mathrm{kGy} \cdot \mathrm{s}^{-1}\right)\end{array}$ & $\begin{array}{c}\text { Fração } \\
\text { mássica de } \\
\text { matriz }\end{array}$ \\
\hline FCA1 & 1,82 e 57,6 & 206,4 & $47 \pm 1$ & $\begin{array}{c}\text { (kG) } \\
\text { carbono }(\%)\end{array}$ \\
FCA2 & 1,82 & 103,6 & $58 \pm 1$ & $42 \pm 1$ \\
FCA2 & 1,82 & 155,0 & $58 \pm 1$ & $42 \pm 1$ \\
FCA2 & 1,82 & 206,4 & $57 \pm 1$ & $43 \pm 1$ \\
FCA2 & 1,82 e 57,6 & 103,6 & $55 \pm 1$ & $45 \pm 1$ \\
FCA2 & 1,82 e 57,6 & 155,0 & $57 \pm 1$ & $43 \pm 1$ \\
FCA2 & 1,82 e 57,6 & 206,4 & $55 \pm 1$ & $45 \pm 1$ \\
FCA3 & 1,82 e 57,6 & 206,4 & $45 \pm 1$ & $55 \pm 1$ \\
FCH2 & 1,82 e 57,6 & 206,4 & $51 \pm 1$ & $49 \pm 1$ \\
\hline
\end{tabular}

\subsection{Determinação das frações volumétricas}

Nas TAB. 5.15 e TAB. 5.16 são apresentadas, respectivamente, as densidades das matrizes curadas pelo processo térmico e por feixe de elétrons. As densidades dos compósitos $\left(d_{c}\right)$ e as respectivas frações volumétricas da fibra de carbono $\left(\mathrm{v}_{\mathrm{f}}\right)$, frações volumétricas das matrizes $\left(\mathrm{v}_{\mathrm{m}}\right)$ e frações volumétricas de vazios $\left(v_{v}\right)$ curados pelo processo térmico e por feixe de elétrons são apresentados, respectivamente, nas TAB. 5.17 e TAB. 5.18.

As densidades das matrizes e compósitos foram determinadas segundo a norma ASTM D 792-98 por intermédio da equação 4.4. Por meio da termogravimetria foram determinadas as massas de fibra de carbono e matrizes contidas nos compósitos, conforme as TAB. 5.13 e TAB. 5.14. Os cálculos das frações volumétricas da fibra de carbono, das matrizes e de vazios foram determinados respectivamente por intermédio das equações 4.5, 4.6 e 4.7 .

TABELA 5.15 - Densidade da matriz curada pelo processo térmico.

$$
\text { Amostra Densidade, } \mathrm{d}_{\mathrm{m}}\left(\mathrm{g} \cdot \mathrm{cm}^{-3}\right)
$$


TABELA 5.16 - Densidades das matrizes curadas por feixe de elétrons.

\section{Condição de cura}

Amostra

\begin{tabular}{cccc} 
& Taxa de dose $\left(\mathrm{kGy} \cdot \mathrm{s}^{-1}\right)$ & Dose total $(\mathrm{kGy})$ & $\mathrm{d}_{\mathrm{m}}\left(\mathrm{g} \cdot \mathrm{cm}^{-3}\right)$ \\
\hline A1 & 1,82 e 57,6 & 206,4 & $1,21 \pm 0,02$ \\
A2 & 1,82 & 103,6 & $1,21 \pm 0,02$ \\
A2 & 1,82 & 155,0 & $1,21 \pm 0,02$ \\
A2 & 1,82 & 206,4 & $1,21 \pm 0,02$ \\
A2 & 1,82 e 57,6 & 103,6 & $1,21 \pm 0,02$ \\
A2 & 1,82 e 57,6 & 155,0 & $1,21 \pm 0,02$ \\
A2 & 1,82 e 57,6 & 206,4 & $1,21 \pm 0,02$ \\
A3 & 1,82 e 57,6 & 206,4 & $1,21 \pm 0,02$ \\
H2 & 1,82 e 57,6 & 206,4 & $1,21 \pm 0,02$ \\
\hline
\end{tabular}

TABELA 5.17 - Densidade, fração volumétrica de fibra de carbono, fração volumétrica da matriz e fração volumétrica de vazio do compósito curado pelo processo térmico.

\begin{tabular}{ccccc}
\hline Amostra & $\begin{array}{c}\text { Densidade, } \\
\mathrm{d}_{\mathrm{c}}\left({\left.\mathrm{g} \cdot \mathrm{cm}^{-3}\right)}\right.\end{array}$ & $\begin{array}{c}\text { Fração } \\
\text { volumétrica de } \\
\text { fibra de carbono, } \\
\mathrm{v}_{\mathrm{f}}(\%)\end{array}$ & $\begin{array}{c}\text { Fração } \\
\text { volumétrica de } \\
\text { matriz, } \mathrm{v}_{\mathrm{m}}(\%)\end{array}$ & $\begin{array}{c}\text { Fração } \\
\text { volumétrica de } \\
\text { vazio, } \mathrm{v}_{\mathrm{v}}(\%)\end{array}$ \\
\hline Compósito & $1,58 \pm 0,02$ & 65,7 & 33,7 & 0,6
\end{tabular}


TABELA 5.18 - Densidades, frações volumétricas de fibras de carbono, frações volumétricas das matrizes e frações volumétricas de vazios dos compósitos curados por feixe de elétrons.

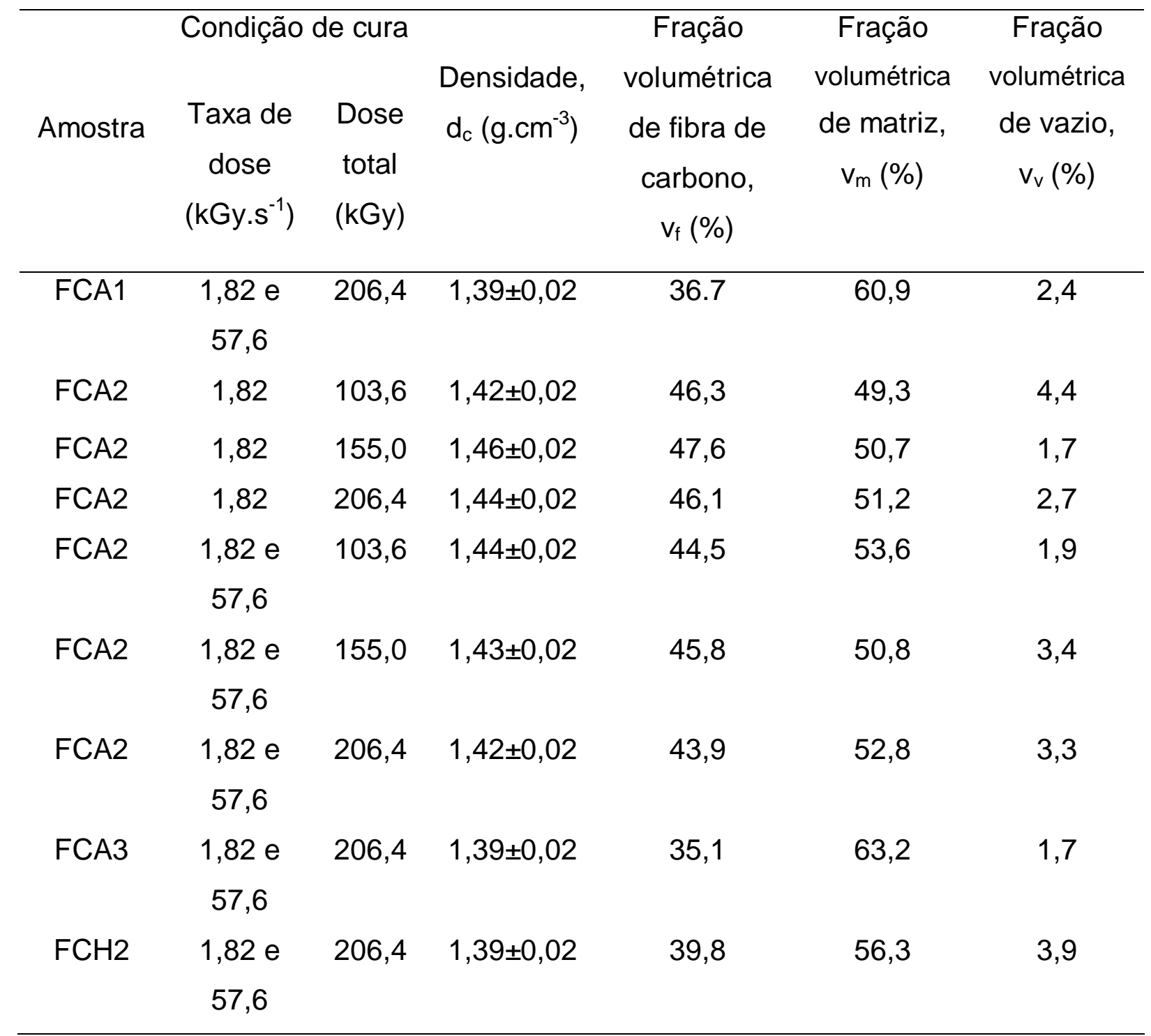

A viscosidade alta das formulações das matrizes de cura por feixe de elétrons e a temperatura baixa no banho de impregnação das matrizes $\left(70^{\circ} \mathrm{C}\right)$ durante o processo do enrolamento filamentar, contribuíram para elevar as frações volumétricas das matrizes e de vazios.

\subsection{Ensaio de tração}

A matriz polimérica deve ser dúctil e garantir uma adequada ligação entre a fibra e a matriz para que as tensões oriundas do carregamento mecânico sejam transferidas para os elementos de reforço. A ductilidade da matriz evita a 
propagação de trincas no compósito, caso contrário esta condição pode acarretar em uma falha catastrófica.

As propriedades mecânicas em tração das matrizes curadas pelo processo térmico e por feixe de elétrons são apresentadas respectivamente nas TAB. 5.19 e TAB. 5.20. O menor limite de resistência à tração obtido na matriz curada por feixe de elétrons foi em virtude da maior densidade de ligações cruzadas e que está de acordo com o relato de Saunders et al. (1997). Este fenômeno pode exigir a adição de modificadores ou agentes tenacificadores, como termoplásticos de engenharia ou elastômeros (Bucnall e Partiridge, 1986 e Riew e Gillham, 1984).

TABELA 5.19 - Propriedades mecânicas da matriz curada pelo processo térmico.

\begin{tabular}{cccc}
\hline Amostra & $\begin{array}{c}\text { Limite de resistência à } \\
\text { tração }(\mathrm{MPa})\end{array}$ & $\begin{array}{c}\text { Módulo de } \\
\text { elasticidade } \\
(\mathrm{MPa})\end{array}$ & $\begin{array}{c}\text { Alongamento à } \\
\text { ruptura (\%) }\end{array}$ \\
\hline Matriz & 78 & 2910 & 3,3 \\
\hline Desvio padrão & 7 & 139 & 0,7 \\
\hline
\end{tabular}

TABELA 5.20 - Propriedades mecânicas da matriz A2 curada por feixe de elétrons.

\begin{tabular}{cccc}
\hline Amostra & $\begin{array}{c}\text { Limite de } \\
\text { resistência à tração } \\
(\mathrm{MPa})\end{array}$ & $\begin{array}{c}\text { Módulo de } \\
\text { elasticidade } \\
(\mathrm{MPa})\end{array}$ & $\begin{array}{c}\text { Alongamento à } \\
\text { ruptura }(\%)\end{array}$ \\
\hline $\mathrm{A} 2$ & 51 & 2807 & 1,5 \\
\hline Desvio padrão & 6 & 62 & 0,2 \\
\hline
\end{tabular}




\section{CONCLUSÕES}

O processo de cura por feixe de elétrons proporcionou a redução de tempo do ciclo de cura da matriz de cura térmica de 16 horas para apenas 40 minutos.

As matrizes epoxídicas com $2 \%$ do iniciador catiônico, utilizadas neste trabalho, quando combinadas com reforços de fibras de carbono e curadas com taxa de dose baixa, na etapa inicial do processo, seguida de uma taxa alta até completar a dose total aproximada de 200kGy, proporcionaram uma temperatura de transição vítrea ( $\tan \delta$ ), aproximadamente, $20 \%$ superior à obtida pelo sistema de cura térmica de uma mesma resina. Nos compósitos FCH2 e FCA2 curados com estas condições de irradiação atingiu-se, respectivamente, o grau de cura de $94 \%$ e $96 \%$. Pelos resultados obtidos por meio da técnica de DMTA concluiu-se que estes compósitos podem ser utilizados sem a necessidade de submetê-los ao processo de pós-cura térmica. Esta técnica permitiu determinar as temperaturas de transição vítrea e avaliar os comportamentos dinâmico-mecânicos dos materiais irradiados sem a pós-cura térmica.

As propriedades mecânicas das matrizes curadas por feixe de elétrons ocasionaram uma redução no limite de resistência à tração e no alongamento na ruptura. Em razão da maior densidade de ligações cruzadas que este processo de cura proporciona, pode ser necessária a adição de agentes tenacificadores como elastômeros, termoplásticos de engenharia ou nanopartículas.

A cura por feixe de elétrons foi realizada a temperatura ambiente que favorece a possibilidade da redução de custos associadas aos moldes, haja vista que os mesmos podem ser feitos de materiais mais baratos que o aço-inoxidável e o alumínio.

As matrizes poliméricas curadas por feixe de elétrons oferecem um tempo de armazenamento (shelf life) de até dois anos e um tempo de fabricação (pot life) longo, desde que sejam protegidas da irradiação ultravioleta. Isto evita toda a logística necessária para controle e armazenamento das matrizes de cura térmica, sobretudo quando são utilizados materiais pré-impregnados (prepreg). 


\section{TRABALHOS FUTUROS}

i. Desenvolver matrizes epoxídicas para cura por feixe de elétrons com outros tipos de resinas;

ii. Desenvolver matrizes epoxídicas modificadas com tenacificadores para cura por feixe de elétrons;

iii. Estudar a interface entre a matriz e os elementos de reforços dos compósitos curados por feixe de elétrons. 


\section{APÊNDICE A - CURVAS DMTA DAS MATRIZES CURADAS POR FEIXE DE ELÉTRONS}

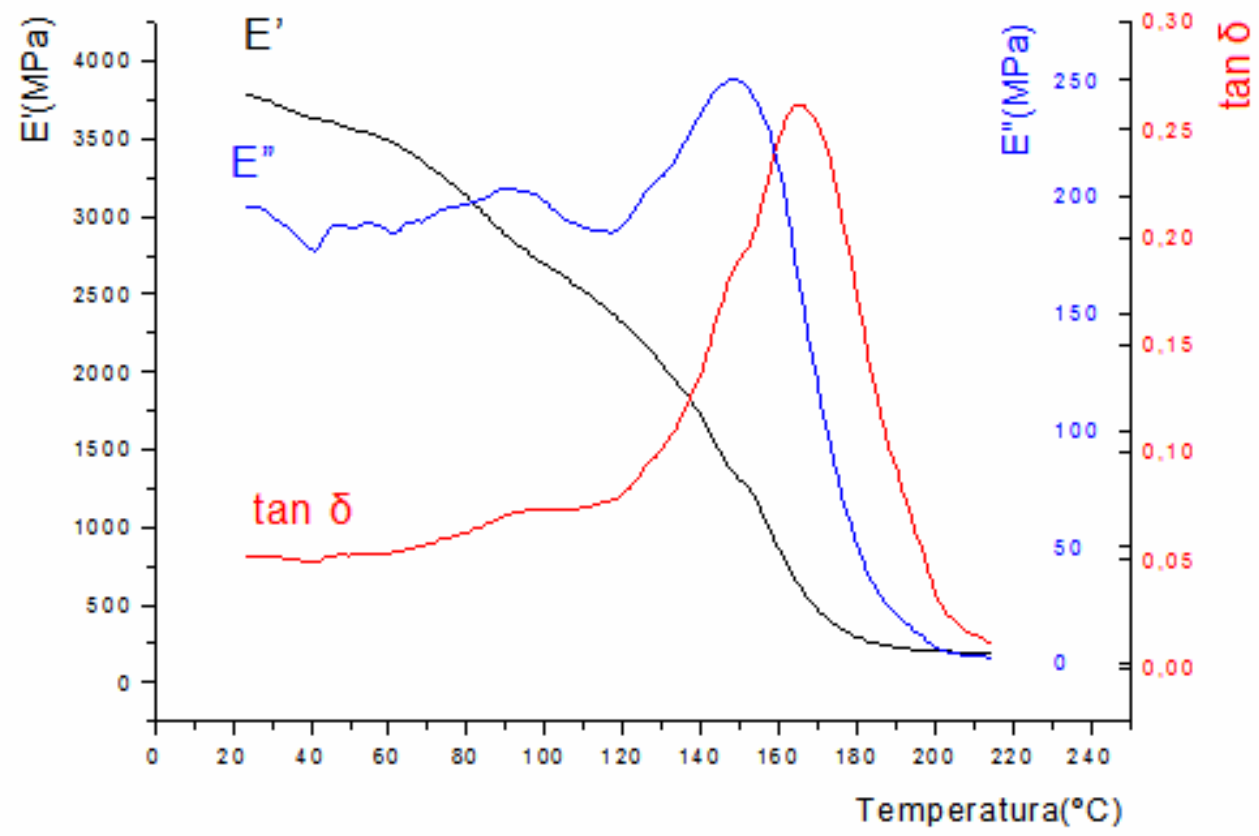

FIGURA A.1 - Curvas DMTA da matriz A1 curada por feixe elétrons com taxas de doses de $1,82 \mathrm{kGy} \cdot \mathrm{s}^{-1}$ e 57,6 kGy.s ${ }^{-1}$ e dose total de 206,4kGy.

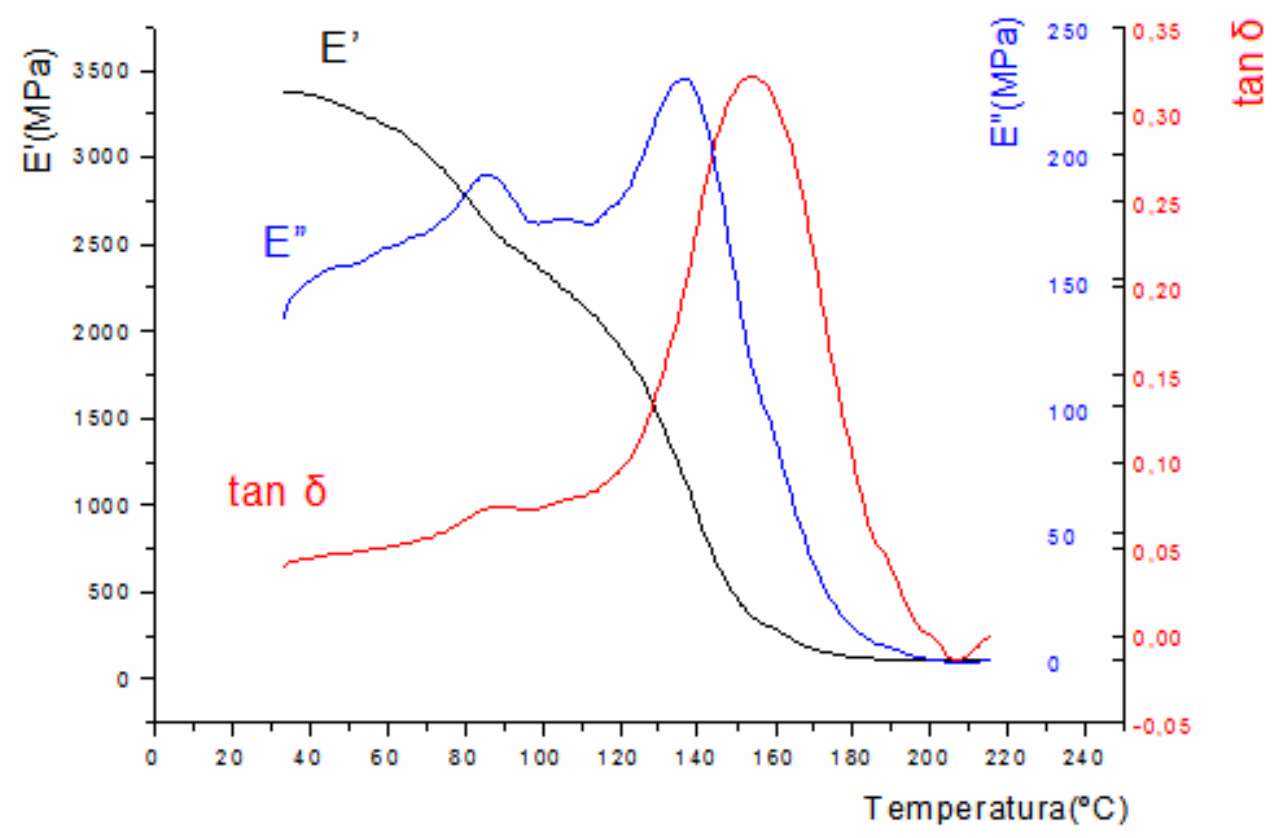

FIGURA A.2 - Curvas DMTA da matriz A2 curada por feixe de elétrons com taxa de dose de $1,82 \mathrm{kGy} . \mathrm{s}^{-1}$ e dose total de 103,6 kGy. 


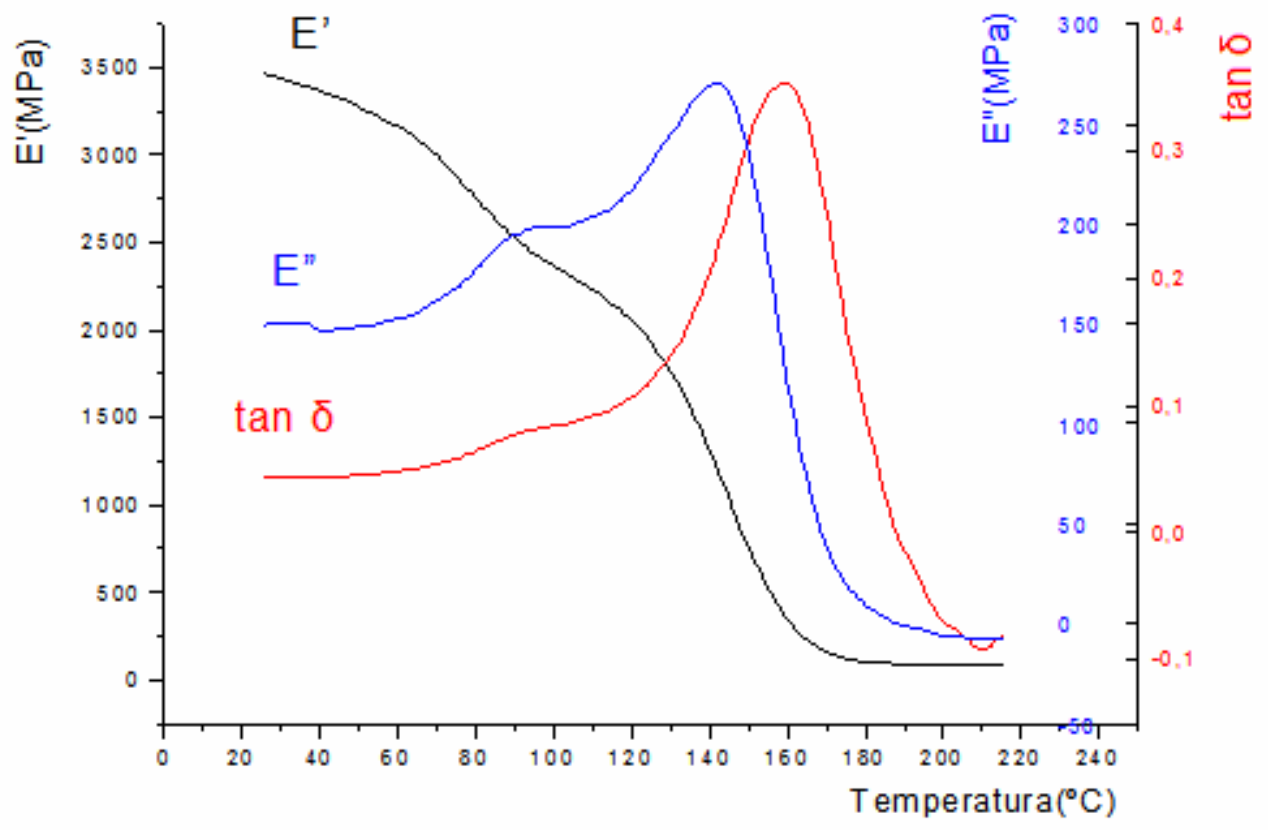

FIGURA A.3 - Curvas DMTA da matriz A2 curada por feixe de elétrons com taxa de dose de 1,82 kGy.s ${ }^{-1}$ e dose total de 155,0kGy.

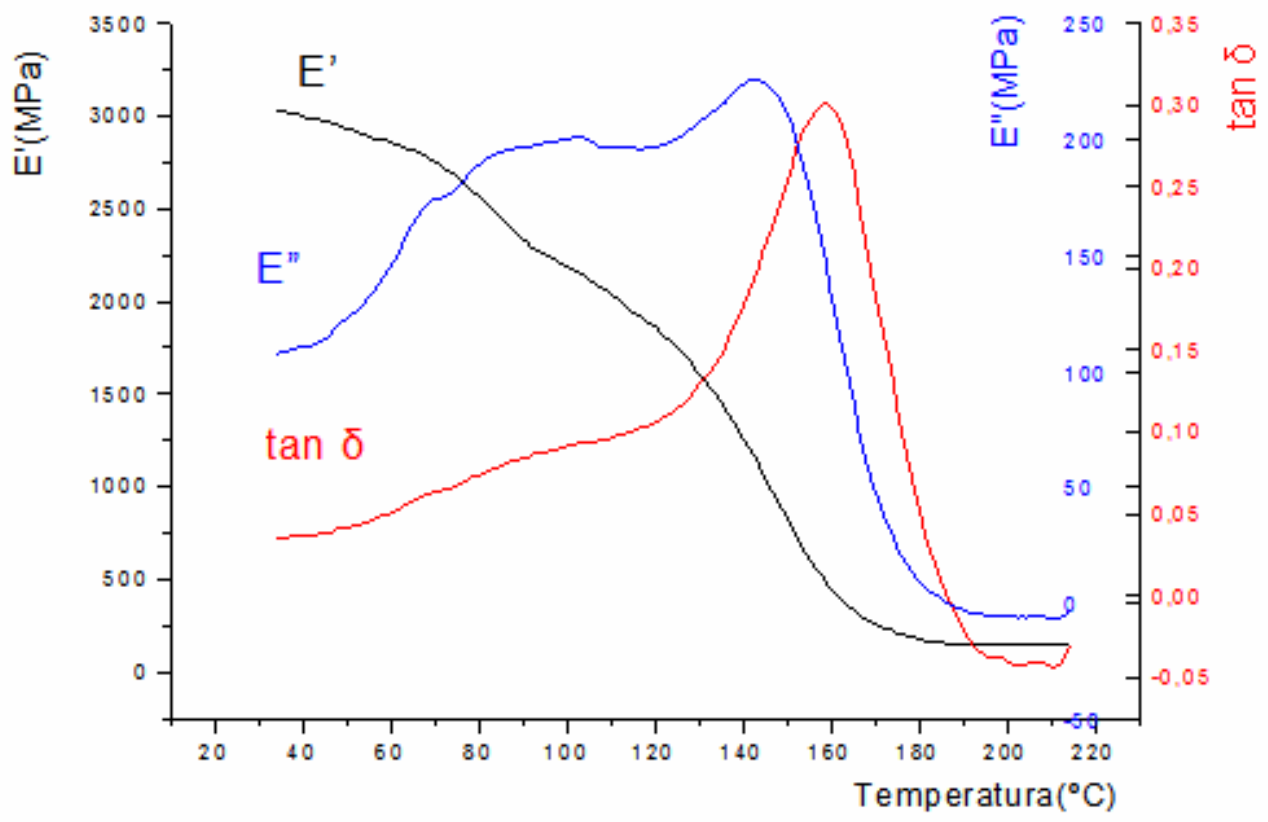

FIGURA A.4 - Curvas DMTA da matriz A2 curada por feixe de elétrons com taxa de dose de $1,82 \mathrm{kGy} \cdot \mathrm{s}^{-1}$ e dose total de $206,4 \mathrm{kGy}$. 


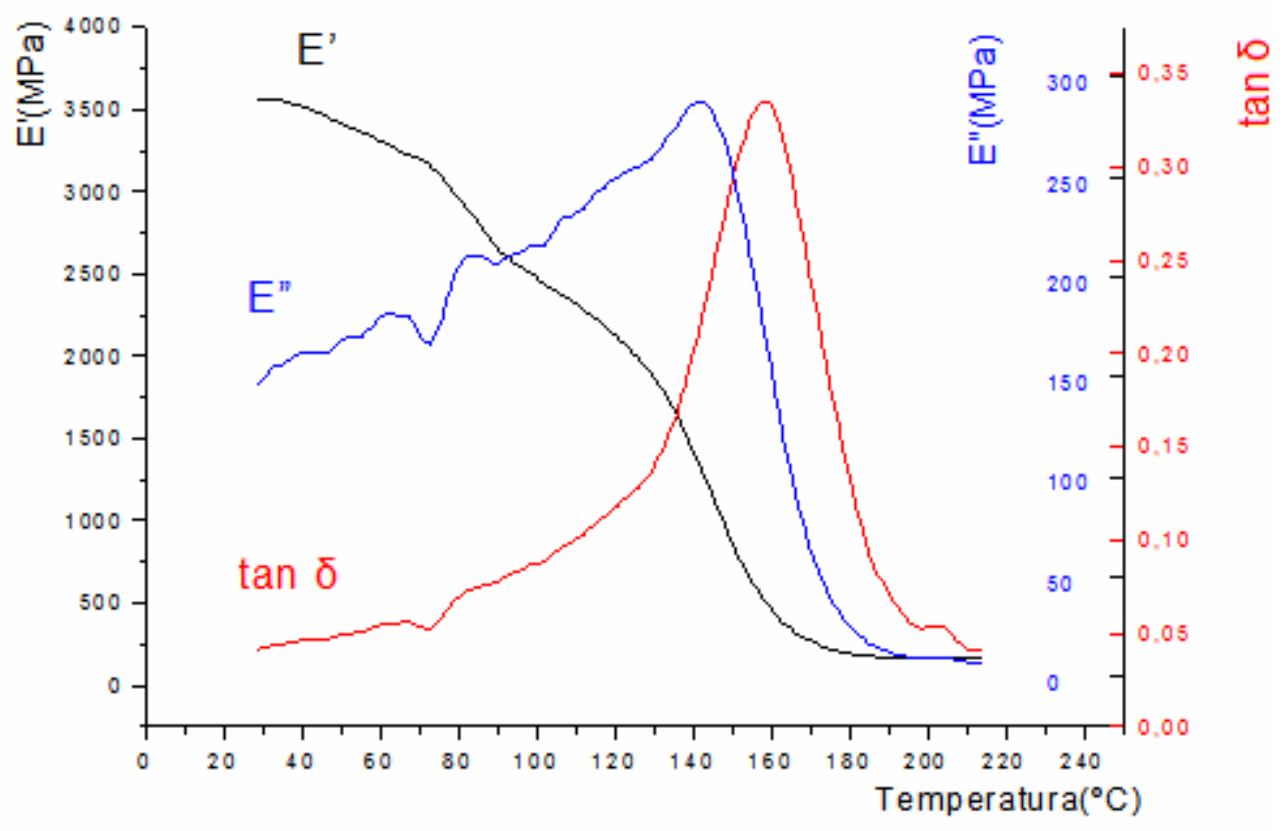

FIGURA A.5 - Curvas DMTA da matriz A2 curada por feixe de elétrons com taxas de doses de 1,82 kGy.s ${ }^{-1}$ e 57,6 kGy.s ${ }^{-1}$ e dose total de 103,6kGy.

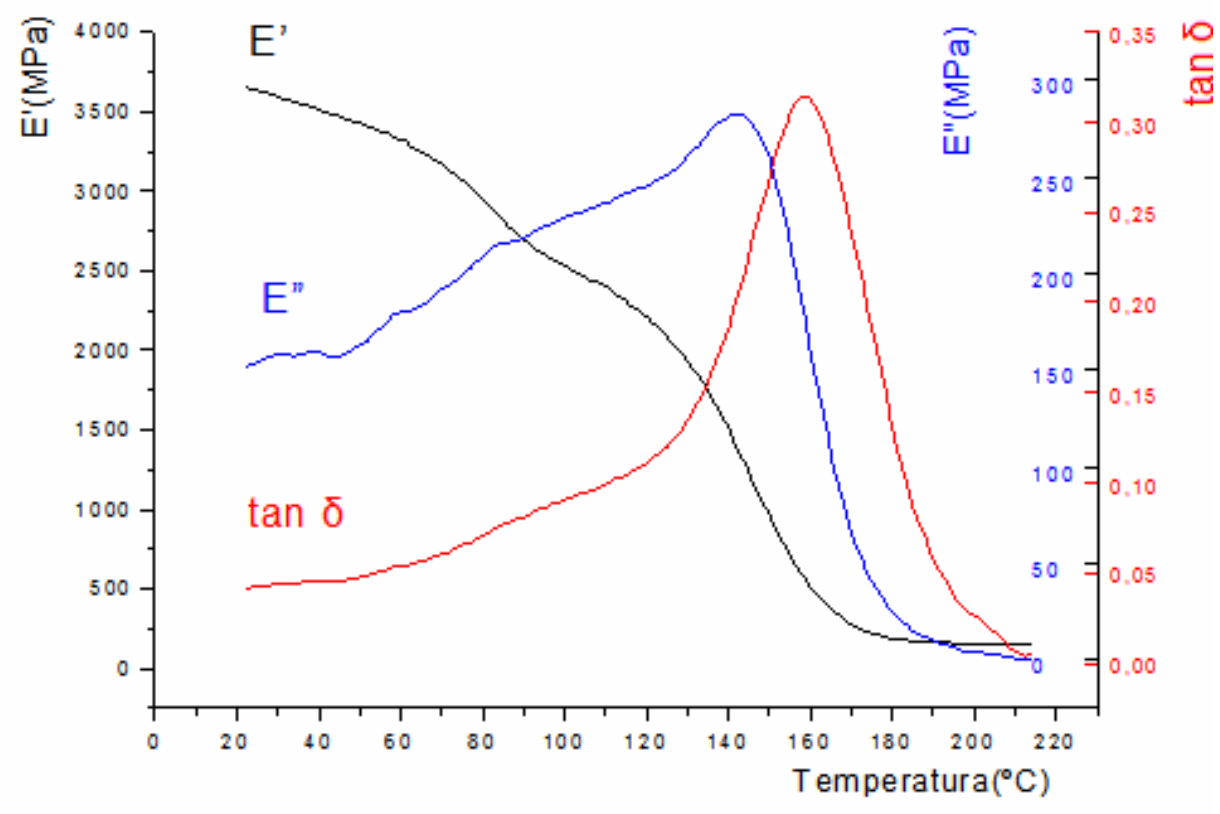

FIGURA A.6 - Curvas DMTA da matriz A2 curada por feixe de elétrons com taxas de doses de 1,82 kGy.s $\mathrm{s}^{-1}$ e 57,6 kGy.s ${ }^{-1}$ e dose total de 155,0kGy. 


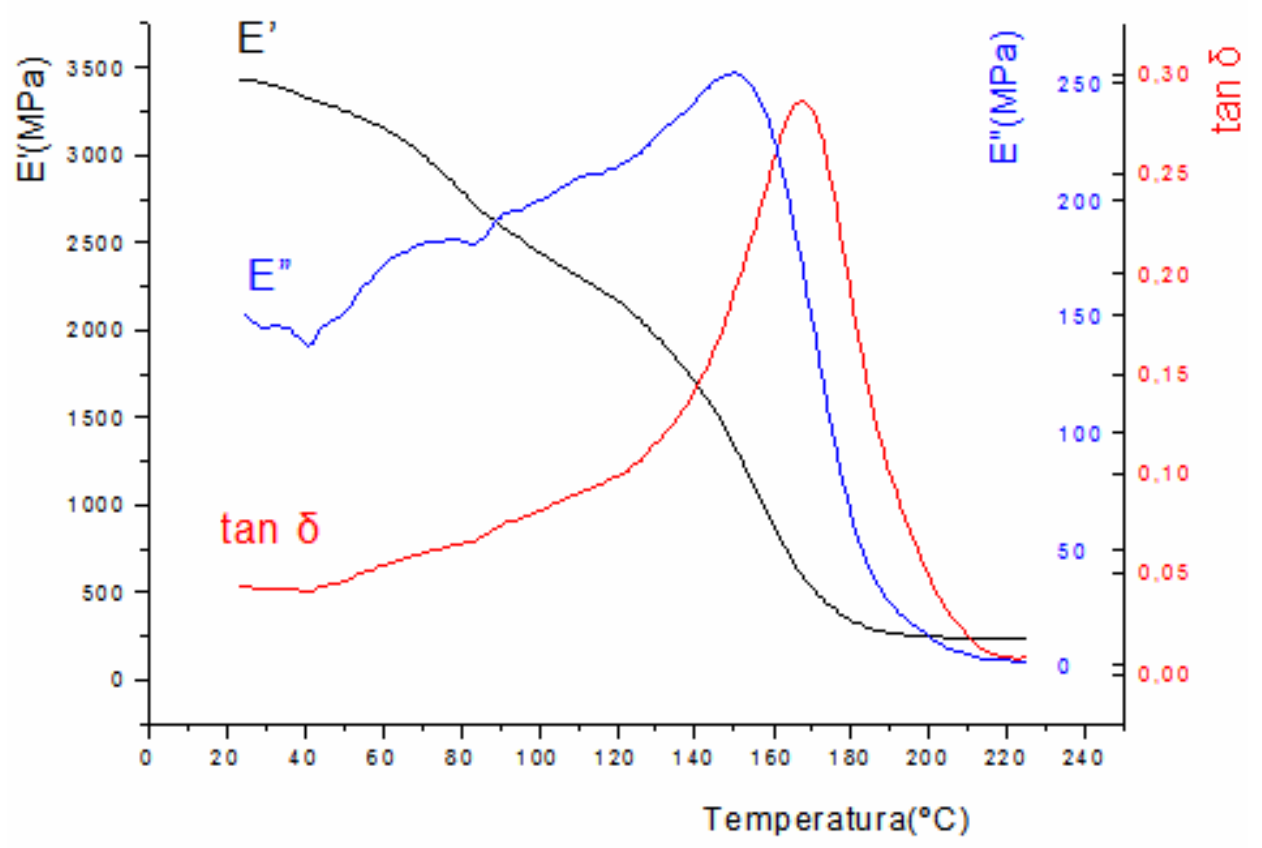

FIGURA A.7- Curvas DMTA da matriz A2 curada por feixe de elétrons com taxas de doses de $1,82 \mathrm{kGy} \cdot \mathrm{s}^{-1}$ e 57,6 kGy.s ${ }^{-1}$ e dose total de 206,4kGy.

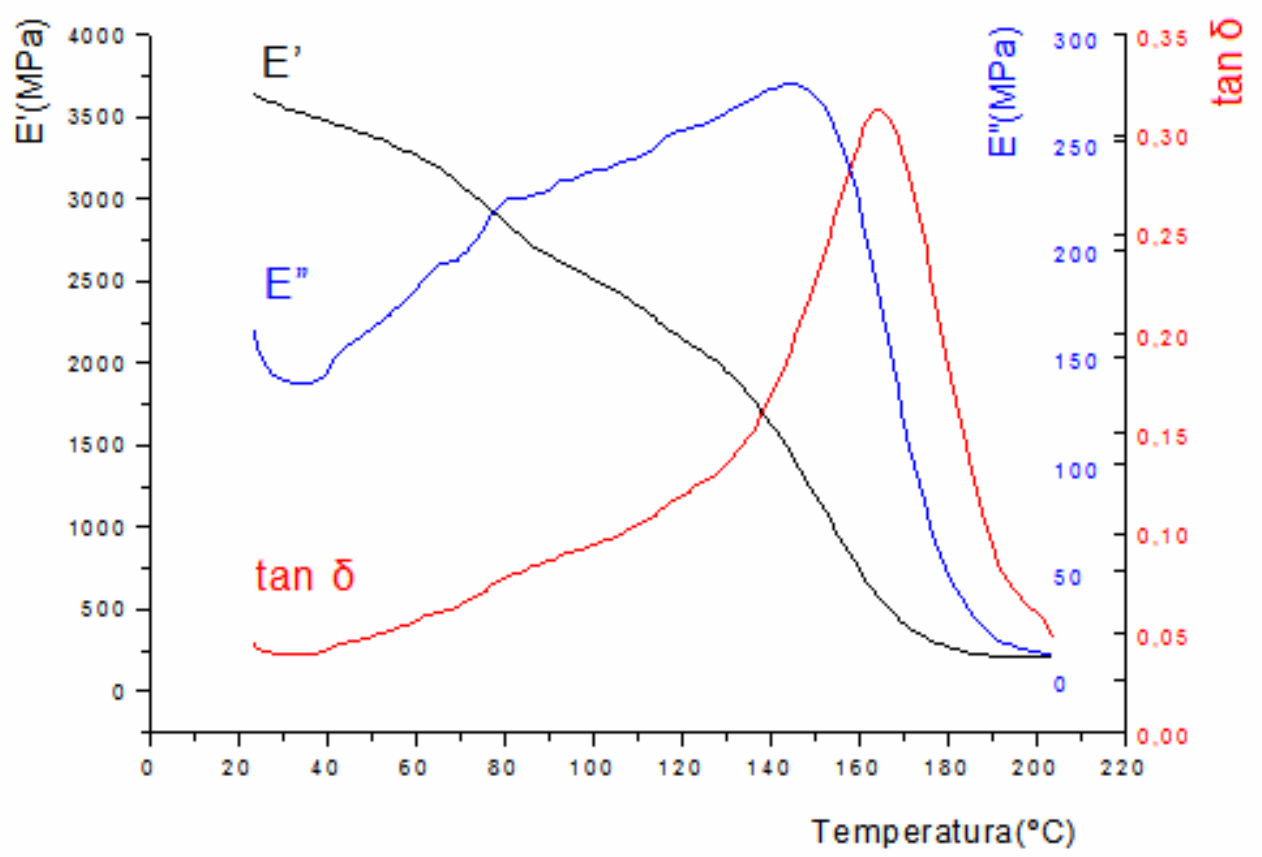

FIGURA A.8 - Curvas DMTA da matriz A3 curada por feixe de elétrons com taxas de doses de $1,82 \mathrm{kGy} \cdot \mathrm{s}^{-1}$ e 57,6 kGy.s ${ }^{-1}$ e dose total de 206,4kGy. 


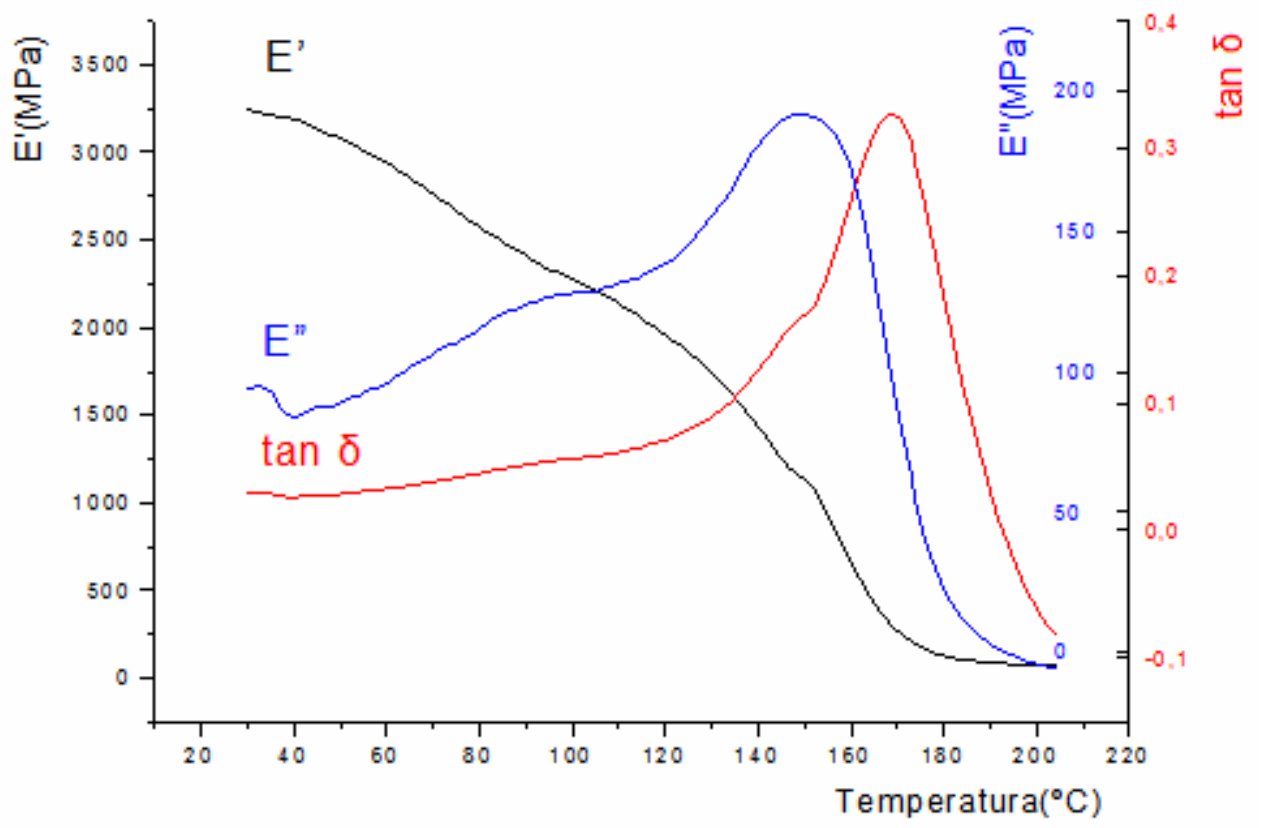

FIGURA A.9 - Curvas DMTA da matriz H2 curada por feixe de elétrons com taxas de doses de 1,82 kGy.s ${ }^{-1}$ e 57,6 kGy.s ${ }^{-1}$ e dose total de 206,4kGy. 


\section{APÊNDICE B - CURVAS DMTA DOS COMPÓSITOS CURADOS POR FEIXE DE ELÉTRONS}

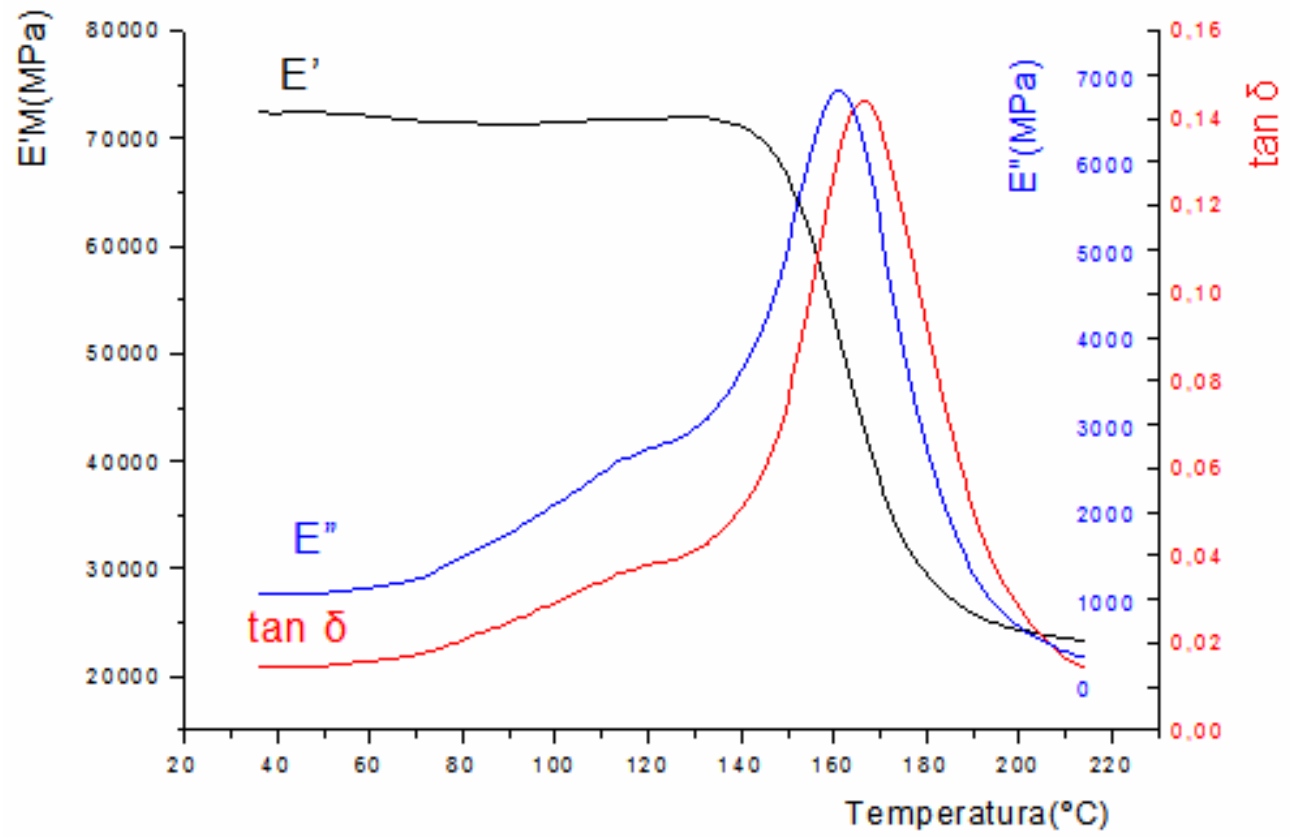

FIGURA B.1 - Curvas DMTA do compósito FCA1 curado por feixe de elétrons com taxas de doses de 1,82 kGy.s ${ }^{-1}$ e 57,6 kGy. $\mathrm{s}^{-1}$ e dose total de 206,4kGy.

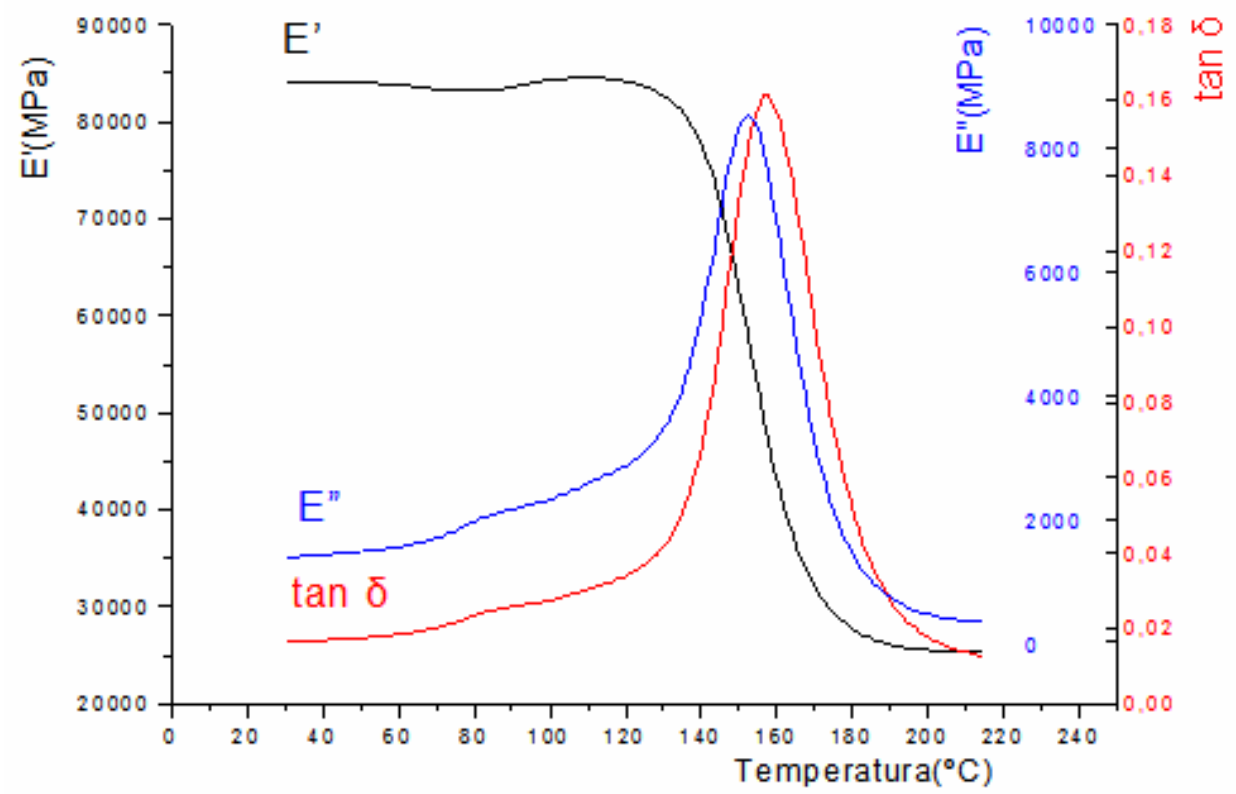

FIGURA B.2 - Curvas DMTA do compósito FCA2 curado por feixe de elétrons com taxa de dose de $1,82 \mathrm{kGy} . \mathrm{s}^{-1}$ e dose total de 103,6kGy. 


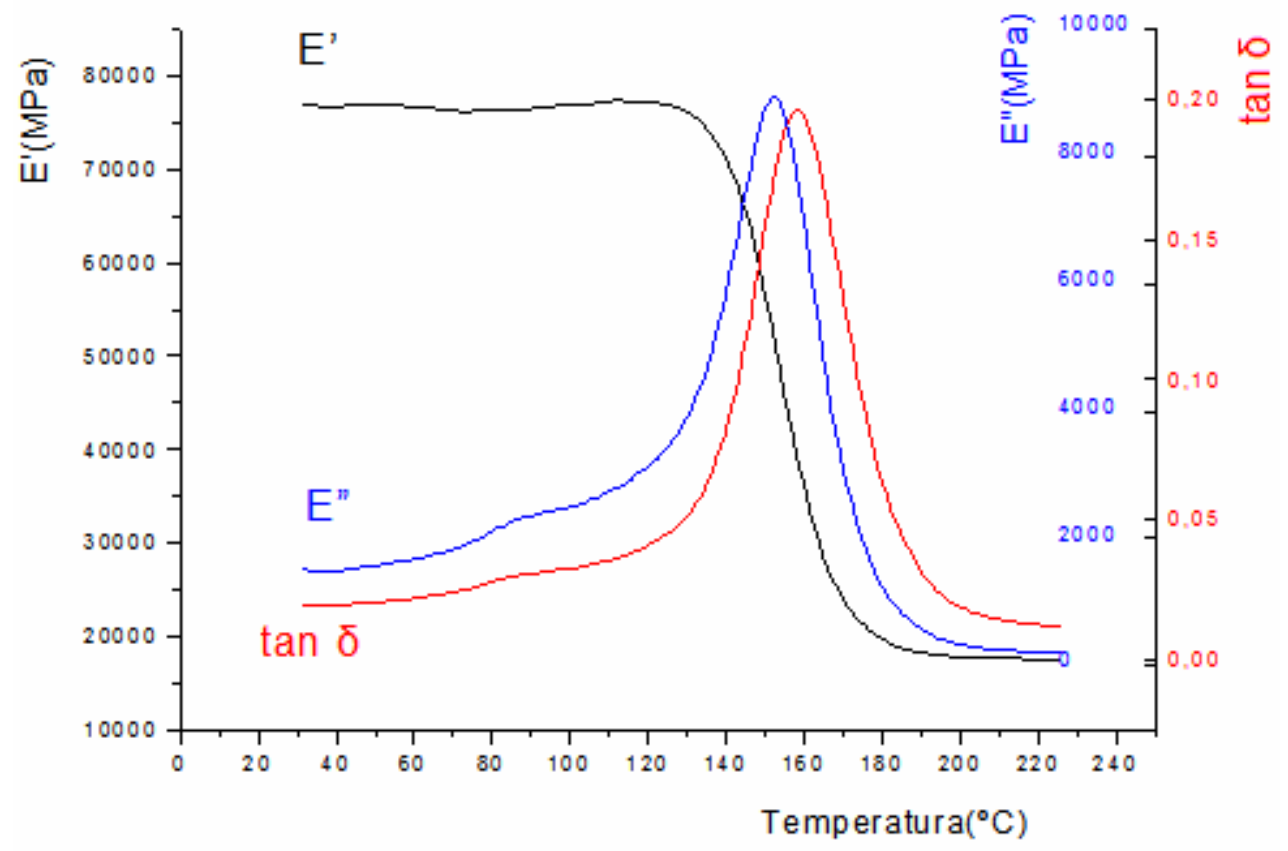

FIGURA B.3 - Curvas DMTA do compósito FCA2 curado por feixe de elétrons com taxa de dose de 1,82 kGy.s ${ }^{-1}$ e dose total de 155,0kGy.

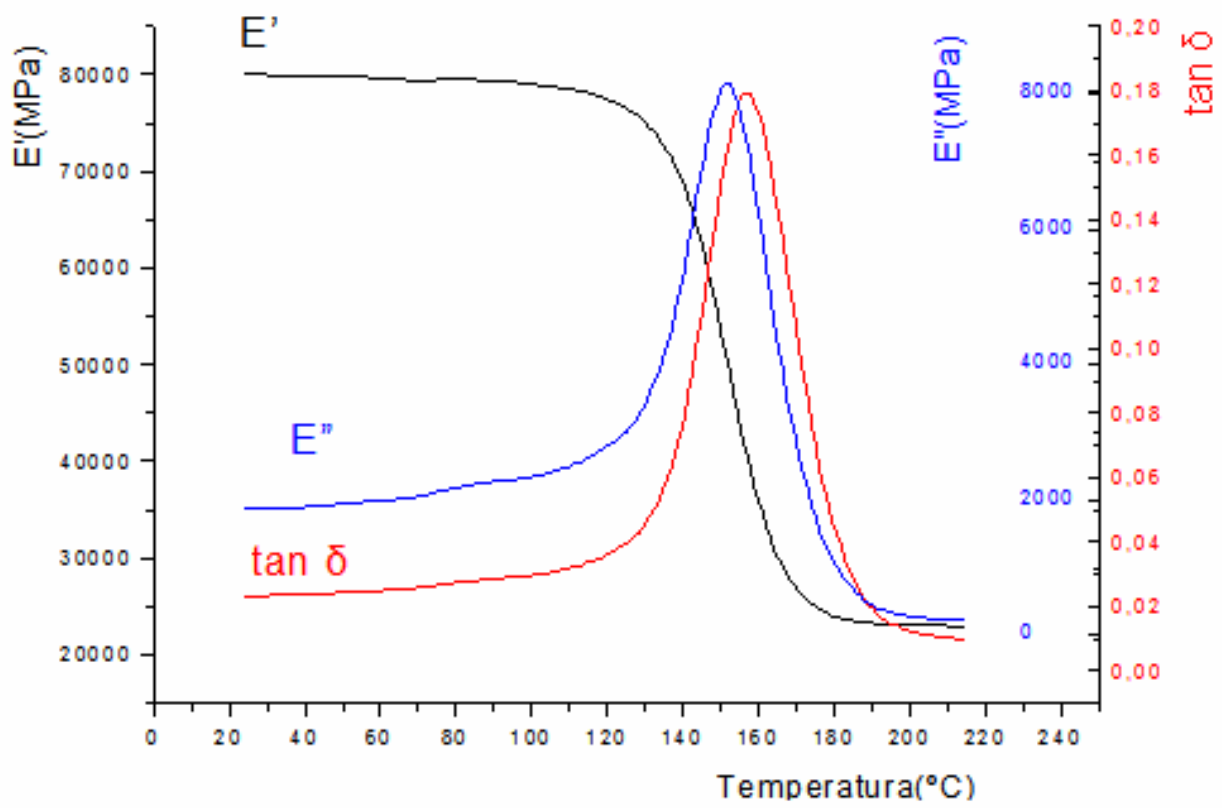

FIGURA B.4 - Curvas DMTA do compósito FCA2 curado por feixe de elétrons com taxa de dose de 1,82 kGy.s ${ }^{-1}$ e dose total de 206,4kGy. 


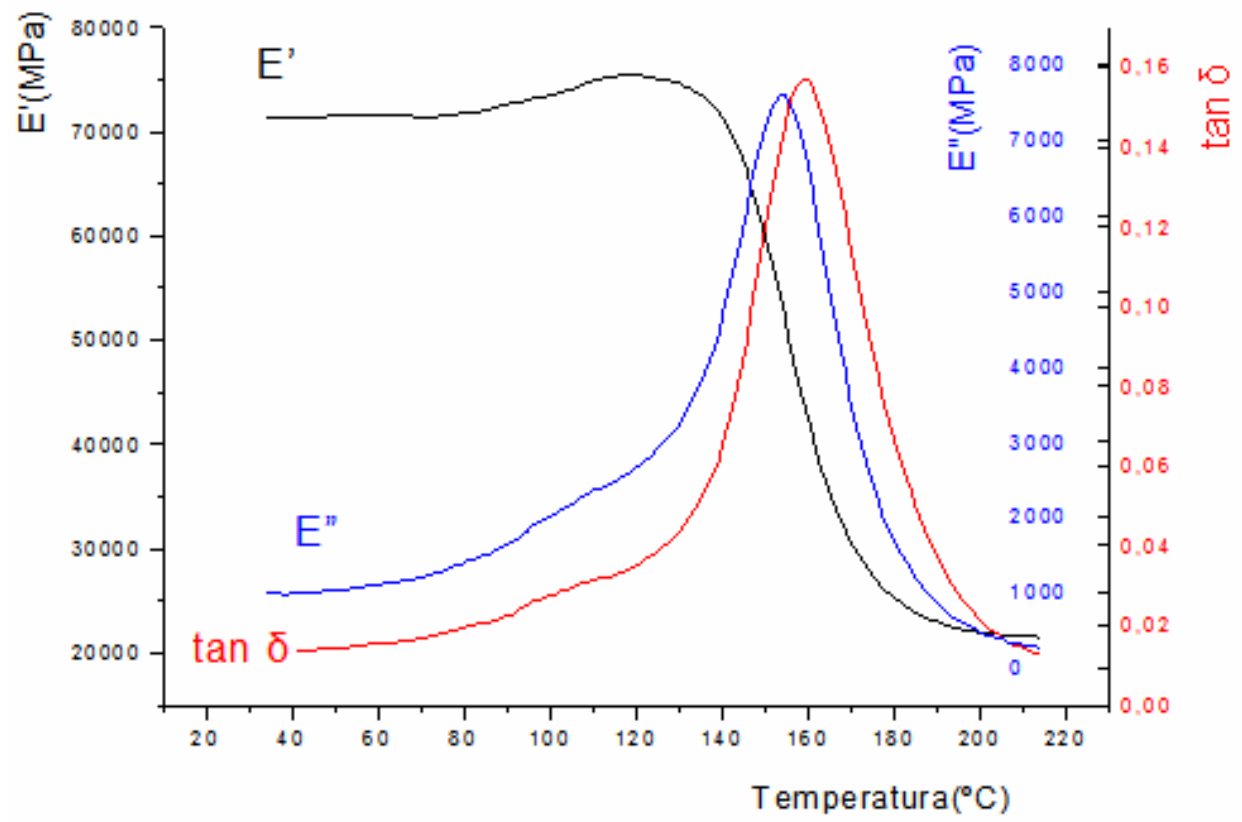

FIGURA B.5 - Curvas DMTA do compósito FCA2 curado por feixe de elétrons com taxas de doses de 1,82 kGy.s ${ }^{-1}$ e 57,6 kGy.s ${ }^{-1}$ e dose total de 103,6kGy.

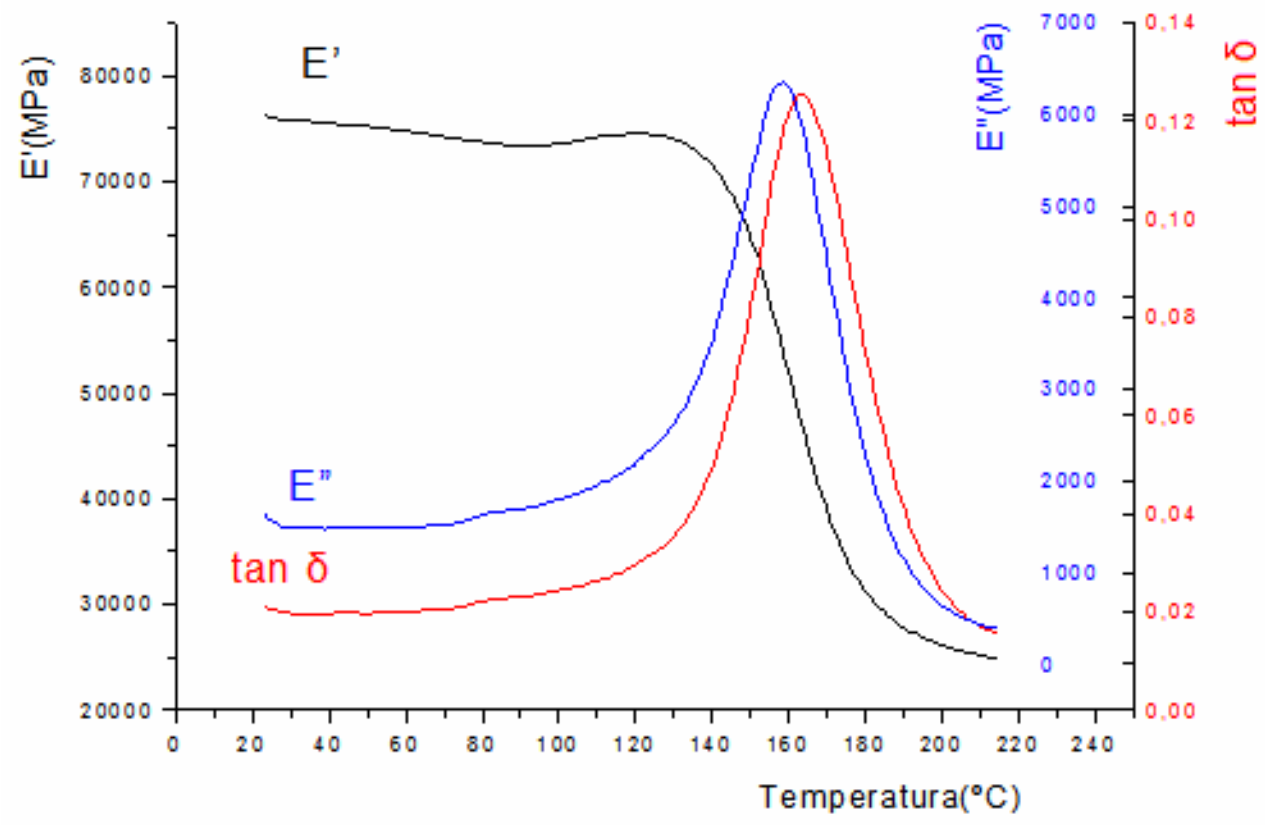

FIGURA B.6 - Curvas DMTA do compósito FCA2 curado por feixe de elétrons com taxas de doses de 1,82 kGy.s ${ }^{-1}$ e 57,6 kGy.s ${ }^{-1}$ e dose total de 155,0kGy. 


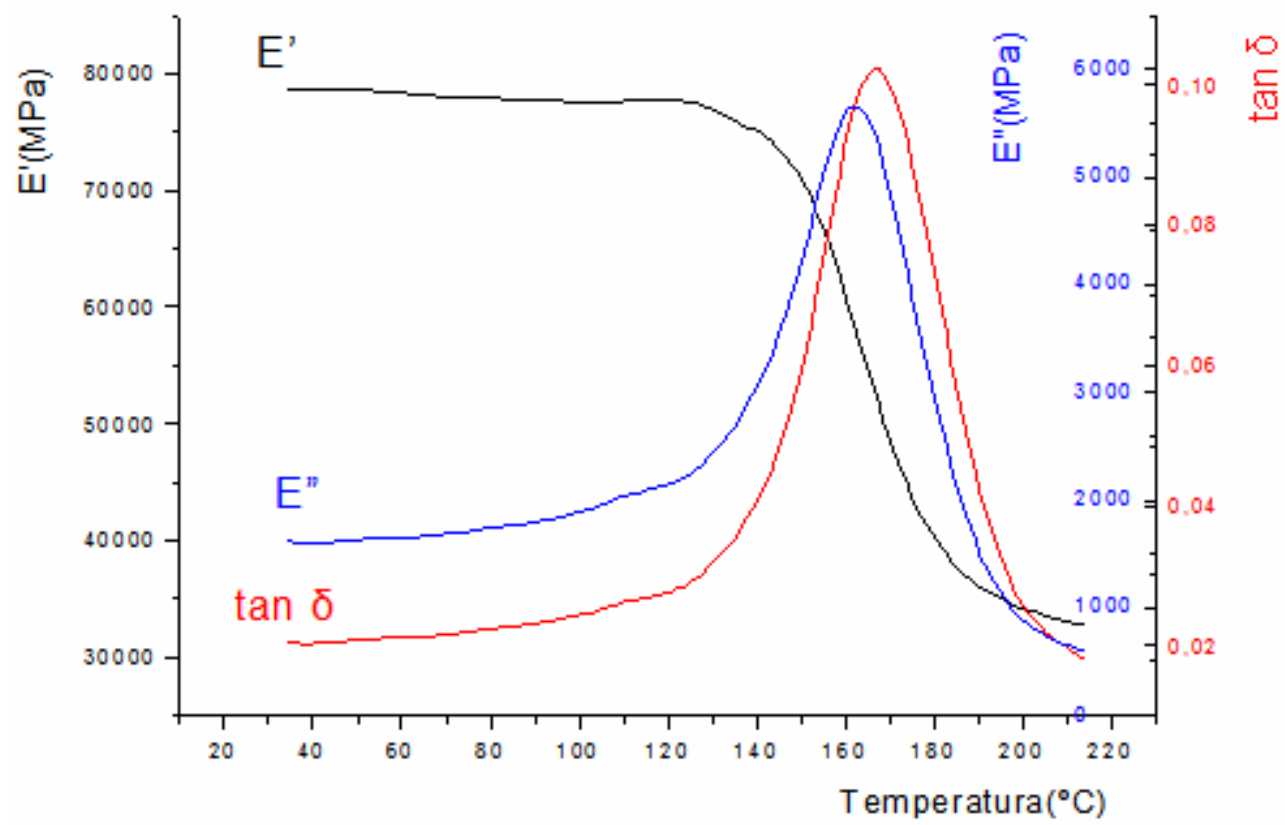

FIGURA B.7 - Curvas DMTA do compósito FCA2 curado por feixe de elétrons com taxas de doses de 1,82 kGy.s ${ }^{-1}$ e 57,6 kGy.s ${ }^{-1}$ e dose total de 206,4kGy.

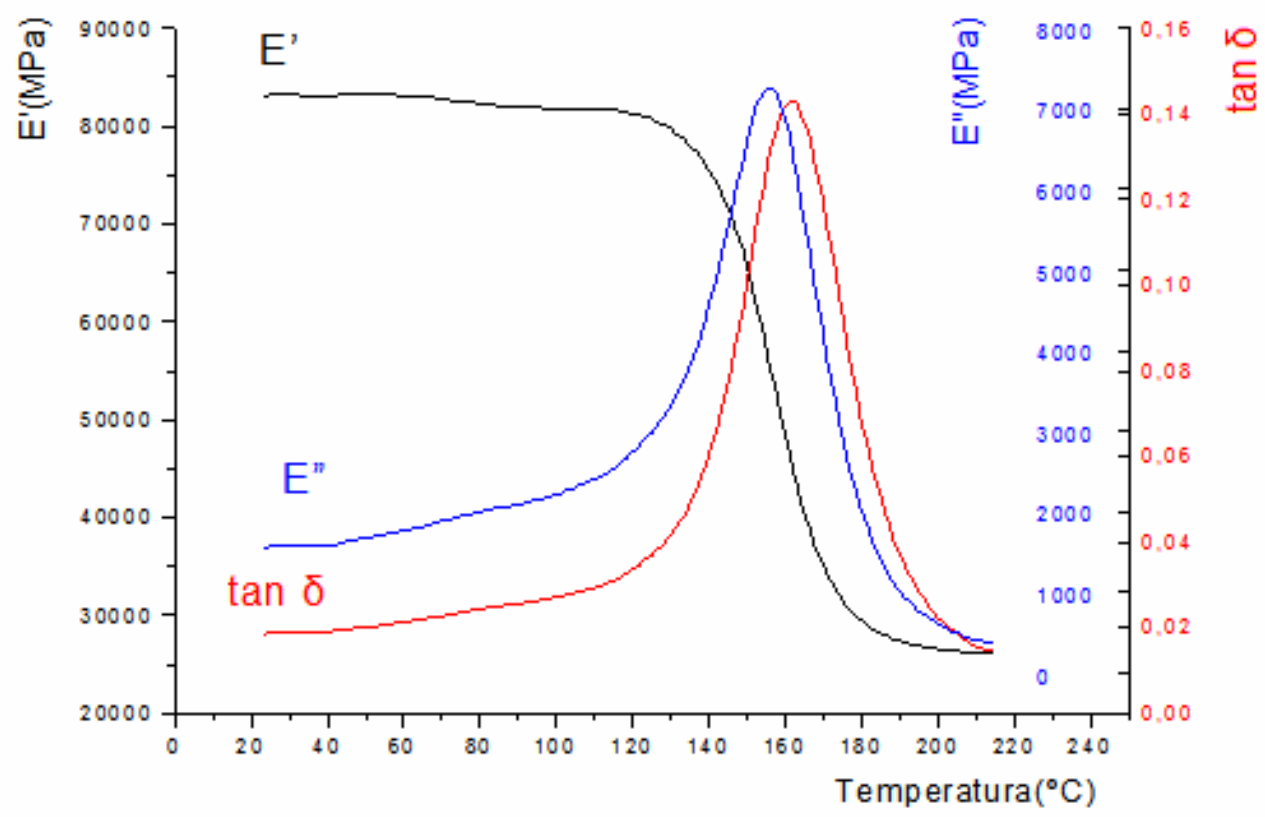

FIGURA B.8 - Curvas DMTA do compósito FCA3 curado por feixe de elétrons com taxas de doses de 1,82 kGy.s ${ }^{-1}$ e 57,6 kGy.s ${ }^{-1}$ e dose total de 206,4kGy. 


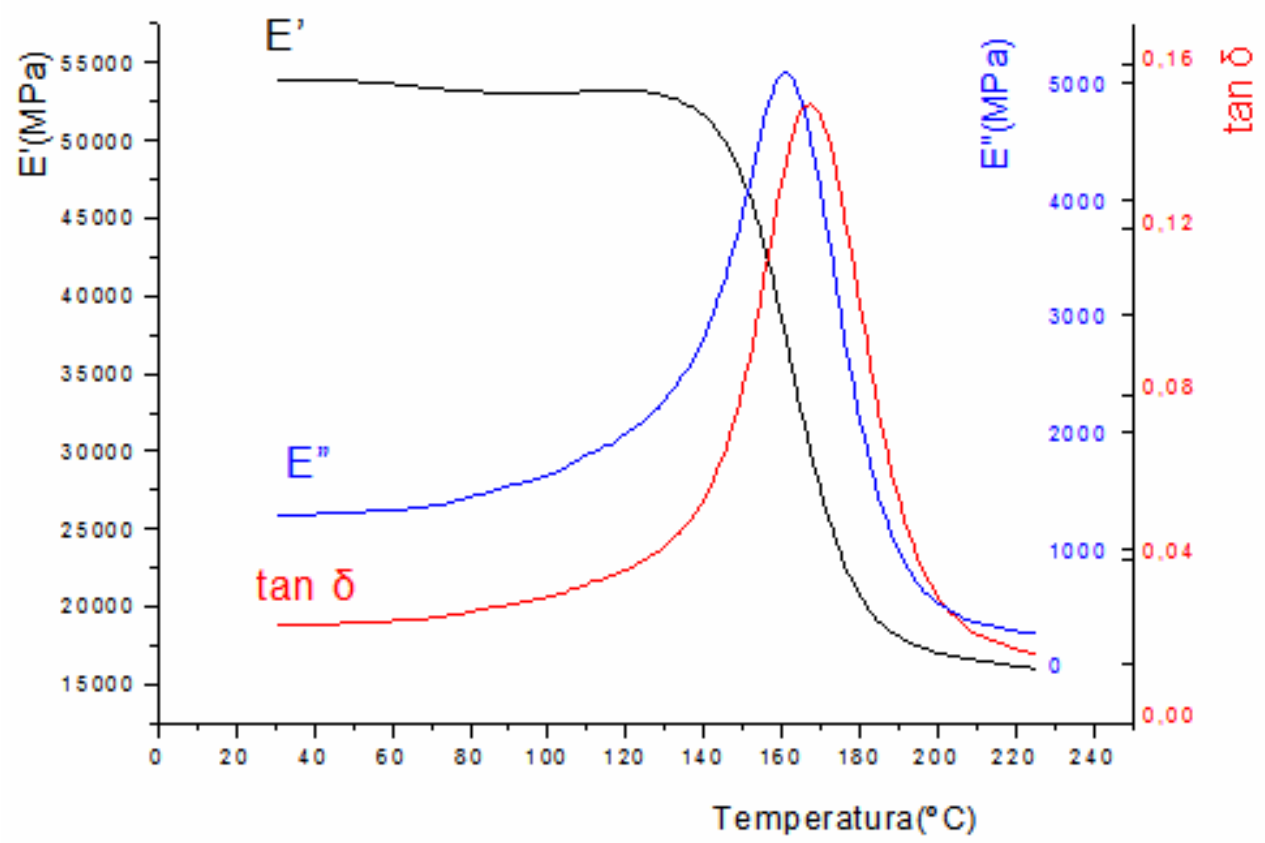

FIGURA B.9 - Curvas DMTA do compósito FCH2 curado por feixe de elétrons com taxas de doses de $1,82 \mathrm{kGy} . \mathrm{s}^{-1}$ e 57,6 kGy. $\mathrm{s}^{-1}$ e dose total de 206,4kGy. 


\section{APÊNDICE C - CURVAS DMTA DAS MATRIZES E COMPÓSITOS CURADOS POR FEIXE DE ELÉTRONS E PÓS-CURADOS TERMICAMENTE}

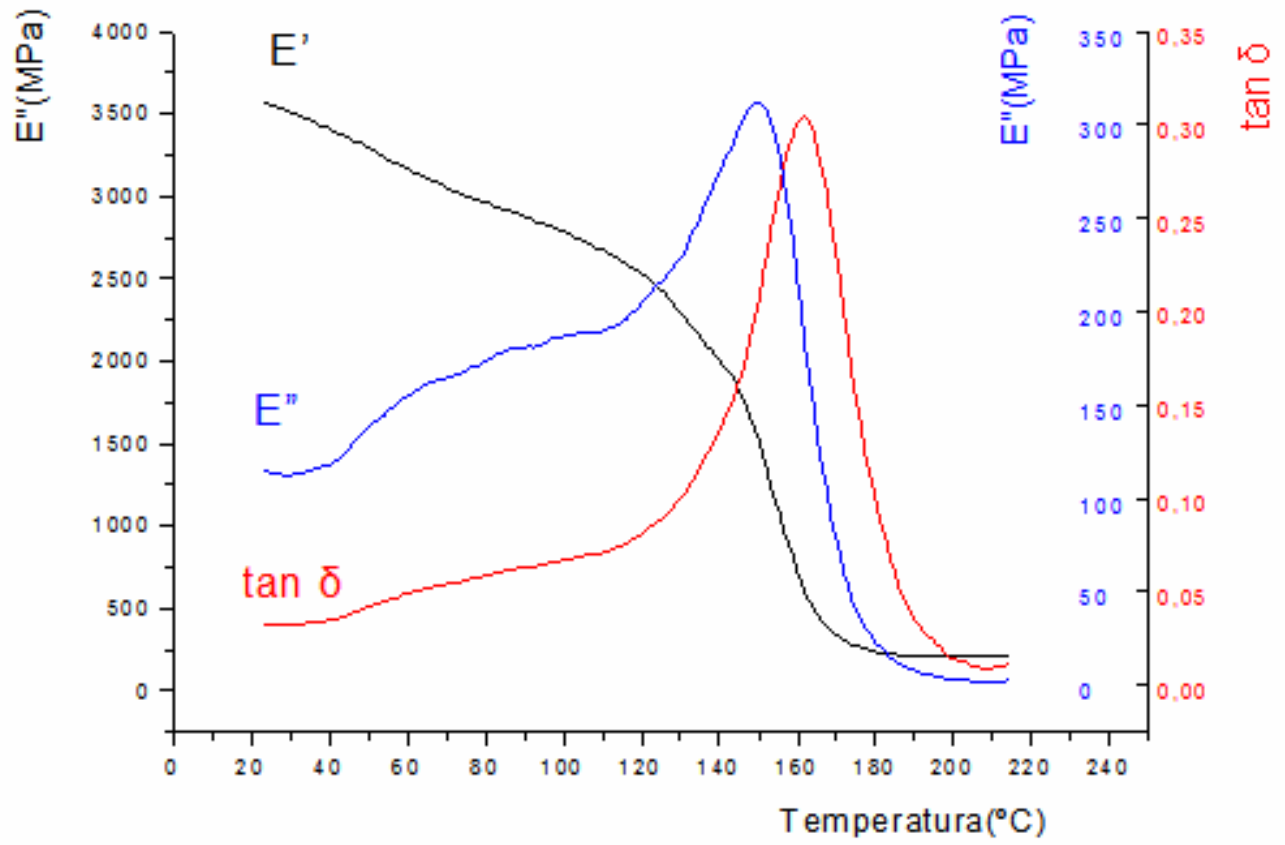

FIGURA C.1- Curvas DMTA da matriz A2 curada por feixe de elétrons com taxa de dose de $1,82 \mathrm{kGy} \cdot \mathrm{s}^{-1}$, dose total de 206,4kGy e pós-curada termicamente.

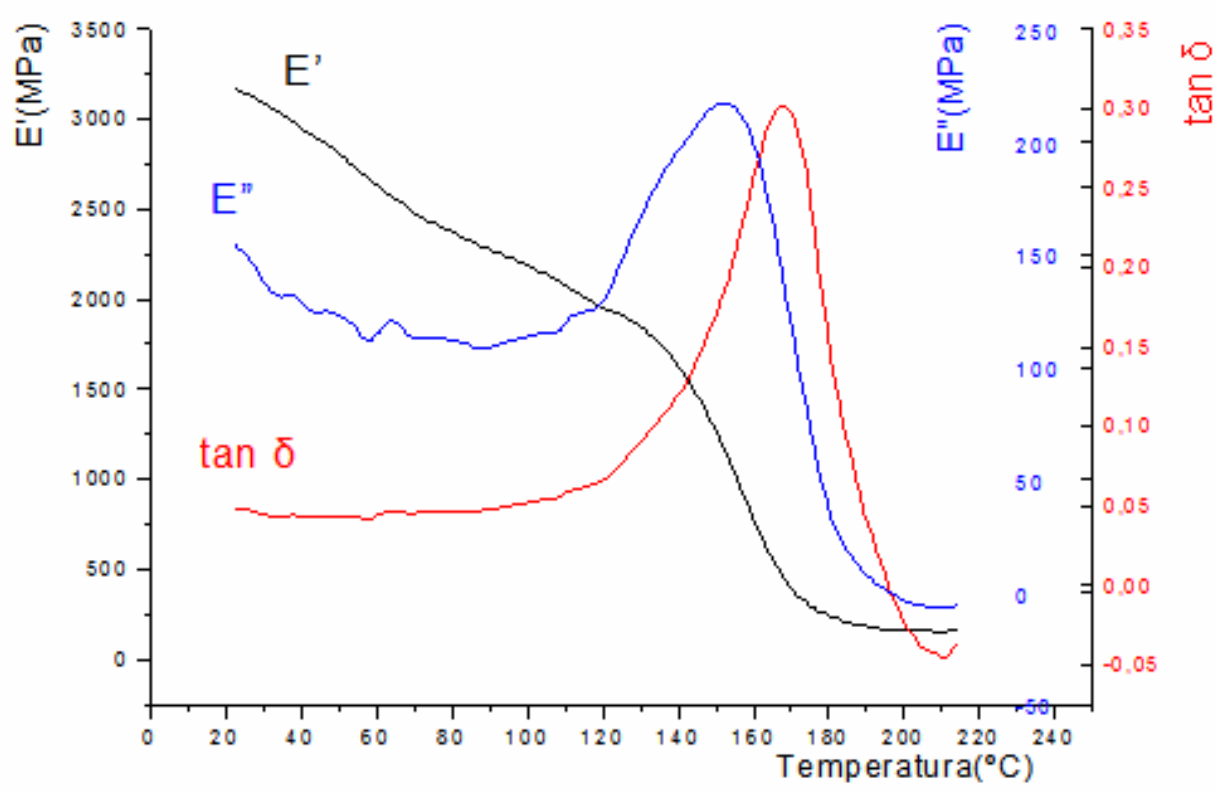

FIGURA C.2 - Curvas DMTA da matriz A2 curada por feixe de elétrons com taxas de doses de 1,82 kGy.s ${ }^{-1}$ e 57,6 kGy.s ${ }^{-1}$, dose total de 206,4kGy e pós-curada termicamente. 


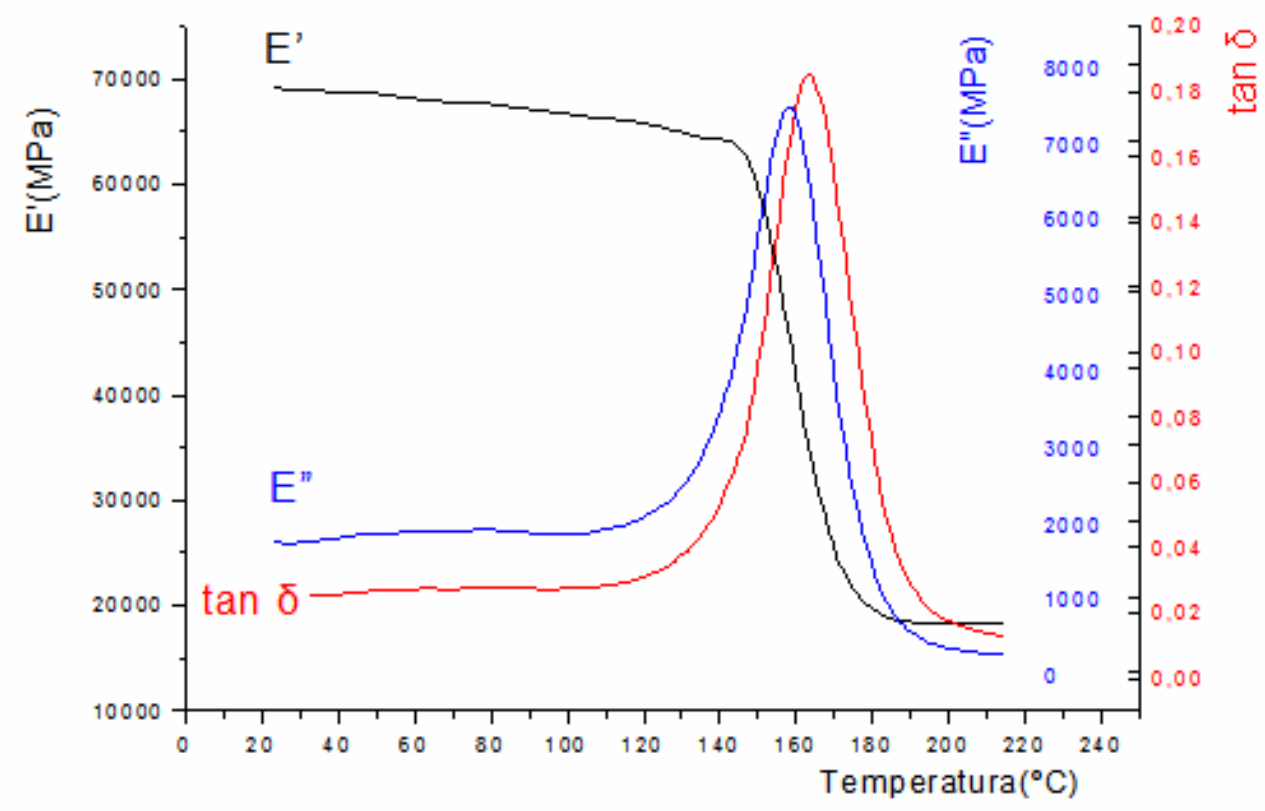

FIGURA C.3 - Curvas DMTA do compósito FCA2 curado por feixe de elétrons com taxa de dose de $1,82 \mathrm{kGy} \cdot \mathrm{s}^{-1}$, dose total de $206,4 \mathrm{kGy}$ e pós-curado termicamente.

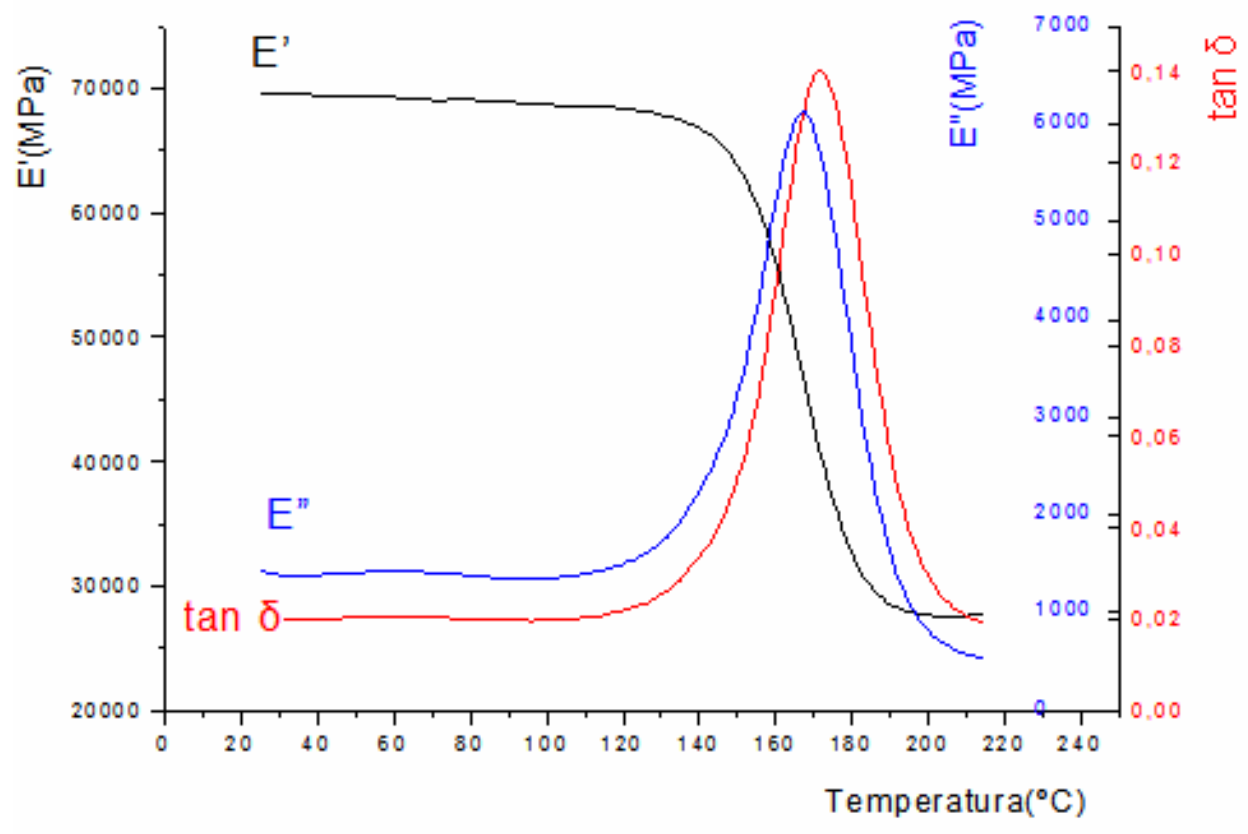

FIGURA C.4 - Curvas DMTA do compósito FCA2 curado por feixe de elétrons com taxas de doses de 1,82 kGy.s ${ }^{-1}$ e 57,6 kGy.s ${ }^{-1}$, dose total de 206,4kGy e pós-curado termicamente. 


\section{REFERÊNCIAS BIBLIOGRÁFICAS}

ASM INTERNATIONAL, Composites, v. 21, USA, 2001.

ASTM STANDARDS, D 638-99 Standard Test Method for Tensile Properties of Plastics, v. 08.01, USA, 2000.

ASTM STANDARDS, D 792-98 Standard Test Methods for Density and Specific Gravity (Relative Density) of Plastics by Displacement, v. 08.01, USA, 2000.

ASTM STANDARDS, D 3418-99 Standard Test Method for Transition Temperatures of Polymers by Differential Scanning Calorimetry, v. 08.02, USA, 2000.

ASTM STANDARDS, D 5023-99 Standard Test Method for Measuring the Dynamic Mechanical Properties of Plastics Using Three-Point Bending, $V$. 08.03, USA, 2000.

ASTM STANDARDS, E 1356-98 Standard Test Method for Assignment of the Glass Transition Temperature by Differential Scanning Calorimetry or Differential Thermal Analysis, v. 14.02, USA, 2000.

ASTM STANDARDS, E 1640-99 Standard Test Method for Assignment of the Glass Transition Temperatures by Dynamic Mechanical Analysis, v. 14.02, USA, 2000.

BEREJKA, A. J., Barriers to the commercial acceptance of radiation processing in the manufacture of fiber reinforced composites, Proceedings of $\mathbf{5 2}^{\text {th }}$ International SAMPE Symposium and Exhibition, WA, USA, 2007.

BEZIERS, D.; CAPDEPUY, B., Electron beam curing of composites, Proceedings of $35^{\text {th }}$ International SAMPE Symposium, p. 1220-1232, 1990.

BUCNALL, C. B.; PARTIRIDGE, I. K., Phase separation in crosslinked resins containing polymeric modifiers, Polymer Engineering Science, v. 26, p 54-62, 1986.

CAMPBELL, F. C., Manufacturing technology for aerospace structural materials, Elsevier, Great Britain, p. 273-327, 2006. 
CHAWLA, K. K., Composite materials science and engineering, Spring-Verlag, 1987.

COLE, K. C.; TON-THAT, M. T.; JOHNSTON, A.; HOJJATI, M.; VALCOURT, K.; LOPATA, V. J., Investigations into the mechanism of electron-beam curing of an epoxy resin, Proc. Fourth Canada-Japan Workshop on Composites, p. 43-52, Vancouver, British Columbia, Canada, Sept. 19-21, 2002.

CRIVELLO, J. V.; WALTON, T. C.; MALINK, R. Fabrication of epoxy matrix composites by electron beam induced cationic polymerization, Chem. Mater., v. 9 , p. 1273-1284, 1997.

CRIVELLO, J. V. UV and electron beam-induced cationic polymerization, Nuclear Instruments and Methods in Physics Research, v. 151, p. 8-21, 1999.

DEFOORT, B.; DRZAL, L. T., Influence of thermal post curing on electron beam cured composites, Proc. $\mathbf{4 4}^{\text {th }}$ International SAMPE Symposium, p. 2550-2561, USA, 2001.

HEXCEL, Catálogo técnico, 2004.

HUNTSMAN, Catálogo técnico, 2004.

JANKE, C. J.; NORRIS, R. E.; YARBOROUGH, K.; HAVENS, S. J.; LOPATA; V. J., Critical parameters for electron beam curing of cationic epoxies and property comparison of electron beam cured cationic epoxies versus thermal cured resins and composites, Proc. $\mathbf{4 2}^{\text {th }}$ International SAMPE Symposium, p. 477, Anaheim, CA, USA,.1997.

KOLESKE, J. V., Radiation curing of coatings, ASTM International, p. 55-128, 2002.

KOOG, D. A.; HOLleR, F. J.; NIEMAN, T. A., Princípios de análise instrumental, Editora Bookman, 2002.

LOPATA, V. J.; CHUNG M., Electron curing of epoxy resins: initiator and concentration effects on curing dose and rheological properties, Proceedings of $2^{\text {th }}$ International SAMPE Technical Conference, USA, p.901-910, 1996.

LOPATA, V. J.; SIDWELL, D. R.; FIDGEON, E.; WILSON, F.; BERNIER, D.; LOUTIT, R.; LOUTIT, W., Preliminary test results for a type-trial repair on Air Canada Airbus Aircraft fleet, Proceedings of $43^{\text {th }}$ International SAMPE Technical Conference, CA, USA, p. 1672, 1998. 
LOPATA, V. J.; JANKE, C. J., Analysis of identical epoxy resin formulations cured thermally or by electron beam, Proc. $\mathbf{4 4}^{\text {th }}$ International SAMPE Symposium, USA, p. 602-610, 1999.

LOPATA, V. J.; SAUNDERS, C. B.; SINGH A.; JANKE C. J.; WRENN G. E.; HAVENS S. J. Electron-beam-curable epoxy resins for the manufacture of high-performance composites, Radiat. Phys. Chem., v. 56, p. 405-415, 1999.

LOPATA, V. J.; PUZIANOWSKI, A. A.; KIERNICKI, S. L. L.; MCKIMMIE R.; DEWEY C.; SAMSON, J., Aircraft contaminants' effects on EB repair of composites, $3^{\text {rd }}$ Cdn Intern. Conf. Composites, p. 663-640, 2001.

LOPATA, V. J.; SIDWELL, D. R., Electron beam processing for composite. Manufacturing and repair. Radtech Report, p. 32-42, set./out. 2003.

LQES - Laboratório de Química do Estado Sólido - Instituto de Química UNICAMP. Disponível em: <http://iqes.iqm.unicamp.br>. Acesso em 10 jan. 2008.

MENARD, K. P., Dynamic mechanical analysis, CRC Press, New York, USA, p. 125-135, 1999.

MORGAN, R. J.; LI, D.; LU, J., RIBEIRO, R.; MOON, S. W., Development and characterization of non-autoclave processes for composites, Proceedings of $\mathbf{4 7}^{\text {th }}$ International SAMPE Symposium, p. 585, USA, 2002.

NISHITSUJI, D. A.; MARINUCCI, G.; EVORA, M. C.; SILVA, L. G. A., Study of electron beam curing process using epoxy resin system, Nuclear Instruments and Methods in Physics Research B, v. 265, p. 135-138, 2007.

OHAMAD, A.; MCLAUGHIN, W. L., On the mechanisms of radiation-induced curing of epoxy-fiber composites, Radiat. Phys. Chem., v. 48, p. 201-206, 1996.

PALMESE, G. R.; GHOSH, N. N.; MCKNIGHT, S. H., Investigation of factors influencing the cationic polymerization of epoxy resins, Proceedings of $45^{\text {th }}$ International SAMPE Symposium, USA, p. 1874-1887, 2000.

RAGHAVAN, J.; LOPATA, V. J.; BAILLIE, R. M., Influence of process parameters on electron beam curing of a polymer composite, Proceedings of $30^{\text {th }}$ International SAMPE Technical Conference, TX, USA, p. 156, 1998.

RIEW, C. K.; GILLHAM, J., Advances in Chemistry Series: Rubber Modified Thermoset Resins, America Chemical Society, v. 28, 1984. 
SAUNDERS, C.; LOPATA, V. J.; KREMERS, W., Electron curing of composite structures for space applications, executive summary submitted to Phillips Laboratory Kirtland AFB, NM, USA, June 1997.

SKEIST, L., Handbook of adhesives, Van Nostrand Reinhold Company, New York, USA, 1977.

STRONG, A. B., Fundamentals of composites manufacturing: materials, methods and applications, Society of Manufacturing Engineers, USA, 1989.

WILENSKI, M. S.; AIKEN, R.; GERZESKI, R., Evaluation of an e-beam cured material for cryogenic structure usage, $47^{\text {th }}$ International SAMPE Symposium, USA, 2002.

WUNDERLICH, B., Thermal characterization of polymer materials, Academic Press Inc., New York, USA, vol. 1, 1997.

ZHANG, Z.; LIU, Y.; HUANG, Y.; LIU, L.; BAO, J., The effect of carbon-fiber surface properties on the electron-beam curing of epoxy-resin composites, Composite Science and Technology, v. 62, p. 331-337, 2002. 